Athanasios Orphanides, Brian Reid and David H. Small

Athanasios Orphanides, Brian Reid and David H. Small are staff economists with the Board of Governors of the Federal Reserve System, Division of Monetary Aftairs.

\title{
The Empirical Properties of a Monetary Aggregate That Adds Bond and Stock Funds to M2
}

VER THE PAST FEW YEARS, the unexpected slowdown of M2 growth and strength in its velocity have coincided with a surge in outstanding balances in bond and stock mutual funds. Although this surge partly reflects capital gains from rising prices in stock and bond markets, it also is due to record inflows of new balances. Indeed, anecdotal and statistical evidence suggests that a significant portion of these inflows have come from $\mathrm{M} 2$, contributing to the unexpected. weakness in this aggregate. Consequently, augmenting M2 with bond and stock funds in order to internalize these flows offers the prospect of an aggregate that is more stably related to income and prices than M2 has been of late.

This article examines empirical issues associated with whether such an augmented aggregate, called $\mathrm{M} 2+$, would be useful in the conduct of monetary policy. The three main issues examined are the stability of its demand function, its information content as an indicator of spending, and its controllability. To assess these characteristics of $\mathrm{M} 2+$, demand functions and reduced-form relationships between $\mathrm{M} 2+$ and income have been estimated. The $\mathrm{M} 2+$ series used in this empirical work includes capital gains and losses on bond and stock funds. M2+ was defined in this manner on the presumption that meaningful behavioral distinctions cannot be made between balances generated in the past by capital gains and balances originally brought into stock and bond funds from outside sources.

Specifying a demand function for $\mathrm{M} 2+$ requires identifying its close substitutes. One broad class of substitutes includes real assets such as commodities and durable goods, while alternative financial assets may include direct holdings of short-term market instruments, bonds and stocks. The estimated demand functions posit direct holdings of Treasury bonds and bills as the sole substitutes for $\mathrm{M} 2$ + because of difficulties in finding plausible measures of expected ex ante returns on real assets and equities. Using rough proxies for ex ante financial returns, including those on stock and bond funds themselves, the estimated demand functions have reasonable behavioral properties. But perhaps because of the problems with measuring ex ante returns, as well as the difficulty in distinguishing between returns on direct and mutual-fund holdings of the same assets, the estimated demand functions are not very stable. Hence, the usefulness of these equations in interpreting and forecasting movements in $\mathrm{M} 2+$ may prove to be limited. Moreover, these relationships have been estimated over a period of major inmovation and growth of the bond and stock fund industry, raising further questions about the stability of the specification. 
In terms of information content, $\mathrm{M} 2+$ and $\mathrm{M} 2$ do not appear to have differed significantly. The velocity of $\mathrm{M} 2$ + may have been more "sensible" than that of M2 over the past three years, given the anomalous behavior of $\mathrm{V} 2$, which was rising while the opportunity cost of M2 was declining. As a consequence, in reduced-form relations, forecasts of nominal GDP growth for 1992 are somewhat stronger and more accurate when based on $\mathrm{M} 2$ + rather than M2. But leading into the past recession and continuing to the end of 1991 , both aggregates yielded substantial overpredictions of nominal GDP growth. Within $\mathrm{M} 2+$, the volatile monthly swings in M2 are modestly offset by changes in net inflows to stock and bond funds, but capital gains and losses cause growth of $\mathrm{M}_{+}+$ to be more volabile than that of M2. Moreover. the capital gains and losses in M2+ may cause movements in the aggregate that neither reflect shifts in the stance of monetary policy nor provide appropriate signals for changes in policy.

The remainder of the paper addresses these issues in more detail. Section two explains why the inclusion of capital gains and losses in M2+ seems necessary and highlights some of the problems that result from their inclusion. The section also briefly describes the data used to create a bond and stock mutual fund series that is comparable to M2. Section three provides a broad empirical overview of the growth of bond and stock mutual funds over the past decade. The section then goes on to describe the recent behavior of $\mathrm{M} 2+$ and compares its behavior with that of M2. In the final section, we conduct an econometric investigation of $\mathrm{M} 2+$ demand, noting several of the difficulties associated with specifying a demand function for $\mathrm{M} 2+$ and with the stability and controlability of the aggregate. Also in this section, the indicator properties of $\mathrm{M} 2+$ are formally examined and contrasted with those of M2.

\section{DEPNDG M2+AND ASSOUIATD

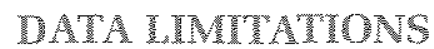

Because stock and bond funds are revalued daily to reflect realized capital gains and losses (unlike the deposit components of the current

\footnotetext{
${ }_{1}^{1}$ For a more complete discussion of the issues associated with constructing the bond and stock fund component of M2+, see Collins and Edwards (1994).

${ }^{2}$ Defiring an aggregate by adding only bond funds to $M 2$ would mitigate some of the problems associated with capital gains because such gains are more volatile for stock funds than for bond funds. However, such an aggregate suffers
}

monetary aggregates whose values are fixed at par), questions arise as to the proper treatment of these changes in value. One option is to exclude capital gains by selecting a value of outstanding balances on a specific historical date to which subsequent inflows (net of capital gains) are added. However, both the selection of this date and the assumption that net capital gains before this date, but not after, constitute money are arbitrary. Presumably after some period of time, mutual fund shareholders cease to distinguish between balances generated by capital gains and those that stem from new investments of funds.

A second problem with excluding net capital gains is that, at least conceptually, M2+ balances (or at least the mutual fund component) could become negative. For example, if an individual starts with no $\mathrm{M} 2+$ and then adds $\$ 100$ to a bond fund, the M2+ holdings would then equal $\$ 100$. If capital gains add $\$ 50$ to the value of the bond fund account, $M 2+$ will still equal $\$ 100$ if capital gains are excluded from $\mathrm{M} 2+$. If the individual then withdraws all $\$ 150$ from the bond fund, net inflows would equal minus $\$ 150$, and $\mathrm{M} 2+$ would equal minus $\$ 50$ for this individual. To avoid such problems, $\mathrm{M} 2+$ is defined to include capital gains. ${ }^{2}$

But the inclusion of capital gains and losses raises issues about the signals that $\mathrm{M} 2+$ can convey about the stance and proper course of monetary policy. For example, a decline in the stock market that reflected lower profit expectations and slower business activity would lower M2+, ceteris paribus, and may appropriately be calling for a more stimulative monetary policy, But, if capital losses and lower $\mathrm{M} 2+$ result from an increase in long-tern interest rates in response to rising inflation, a monetary ease is not likely to be the appropriate response. With bond and stock funds currently amounting to about 15 percent of $\mathrm{M} 2+$, and likely to increase further, capital gains and losses can have noticeable short-run effects on the growth of the expanded aggregate.

Data used to measure bond and stock fund balances are provided to the Federal Reserve by

from the data limitation that a large number of mutual funds invest in both bonds and stocks, and therefore separating mutual funds into these two categories is problematic. An aggregate consisting of M2 plus bond funds has been examined by Duca (forthcoming). 
the Investment Company Institute (ICI). As received from ICI, the bond and stock fund balances include IRA/Keogh and institutional holdings. ${ }^{3}$ Because IRA/Keogh and institutional holdings of M2-type accounts are netted from M2, such holdings of bond and stock funds need to be netted out in constructing the bond and stock fund component of $\mathrm{M} 2+$. Such netted bond and stock fund series will be referred to as M2-type series. For M2-type bond and stock funds, it would be useful to have data on inflows excluding capital gains as a direct measure of portfolio shifts, but this series is not reported by ICI and cannot be constructed from available data. ${ }^{4}$ To proxy for this missing series, we rely on total inflows excluding capital gains. ${ }^{5}$

\section{GROWTI OF THE MUTUAL FUND WVUSTRY AND THE BROAD EMPIRI- CA PROTLRTES OF M2+}

\section{Historical Trends of Bond and Stork Murnal Funds}

Although bond and stock mutual funds have existed in the United States since 1924, most of their growth has been quite recent. In the early 1970 s, there were about 400 such funds with total assets of about $\$ 40$ billion. Today, there are more than 3,000 funds with total assets of about $\$ 1.4$ trillion (see Figure 1, top panel). ${ }^{6}$ The bottom panel of Figure 1 shows that holdings of aggregate bond and stock mutual funds have grown roughly in parallel and are about equal. ${ }^{7}$
This growth may be attributed, in part, to declining transaction costs when investing in mutual funds. Between 1970 and 1992, load fees on mutual funds fell from an average of 8.5 percent to 4.5 percent. In addition, during the past decade, no-load mutual funds have become more widely available, further reducing the transaction costs involved in shifting in and out of mutual funds. ${ }^{8}$

In reducing transaction costs associated with moving into mutual funds, banks have also been playing a role. Large domestic banks sampled for the Federal Reserve System's March 1993 Senior Financial Officer Survey reported significant increases during the past few years in their overall sales staffs for mutual funds, as well as in the share of branch offices with sales representatives located at them. ${ }^{9}$ These developments suggest that investment balances that previously had been held in M2 can now be moved more readily into bond and stock funds, and may be more likely to be switched back and forth between these two lodgings as relative yields shift.

Another innovation that may have contributed to the growth of the industry is that the balances held in such funds can be used more readily as a means of payment in the purchase of goods and services, in part because many funds now allow withdrawals to be made by checks. However, the writing of a check means that mutual fund shares must be sold, so there is a potential capital gain or loss associated with each check. Anecdotal evidence suggests that the inconvenience of

\footnotetext{
${ }^{3}$ See $\mathrm{ICl}$ (1994, Appendix A) for the type of funds classified as stock and bond funds.

4 Inflows to M2-type bond and stock funds can be estimated by starting with the change in the market value of M2-type bond and stock funds and subtracting estimated capital gains. These capital gains and losses can be estimated from capital gains and losses on total bond and slock funds, which are avallable. We have made these estimates by taking total capital gains and losses and mutiplying them by the lagged ratio of $\mathrm{M} 2$-type outstandings to total outstandings of bond and stock funds.

Although we show such estimates of M2-type capital gains and losses in Figure 10, these estimates and the associated estimates of M2-type inflows do not seem reliable enough to use throughout the analysis.

5 Reinvested earnings are included in both the Me-type and total inflows. This treatment is conceptually similat to the interest crediting of M2 balances. According to ICl data, about 75 percent of shareholders automatically reinvest their eamings in the mutual fund.

For an overview of the growth of the mutual fund industry and how mulual funds operate and compete, see Sirri and Tutano (1993).

types of funds offered and much of the growth has occurred in specialized funds. For example, muricipal bond funds, which were introduced in 1976 , had total assets of $\$ 50$ bitlion by 1985 , and had grown to $\$ 225$ billion by 1993 . Government income and Ginnie Mae funds, which had a total of about $\$ 2.5$ billion under management at the start of 1984, had $\$ 175$ billion by 1993 .

a See Mack (1993) for a more extended discussion of the decline in load fees.

${ }^{9}$ The percentage of sampled banks with more than 50 repre. sentatives seling retail mutual funds increased from less than 10 percent three years ago to more than 40 percent currently; and nearly all sampled banks currently have some retail sales force. Also, banks have made mutual funds more accessible through their branches. Over half the sam pled banks have personnel selling retail mutual funds on a part-time basis or by appointment at 90 percent or more of their branches, a significant increase from three years ago, when only 20 percent of the banks had sales representatives available part-time at 90 percent or more of their branches. The results of the March 1993 Senior Financial Officer Survey and the growth of bank-related mutual funds more generally is discussed by Feid and Small (1993).
}

7 This growth of the bond ard stock fund industry has been associated with increased diversity and specialization of the 
Figure 1A

Number and Market Value of Bond and Stock Mutual Funds

Number of funds

Bumions of dollars

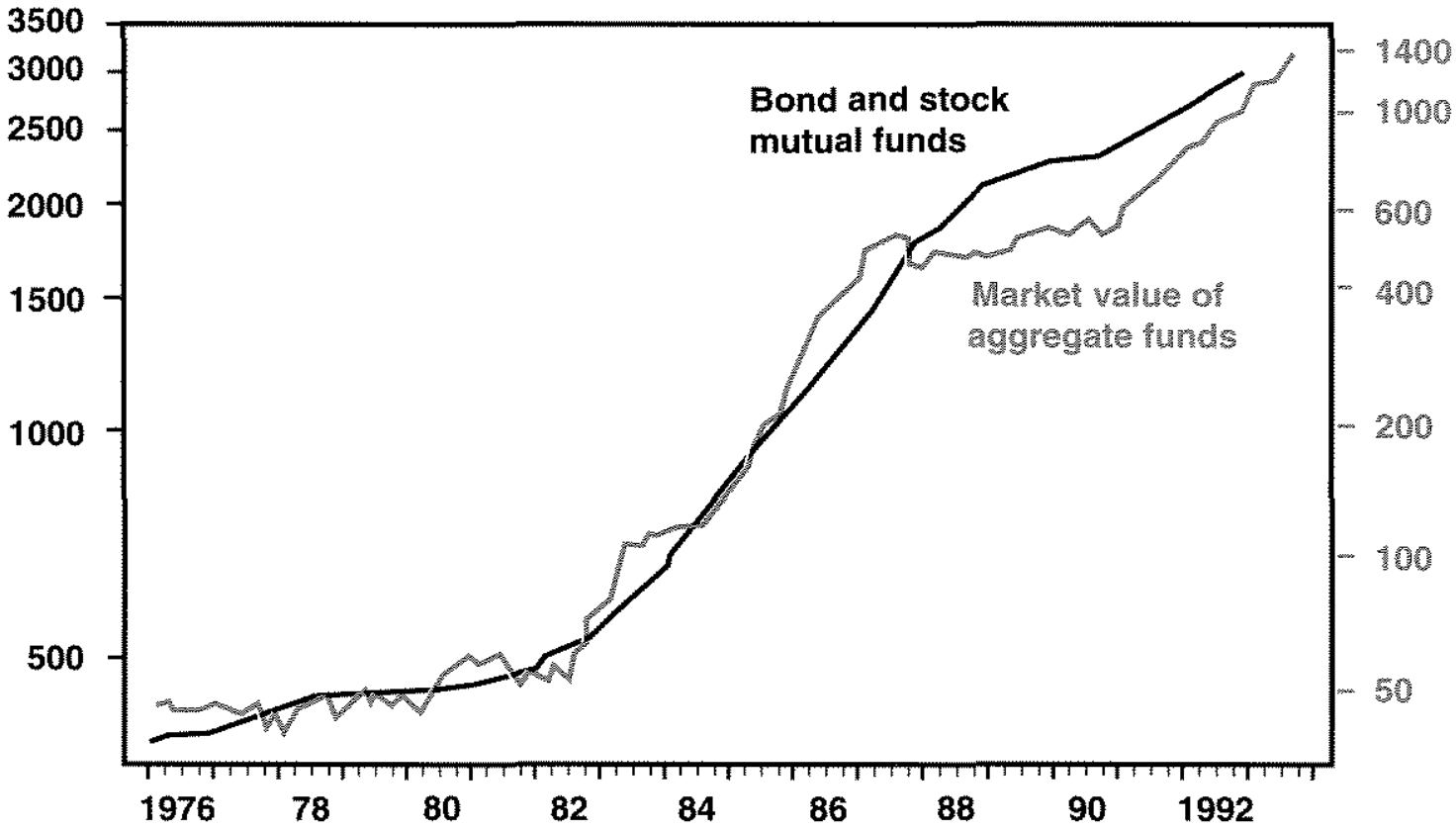

Figure 1B

Market Value of Aggregate Bond and Stock Mutual Funds

Billions of dollars

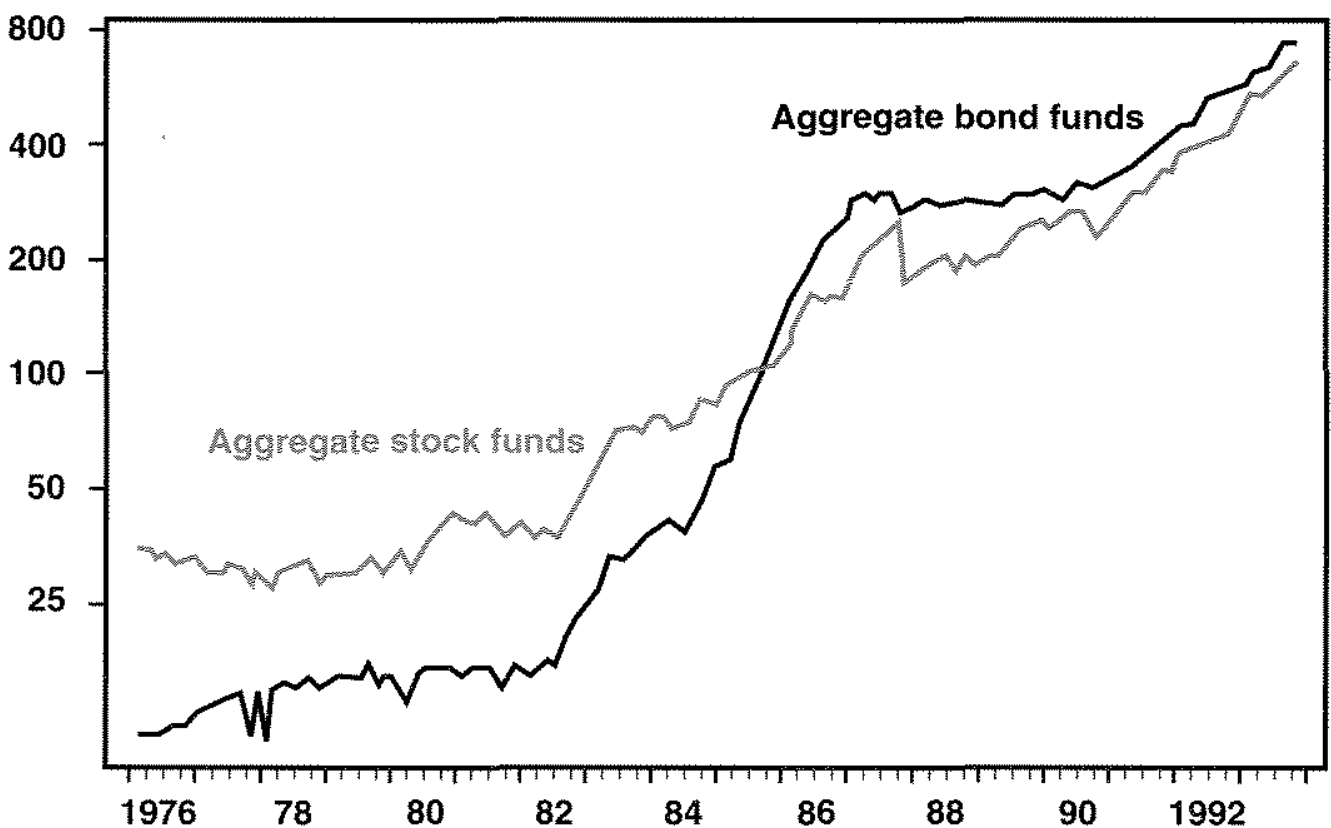

Aggregate bond and stock mutual fund balances include IRA/Keogh balances and institutional holdings. These aggregate mutual fund data are not seasonally adjusted. 
tabulating capital gains and losses for the purpose of income taxes significantly limits the frequency of the writing of checks on stock and bond fund accounts. ${ }^{10}$

The transaction activity in bond and stock funds is presented in Figure 2, which plots gross oufflows from total bond and stock funds measured as a share of outstanding balances. ${ }^{13}$ Contrary to what would be expected if transaction activity had increased, there is no discernible secular trend in the ratio of gross outflows to the value of shares, and the most recent value of the ratio seems rather modest. ${ }^{12}$

Consequently, the rationale that we explore for adding such funds to $\mathrm{M} 2$ is based on the substitutability of bond and stock funds for small time deposits or other M2 balances as savings vehicles, and not on the transactability of bond and stock funds.

\section{Recent Behavior of M2+}

Figure 3 displays the levels of $\mathrm{M} 2$ and $\mathrm{M} 2+$, with $\mathrm{M} 2+$ defined to include capital gains and losses, but excluding IRA/Keogh accounts and institutional holdings. The upper panel of Figure 4 shows the GDP velocities of the two aggregates and the bottom panel shows the growth rates of $\mathrm{M} 2$ and $\mathrm{M} 2+$. Three distinct episodes are evident: (1) From 1984 through 1986, the gap between the two velocity measures increased as growth in M2+ outpaced that of M2 (lower panel); (2) From 1986 through 1990, the velocities moved roughly parallel to each other; (3) From 1990 to the present, the velocity of $\mathrm{M} 2$ rose sharply while that of $\mathrm{M} 2+$ is about unchanged.

Figure 5 shows the monthly growth rates of $\mathrm{M} 2$ and M2t. As shown in the top panel, much of the monthly variability of $\mathrm{M} 2$ growth shows through to $\mathrm{M} 2+$ growth. Monthly net inflows to stock and bond funds apparently are negatively correlated with changes in $\mathrm{M} 2$, but offset only a small portion of the change in $\mathrm{M} 2$, as shown in the middle panel. ${ }^{13}$ However, as shown in the bottom panel, capital gains and losses can induce positive co-movements between the changes in the value of bond and stock funds and changes in M2-such as from 1990:Q4-1991:Q3.

As a consequence, $\mathrm{M} 2+$ is slightly more variable than M2, including the most recent years. In terms of deviations from trend, and as shown in the top panel of Table 1, the mean absolute deviation of M2+ growth over the period from March 1984 through September 1993 is 3.07 percentage points - somewhat greater then that for $\mathrm{M} 2$ growth at 2.46 percentage points. However, during the recent sub-sample of January 1989 to September 1993 , the difference in variability is much smaller. The middle panel of the table indicates that these differences persist using quarterly data. The bottom panel of the table examines the variability of velocity growth about its mean. The variability of $\mathrm{V} 2+$ has been close to that of $V_{2}$ in recent years, but $V_{2}+$ was considerably more variable in the mid-1980s.

\section{MODELING BOND AND STOCK FUNDS AND M2+}

Modeling the demand for any monetary asset requires identifying alternative uses for the balances held in the aggregate. Bond and stock funds compete with M2 for balances, and a potential advantage of considering $\mathrm{M} 2+$ is that this competition need not be addressed in modeling M2+. But bond and stock funds compete with many more assets than just M2-such as commodities or other real assets. Because reasonable proxies for the expected rates of return on real assets are not available, these assets will not be included in the models developed below.

The only alternatives to $\mathrm{M} 2+$ that are included in the models below are direct holdings of Treasury bonds and bills. As a result, analyzing M2+ entails the measurement of own-rates that determine the flows among the following five assets: M2, bond funds, stoek funds, and direct holdings both of bonds and bills. The own-rate for M2 can be calculated from posted rates on M2 deposits. Proxies for ex ante returns on bond and stock funds are examined immediately below.
${ }^{10}$ Although mutual funds could compute the capital gains on the checks written by each shareholder, this does not seem to be a widespread practice as yet. See Clements (1993).

${ }^{11}$ Gross outfows are the value of all batances withdrawn. whether or not the balances are reinvested in another fund.

12 As shown in the figure, recently this ratio has averaged about 2.5 percent, which at an annual rate yields a turnover rate of 0.3 . In comparison, the tumover ratio for traditional savings accounts is 4.7. See Collins and Edwards (1994) for a further discussion.

9 The modest offset is only apparent because the inftows shown are aggregate inflows that include fiows to IRA/Keogh and institutional balances. 
Figure 2

Aggregate Bond and Stock Mutual Fund Outflows (as a percentage of total market value)

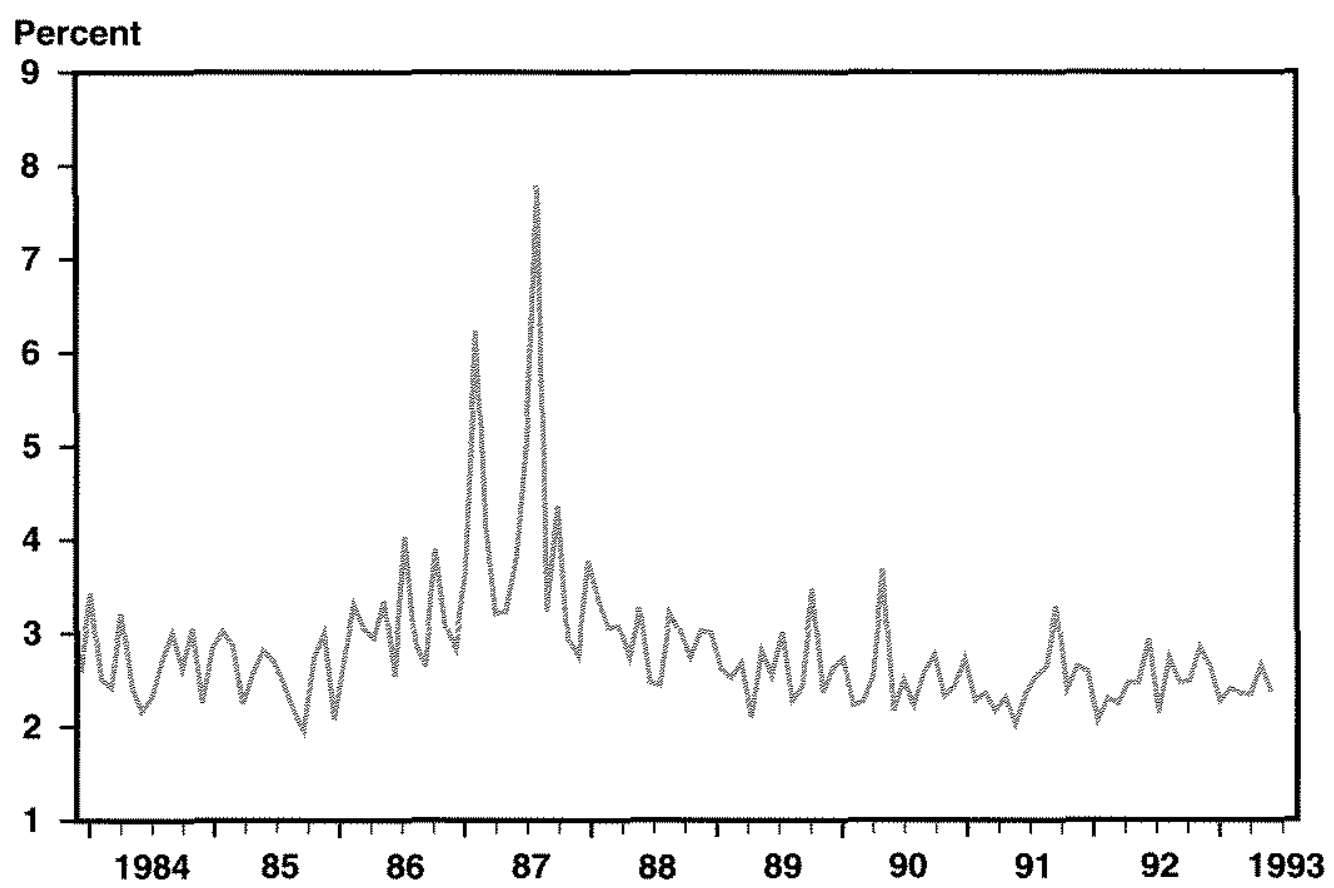

Aggregate bond and stock mutual fund outflows include flows from IRA/Keogh accounts and institutional holdings.

Figure 3

M2 and M2+

Billions of Dollars

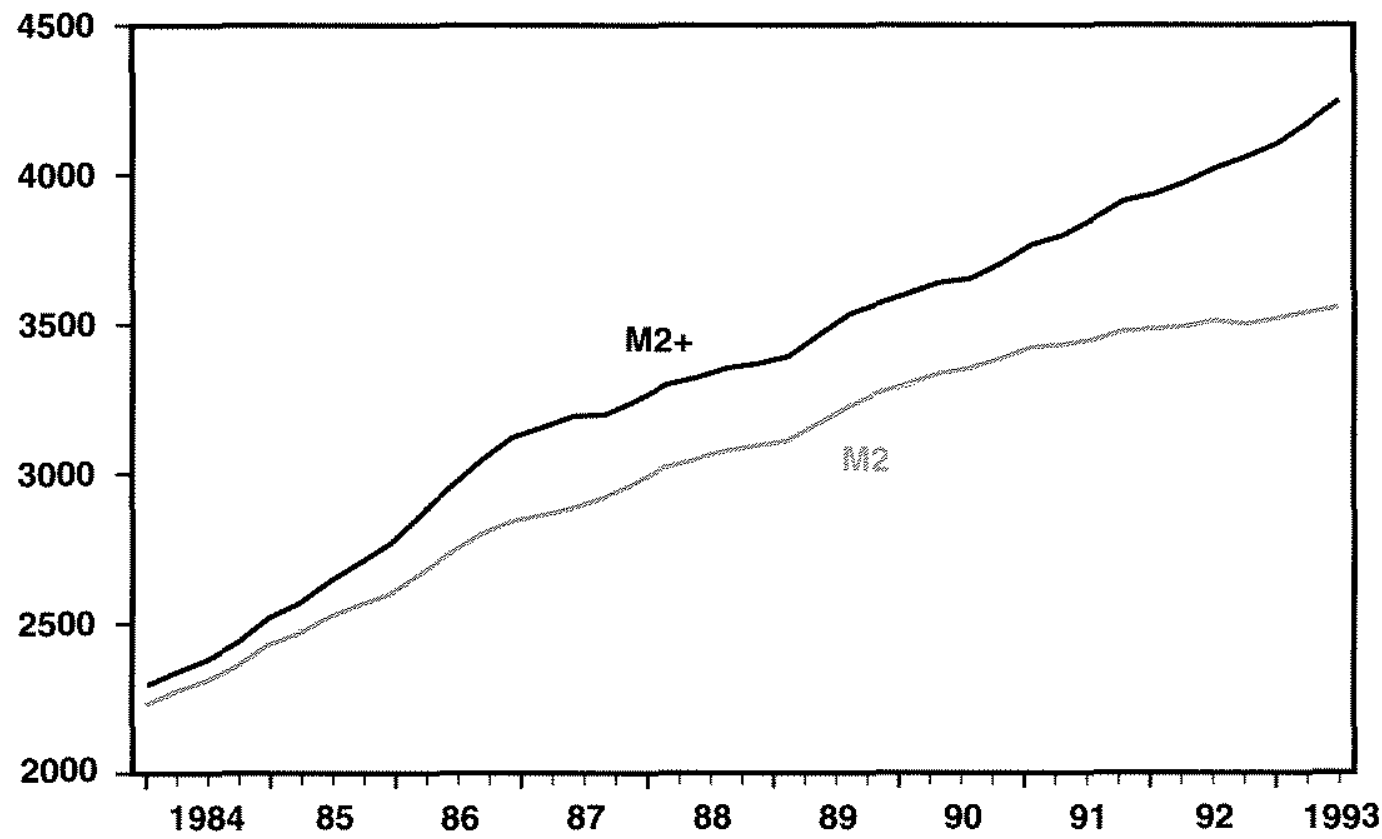


Figure 4A

Velocities of M2 and M2+

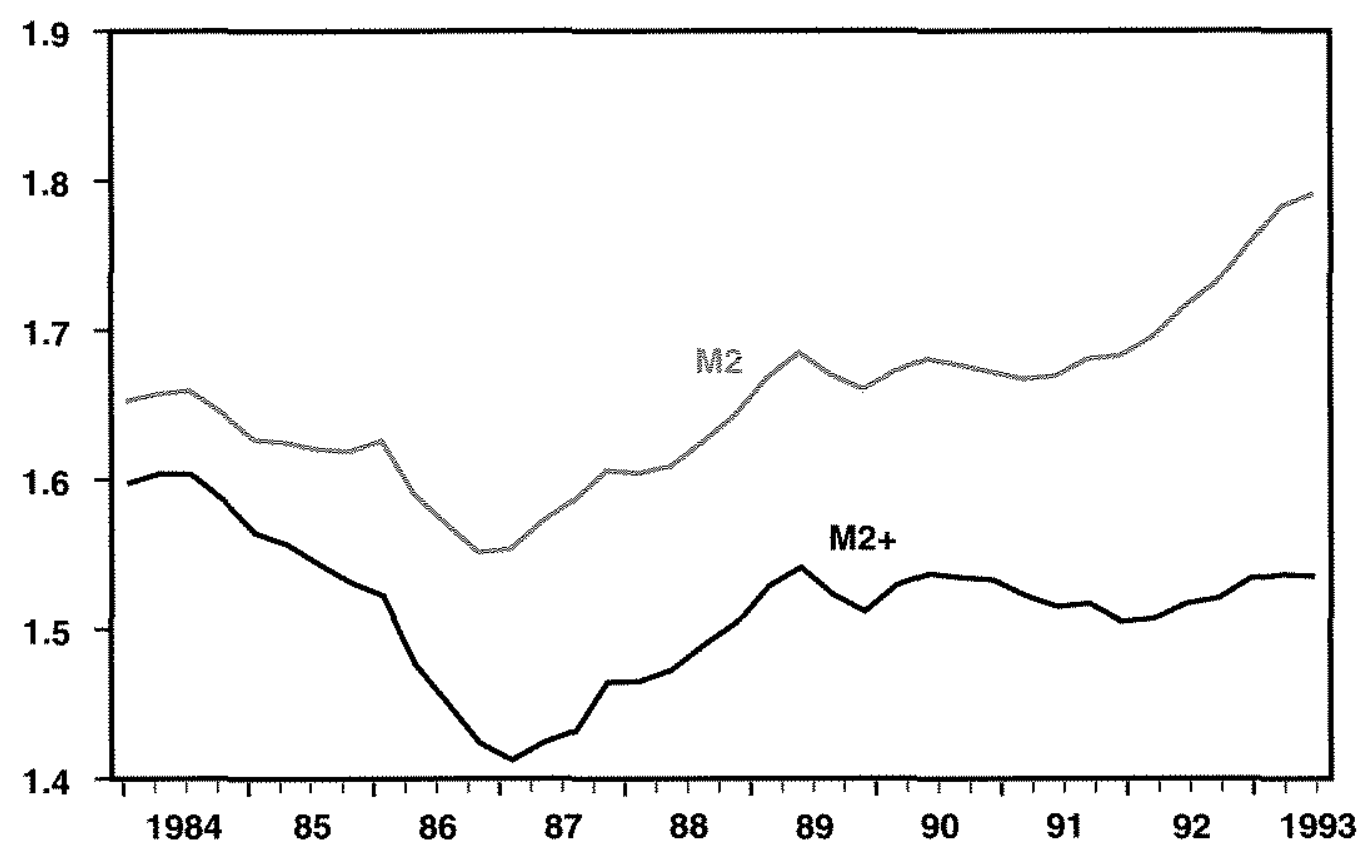

Figure 4B

Growth Rates of M2 and M2+

Percent

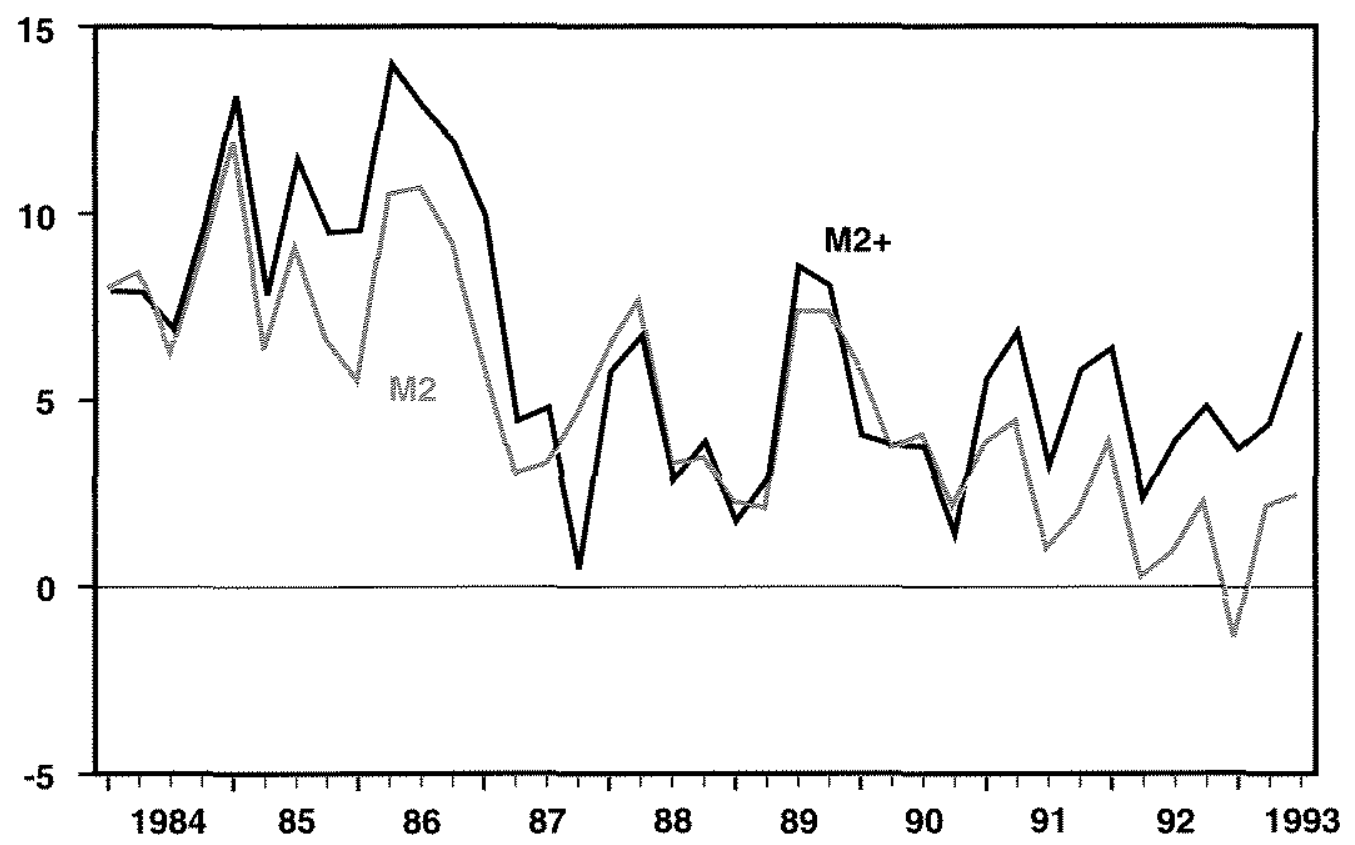


Figure 5

Variability of M2 and M2+

Billions of doltars

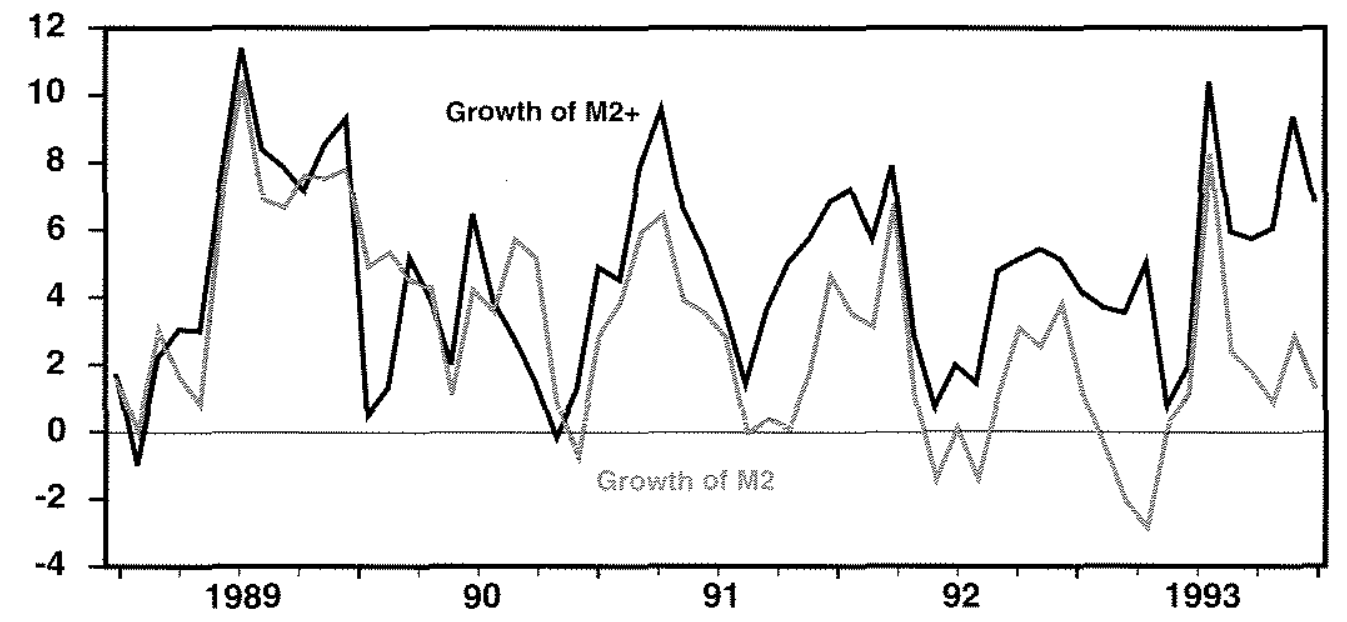

Billions of dollars

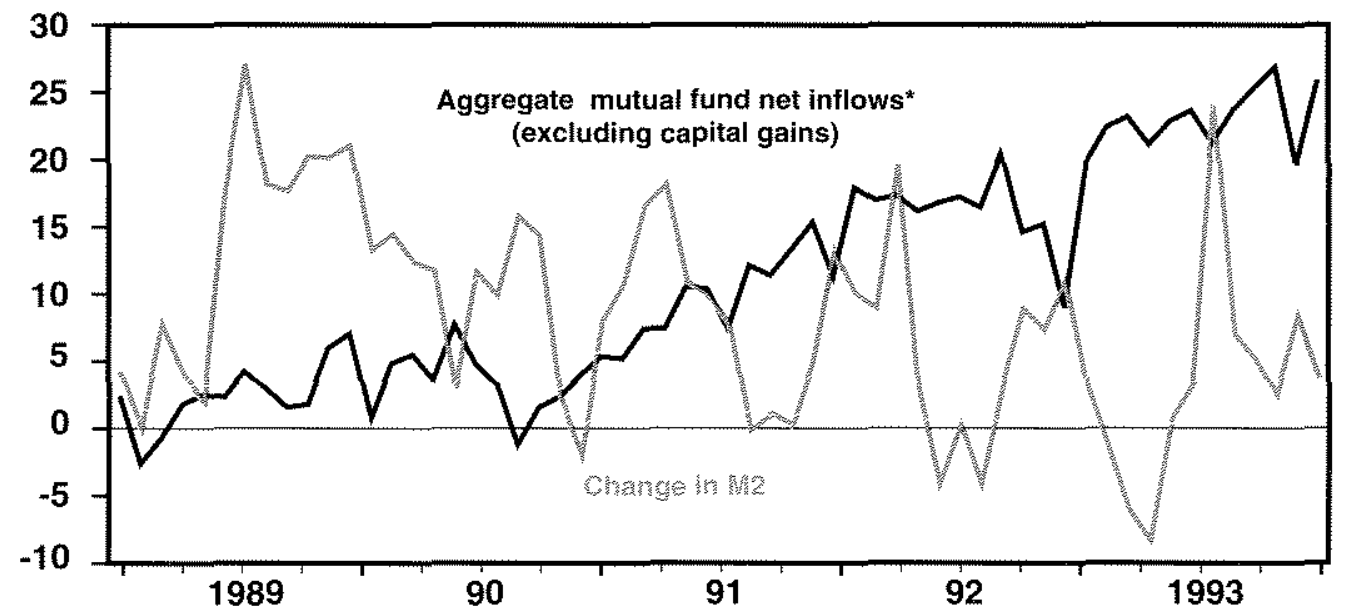

Bitlions of dollars

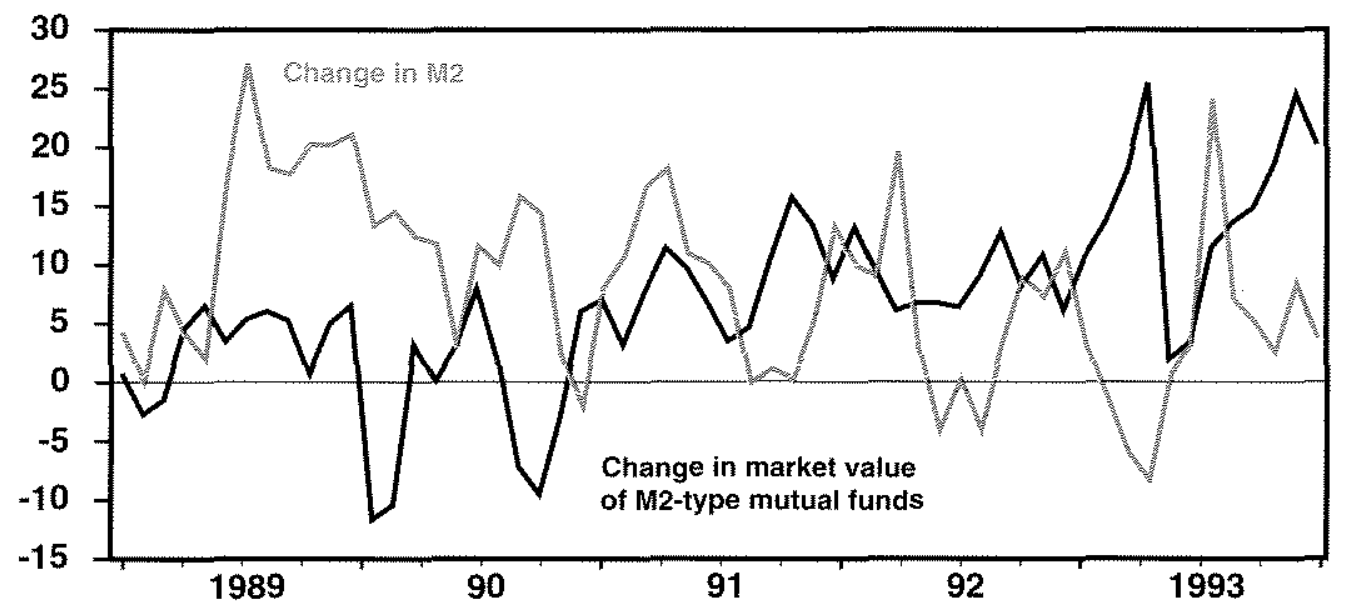

* Aggregate bond and stock mutual fund net inflows include flows to IRA/Keogh accounts and institutional holdings. 


\section{Table 1 \\ Variability of Money and Velocity About Trend* (percent annual rates)

\begin{tabular}{|c|c|c|c|c|}
\hline \multirow[b]{2}{*}{ sample period } & \multicolumn{2}{|c|}{$\begin{array}{l}\text { honey grown } \\
\text { dean abs solute } \\
\text { devion }\end{array}$} & \multicolumn{2}{|c|}{$\begin{array}{l}\text { Standapol } \\
\text { deviation }\end{array}$} \\
\hline & 112 & Not & 112 & $19+$ \\
\hline 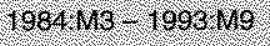 & 2.46 & 307 & 3.04 & 38 \\
\hline $1984 \mathrm{MB}-1988 \mathrm{MI} 2$ & 272 & 837 & 3.25 & 4,15 \\
\hline 1989 Mr 1993 Mo & Wean & $\begin{array}{l}\text { growth } \\
\text { solute } \\
\text { lion }\end{array}$ & 2,82 & 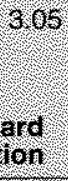 \\
\hline Sample period & Mp & $\mathbf{W}$ & 112 & Mre \\
\hline $1984.03-1998.06$ & 100 & 243 & 210 & 281 \\
\hline $198403-198804$ & 199 & 246 & $2 \times 3$ & 309 \\
\hline 1089.9$)-1098,09$ & $\begin{array}{l}1,56 \\
\text { Wrelo } \\
\text { wean }\end{array}$ & $\begin{array}{l}160 \\
\text { growill } \\
\text { solute } \\
\text { mon }\end{array}$ & 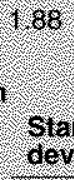 & Gron \\
\hline Sample period & 112 & Met & Me & 12 \\
\hline $198403-19930 \%$ & 280 & 640 & 8.60 & 1225 \\
\hline $198408-1988.04$ & 804 & 406 & 89 & $3+12$ \\
\hline $1989.91-199303$ & 248 & .61 & 296 & 8,10 \\
\hline
\end{tabular}

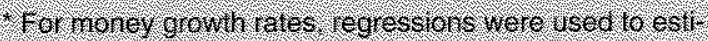
ride serarate hine trends for each sub perod the the trende pick up the general stowing of notey growth since

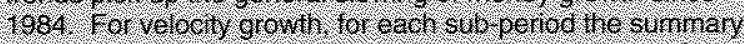

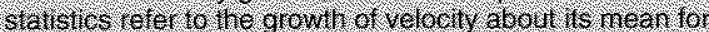
that subperiod. Nollerd in he growil of velocky that is accelerallon of velocith was removed Wetore calculating the summat statistics

Sonne: of the adeitional variabuly in M2 may be because The nonniv t gures tor nutual tunds represent a we ages of ehd ol honth tigures whle Wh data rephesent averages of daly data:

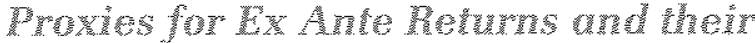 Dfacts on Charges in M2-Type Bond and Stock Punds}

This sub-section attempts to identify determinants of the demands for bond and stock mutual

Increases in these proxies would be expected to increase demands for the relevant type of mutual funds, but may also raise demands for direct holdings.

${ }^{15}$ Decreases in aggregate bond and stock fund inflows in 1987 were related in part to changes in the tax exemption for IRA contributions, which were liberalized in 1981 and tightened in 1987. The latter change in the tax law does not seem to be the dominant reason for the dropoff in aggregate inflows in 1987 . Net inflows went from $\$ 144$ billion in 1986 to $\$ 49$ billion in 1987, but data on IRAs indicate that a drop in their flows account for no more than $\$ 7$ billion of this stowing. funds. In particular, proxies are needed for the ex ante returns on mutual funds.

For bond funds, two alternative proxies are available. One approach relies on contemporaneously observable market rates and the other employs lags of ex post realized returns. ${ }^{14}$ The first approach uses the slope of the Treasury yield curve and recent changes in the Treasury bond rate. The yield curve captures the difference between quoted yields to maturity on long-term bonds and posted returns on short-term assets including small time deposits or money market mutual funds (MMMFs) in M2 as well as money market instruments. As such, increases in the spread will make bond mutual funds (as well as direct holdings) look more attractive. Recent bond rate changes may affect investors' expectations of prospective capital gains or losses if investors have extrapolative expectations.

The top panel of Figure 6 shows that both net aggregate inflows to bond funds and the change in market value of M2-type bond funds surged from 1984 through the first quarter of 1987. This surge may well have reflected the relatively steep yield curve going into that period (middle panel) and capital gains caused by falling bond rates throughout most of the period (lower panel). ${ }^{15}$ But then with the upturn in bond rates in the second quarter of 1987 , bond funds initially experienced modest average outflows during the last half of 1987, and then grew moderately over the next two years as long rates leveled off and the slope of the yield curve fell because of rising short-term rates. More recently, aggregate bond inflows surged as bond rates started to drift down again (although more slowly than during the 1984-1986 period) and as the slope of the yield curve rose to record heights.

A quarterly regression that examines the effects of the slope of the yield curve and recent capital gains and losses is given in equation 1. The change in market value of M2-type bond funds is scaled by the lagged value of $\mathrm{M} 2+{ }^{16}$

EF Bond funds are scaled by $\mathrm{M} 2+$ to avoid placing undue weight on the early years of the regression. Such overemphasis could resut if bond fund changes were scaled by lagged bond funds (that is, if we modeled the growth rate of bond funds) because during the early years when bond funds were modest, a small shift from M2 would represent a farge percentage change in bond funds. 
Figure 6

Changes in Bond Fund Balances

Billions of dollars

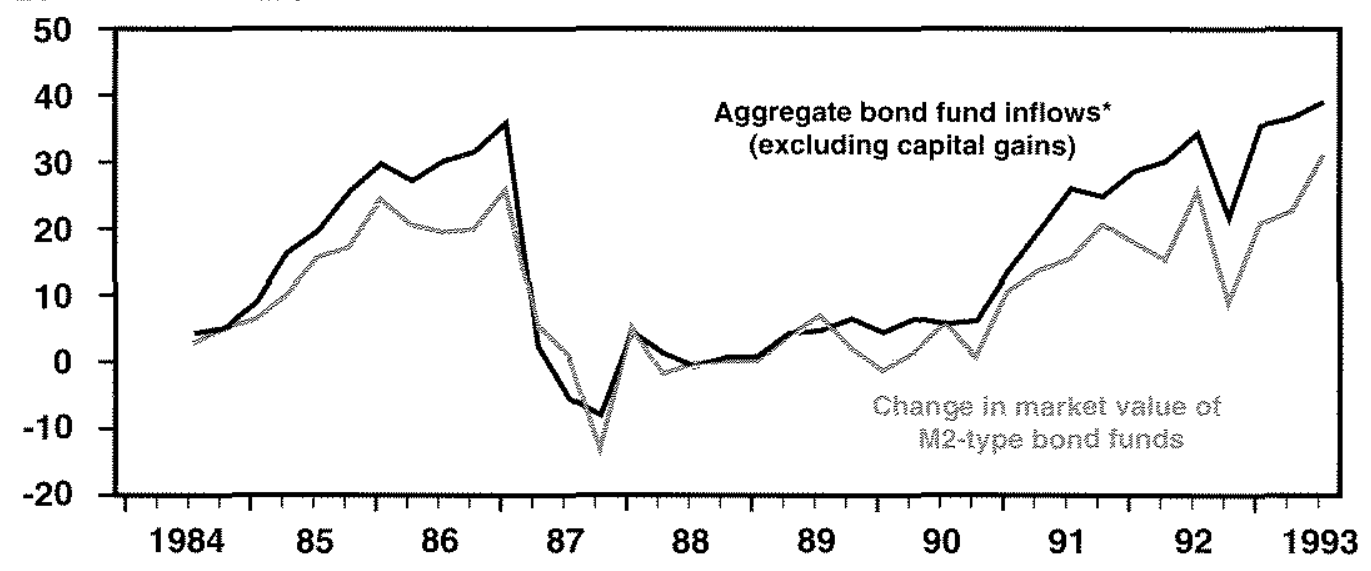

Spread Between the 30-Year Treasury Bond and the 3-Month Treasury Bill Rates

Percentage points

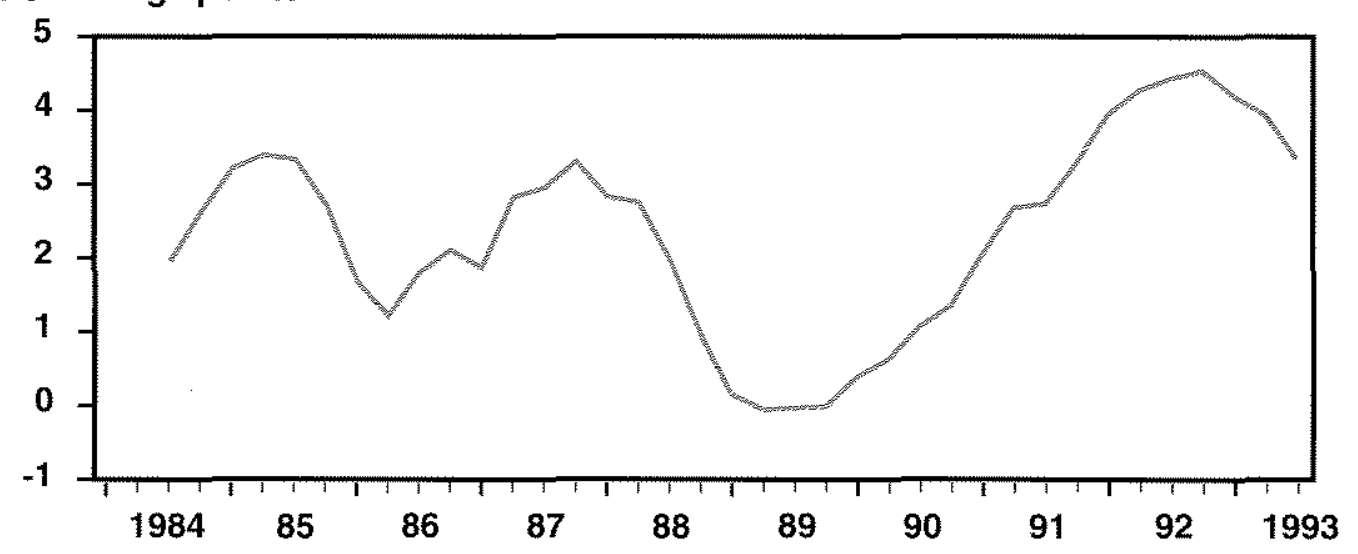

30-Year Treasury Bond Rate

Percent

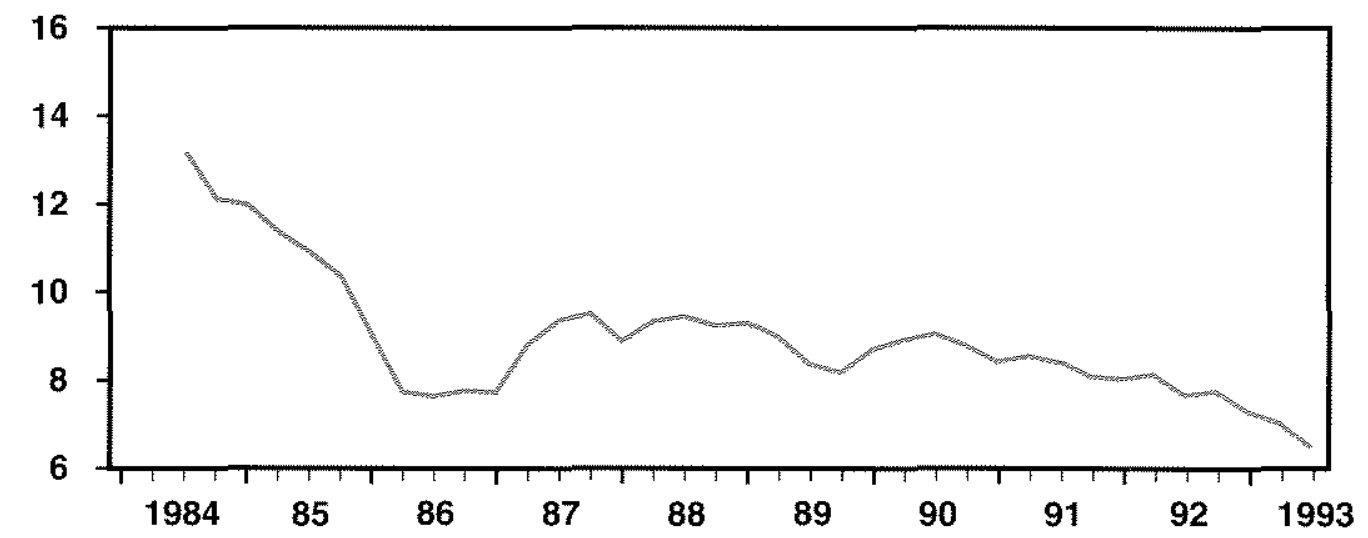

* Aggregate bond fund net inflows include flows to IRA/Keogh accounts and institutional holdings. 

(1) $\triangle$ BFUND $=.00019+.000025$ TIME
$\mathrm{M} 2+_{-1} \quad(.25) \quad(.75)$
+.00047 (RT30Y - RTBE) $)_{-1}$
(1.97)
$-.0022 \Delta \mathrm{RT} 5 \mathrm{Y}-.0014 \Delta \mathrm{RT} 5 \mathrm{Y}_{-1}$
(3.71) (2.28)
$-.0017 \Delta R T 5 Y_{\circ 2}-.0018 \Delta R T 5 Y_{.3}$.
(3.04) (3.14)

$\mathrm{R}^{2}=.735$

$\mathrm{R}^{2}=.676$

D.W. statistic $=1.22$

Estimation period: 1985:Q2 - 1993:Q3,

where: $\triangle B F U N D$ is the change

in the market value of M2-type

bond funds;

RT30Y is the 30-year Treasury bond rate;

RT5Y is the five-year Treasury note rate;

RTBE is the three-month Treasury bill rate;

and the absolute values of t-statistics are in parentheses.

The positive coefficient on the spread variable indicates that a steep yield curve draws balances into bond mutual funds. The negative coefficients on the changes in the five-year Treasury note show that recent capital losses reduce bond fund inflows. The contemporaneous change in the note rate also captures the direct effect of changes in the market values.

While the top panel of Figure 7 repeats that of Figure 6, the lower panel of 7 uses the realized returns on bond funds to proxy for expected returns. Comparisons across the two panels show a rough relation between the changes in bond fund balances and the spread of realized returns over Treasury bill rates. A regression relating the change in market value of M2-type bond funds to the opportunity cost that uses the four-quarter moving average of the realized returns is given in equation $2 .^{17}$

$$
\begin{aligned}
& \frac{\triangle B F U N D}{\mathrm{M} 2+_{-1}}=\underset{(2.03)}{.0012-}-\frac{.000098 \mathrm{TIME}}{(.34)} \\
& \text { - .00036 (RTBE - RETBND4) } \\
& \text { (7.47) } \\
& -.0017 \Delta \mathrm{RT5Y} \text {. } \\
& \text { (3.14) }
\end{aligned}
$$

where: $\quad \triangle B F U N D$ is the change in market value of M2-type

bond funds;

RETBND4 is a four-quarter moving average of the ex post realized return on bond funds;

RTBE is the three-month Treasury rate;

and the absolute values of $t$-statistics are in parentheses.

These results are similar to those reported in equation 1 , with both equations having $R^{2} s$ of about .75 .

For stock funds, the upper panel of Figure 8 shows two measures of changes in balances and the lower shows the spread of the realized returns over the Treasury bill rate. Comparing the two panels, the surge in balances prior to the stock market crash of 1987, the subsequent falloff, and then the resurgence in balances in 1989 are all tracked by the movements in realized returns minus the Treasury bill rate. The latest spurt in balances seems anomalous, but some of this rise is lessened when the changes in market values are scaled by $\mathrm{M} 2+$ as in the following regression, which explains the change in the market value of M2-type stock funds:

\footnotetext{
17 The four-quarter moving average is used for realized returns

to save on the number of freely estimated parameters, in

comparison to using four lags of realized returns. When the spread between the quarterly realized retum and the

Treastry bill rate is entered with four lags, the four individual coefficients are roughly of the same magnitude and the sum of the coefficients is statistically insignificantly difterent from the estimated coefficient on the four-quarter moving average reported in equation 2 .

Also, the realized return is entered in the form of the spread of the Heasury bill rate over the realized return in keeping with standard usage of entering opportunity costs.
} 
Figure 7A

Changes in Bond Fund Balances

Billions of dollars

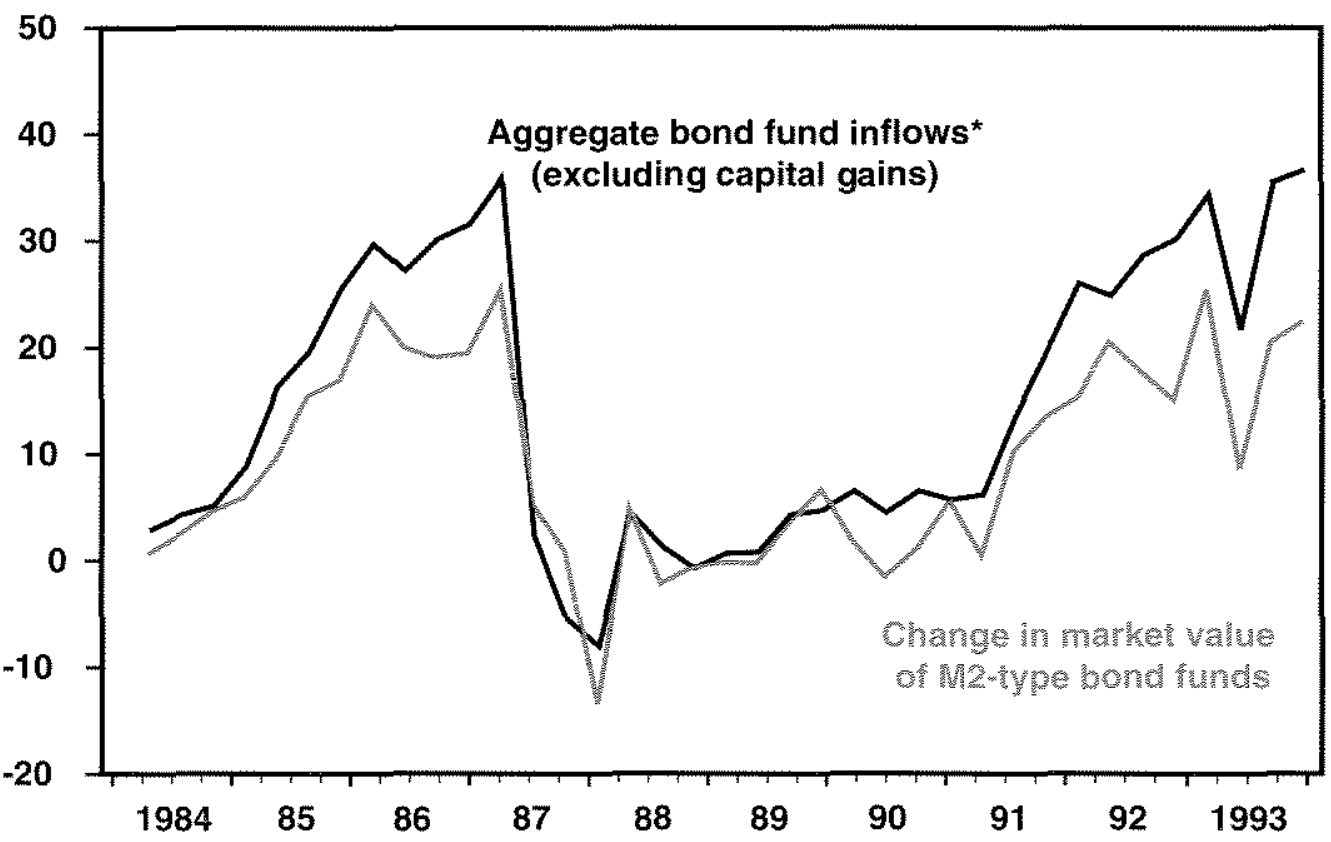

Figure 7B

Realized Returns on Bond Funds Minus the 3-Month T-Bill Rate

Percent

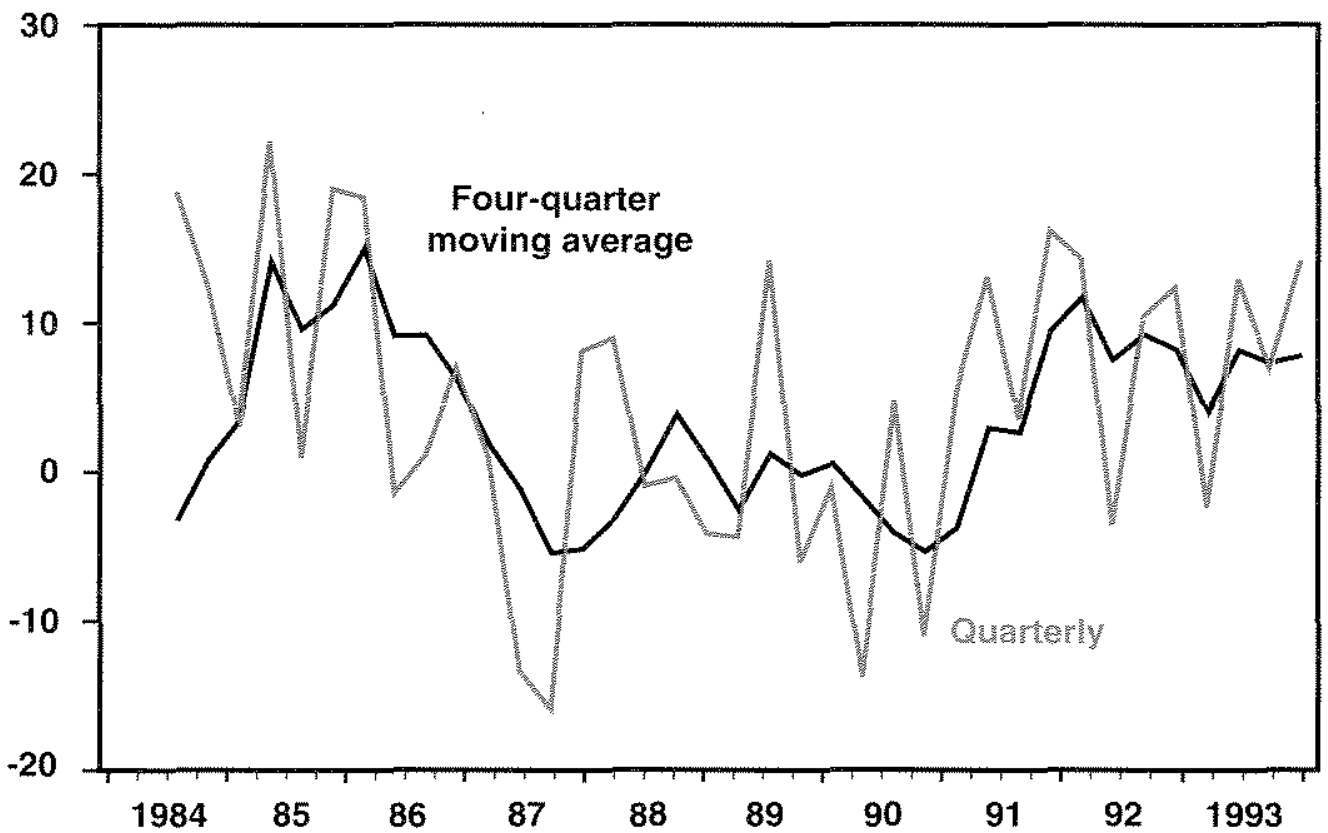

* Aggregate bond fund net inflows include flows to IRA/Keogh accounts and institutional holdings. 
Figure 8A

\section{Changes in Stock Fund Balances}

Billions of dollars

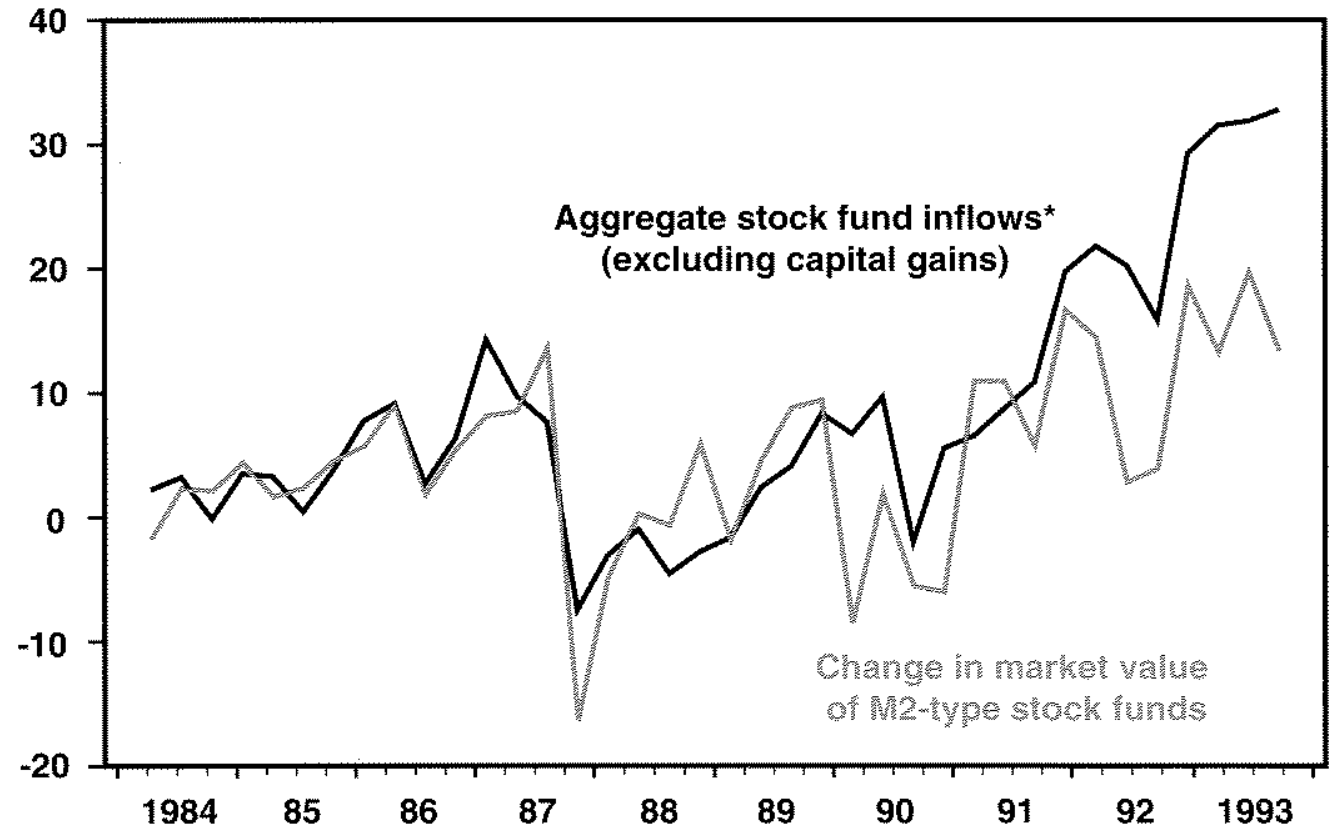

Figure 8B

Realized Returns on Stock Funds Minus the 3-Month T-Bill Rate

Percent

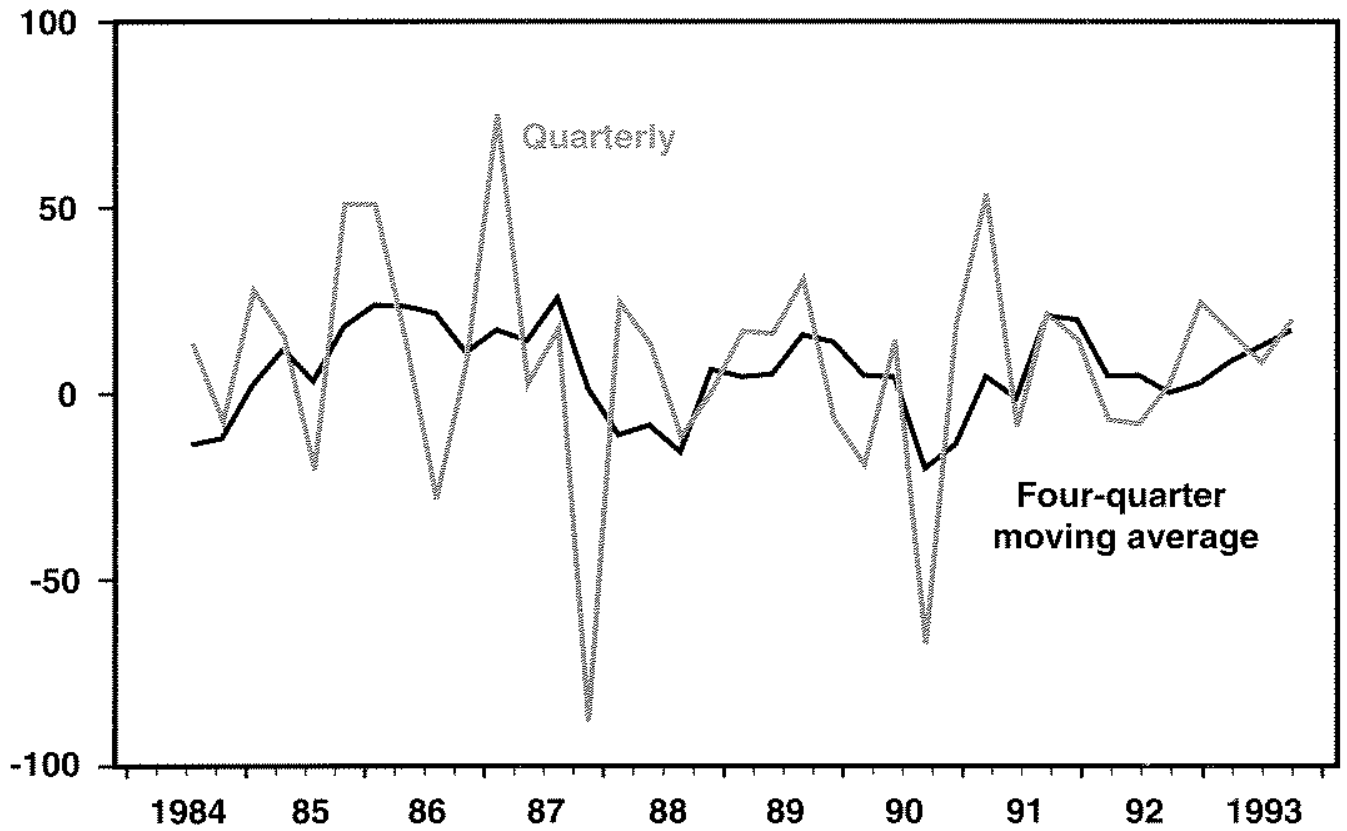

* Aggregate bond fund net inflows include flows to IRA/Keogh accounts and institutional holdings. 
(3) $\triangle$ SFUND $=-.00093+.000072$ TIME

${\mathrm{M} 2+_{-\mathrm{I}}} \quad(1.68) \quad(2.96)$

$-.000054(\mathrm{RTBE}-\mathrm{RETEQ} 4)_{-1}$

(2.59)

$+.00017 \Delta \log (\mathrm{NYSE})$.

(6.98)

$\mathrm{R}^{2}=.661$

$\overline{\mathrm{R}}^{2}=.628$

D.W. statistic $=2.15$

Estimation period $=1985: Q 2-1993: Q 3$,

where: $\triangle S F U N D$ is the change in market value of M2-type stock funds;

RETEQ4 is a four-quarter moving average of the ex post realized return on stock funds;

NYSE is the New York Stock Exchange price index;

and the absolute values of t-statistics are in parentheses.

As with the bond inflow equations, the spread of the three-month Treasury bill rate over the realized return has a significant, negative impact. Moreover, the overall fit of the equation is quite high, as the capital gains reflected in the contemporaneous change of stock prices explain most of the variation in the market value of stock fund balances.

An unattractive aspect of equations 1-3 is the absence of a scale variable such as income or wealth and, consequently, the absence of well-defined, long-run equilibrium levels of bond and stock funds relative to income or wealth, or even to M2+. Specifications of such relations were unsuccessful, apparently because innovation and growth of the bond and stock fund industry have caused bond and stock fund balances to grow relative to other nominal quantities. As a result, in what follows we do not attempt to provide a model of the components of $\mathrm{M} 2+$ but only of $\mathrm{M} 2+$ as a whole, which can be modeled with such a scale variable.

${ }_{18}$ These are error correction models. To derive the long wrun properties of the model, let nominat GDP and all interest rates be constant. Then $\mathrm{M} 2+$ will also be constant and the left-hand side of the regression model can be set to zero. The logarithm of velocity can then be solved for as a linear function of the opportunity costs and the Treasury yield curve spread

${ }^{19}$ Recent models that estimate significant yield-curve effects on M2 demand were developed by Hess(1990). Subsequently, Feinman and Potter (1992) found the same effect and Mehra (1992) obtained similar resuits.

\section{Modeling the Demand hom Mat}

This section presents and evaluates simple models of the demand for M2+. The models are similar to earlier specifications for the demand for M2 that posit a long-run demand in which velocity is a linear function of opportunity costs. The regression models are of the general form: ${ }^{18}$

$$
\begin{aligned}
\Delta \log (\mathrm{M} 2+) & =\mathrm{c} 0+\mathrm{c} 1 \text { Time }+\mathrm{c} 2 \log (\mathrm{M} 2+/ \mathrm{GDP})_{-1} \\
& +\mathrm{c} 3 \text { (opportunity cost variables })_{-1} \\
& +\mathrm{c} 4(\mathrm{RT} 30 \mathrm{Y}-\mathrm{RTBE})_{-1}+\text { error. }
\end{aligned}
$$

Opportunity costs are defined as the difference between the yield on the three-month Treasury bill and the own-rate of return on monetary assets. For own-rates we use the own-rate on M2 (RM2E), and as proxies for the own-rates of return on bond and stock mutual funds, we use the four-quarter moving averages of realized returns on bond and stock mutual funds (RETBND4 and RETEQ4), as in equations 2 and 3 . Because we assume direct holdings of bonds and bills are the primary competing asset for $\mathrm{M} 2+$ balances, the opportunity cost variables all incorporate Treasury rates as the competing rate. For this, the three-month Treasury bill rate is used.

Because longer-maturity Treasury securities may also be competing assets for M2+, especially for the M2 balances in $\mathrm{M} 2+$, all specifications considered below include the slope of the term structure. This variable has been found to have a significant, negative impact on M2 in recent years and above we found that it had a positive impact on bond-fund inflows. ${ }^{19}$ If the substitution away from M2 that this variable captures is towards bond and stock funds only, there would be no net impact on $\mathrm{M} 2+{ }^{20}$ Indeed, it is the internalization of just such substitutions that makes $\mathrm{M} 2+$ a potentially useful aggregate. However, if the slope of the term structure captures some substitution of M2 into direct holdings of stocks and bonds, then it would have a negative impact on $\mathrm{M} 2+$.
${ }^{20}$ Indeed, such substitution is consistent with the findings of equation 1 , which showed a positive impact of the yield curve on bond fund balances. 
Table 2

\section{Estimated Demand Equations for M2+}

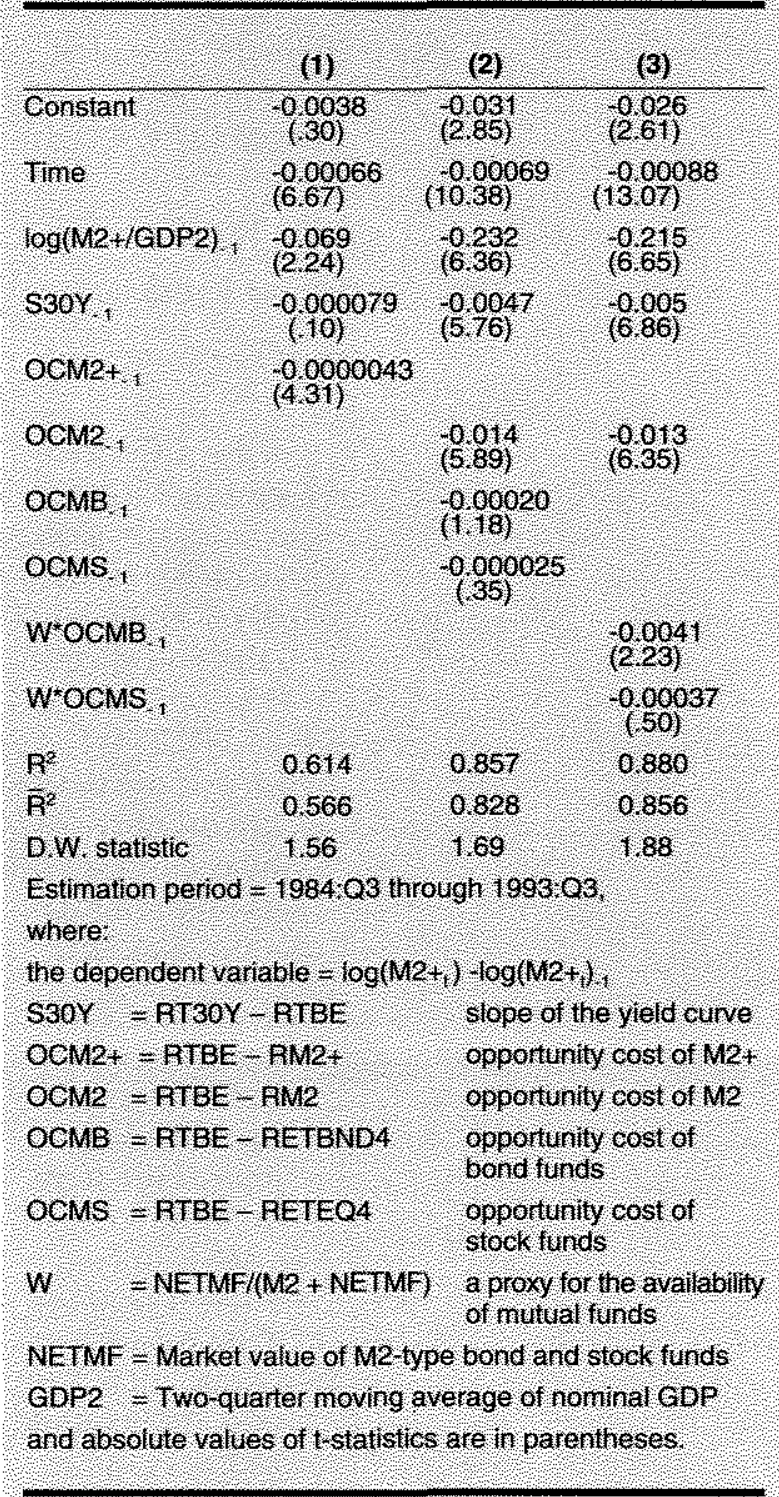

${ }^{2 t}$ In this setting, the M2+ own-rate, RM2+, is constructed as the weighted average of RM2E, RETBND4 and RETEQ4, weighted by the quantities of M2, bond funds and stock funds held in the previous quarter relative to $\mathrm{M} 2+$. The opportunity cost of $\mathrm{M} 2+$ is defined as OCM2+ = RTBE $-\mathrm{RM} 2+$, where RTBE is the yield on three-month Treasury bills.

22 There are several reasons to believe that separating the two opportunity costs will produce better estimates. First, given the likely error in measuring expected ex ante own-rates for bond and stock mutual funds, the aggregation of those wo rates with the better-measured $\mathrm{M} 2$ own-rate will contaminate the estimated response to all three own-rates, in general lowering the estimated coefficient from its true value. Second, and equally important, since the relevant alternative assets for stock and bond mutual funds outside $\mathrm{M}_{2}$; are likely to include assets other than three-month Treasury bills, the opportunity cost relative to the three-month
Within this general specification, we fit three alternative $\mathrm{M} 2+$ demand functions. In the first alternative (shown in column one of Table 2), we used the slope of the yield curve and one opportunity cost that incorporates a weighted-average own-rate on $\mathrm{M} 2+{ }^{21}$ The regression in column one implicitly contains the restriction that the responses of $\mathrm{M} 2+$ to the opportunity costs of the three components (M2, bond funds and stock funds) after being weighted by dollar shares are equal. To allow for different responses to changes in the individual opportunity costs, column two of Table 2 shows a regression in which the unweighted opportunity cost for each of the three components of M2+ (OCM2, OCMB and OCMS) is entered separately. ${ }^{22}$ As can be seen, the adjusted $R^{2}$ rises significantly when the constraint is relaxed. However, the opportunity costs of bond and stock funds are statistically insignificant.

As a final specification, an attempt is made to incorporate the effects of the increasing access of retail customers to bond and stock funds. In column three of Table 2, the bond and stock fund opportunity costs are weighted by the ratio of bond and stock fund balances to the value of $\mathrm{M} 2+.^{23}$ As can be seen, the fit of the equation improves modestly with the incorporation of these weights. In addition, the statistical significance of the opportunity cost of bond funds improves noticeably. The opportunity cost of stock funds remains insignificant, which may not be surprising because the highly volatile ex post returns on stock funds may be little used by investors in forming expectations of future movements in the market.

\section{Shably of

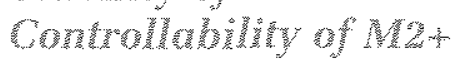

The stability of the above estimated demand functions for $\mathrm{M} 2+$ is generally suspect for a

Treasury bill may be more important for M2 than for stock and bond mutual funds.

23 As a proxy for the availability of mutual fund accounts, these weights suffer from being determined in part by the other factors driving demand for M2t. A better, but unavailable, proxy would be one based on transaction costs.

The weight grows from about 3 percent in 1984 to around 8 percent in 1988 and then to 15 percent currently. 


\section{Figure 9}

\section{Growth of Actual and Simulated M2+}

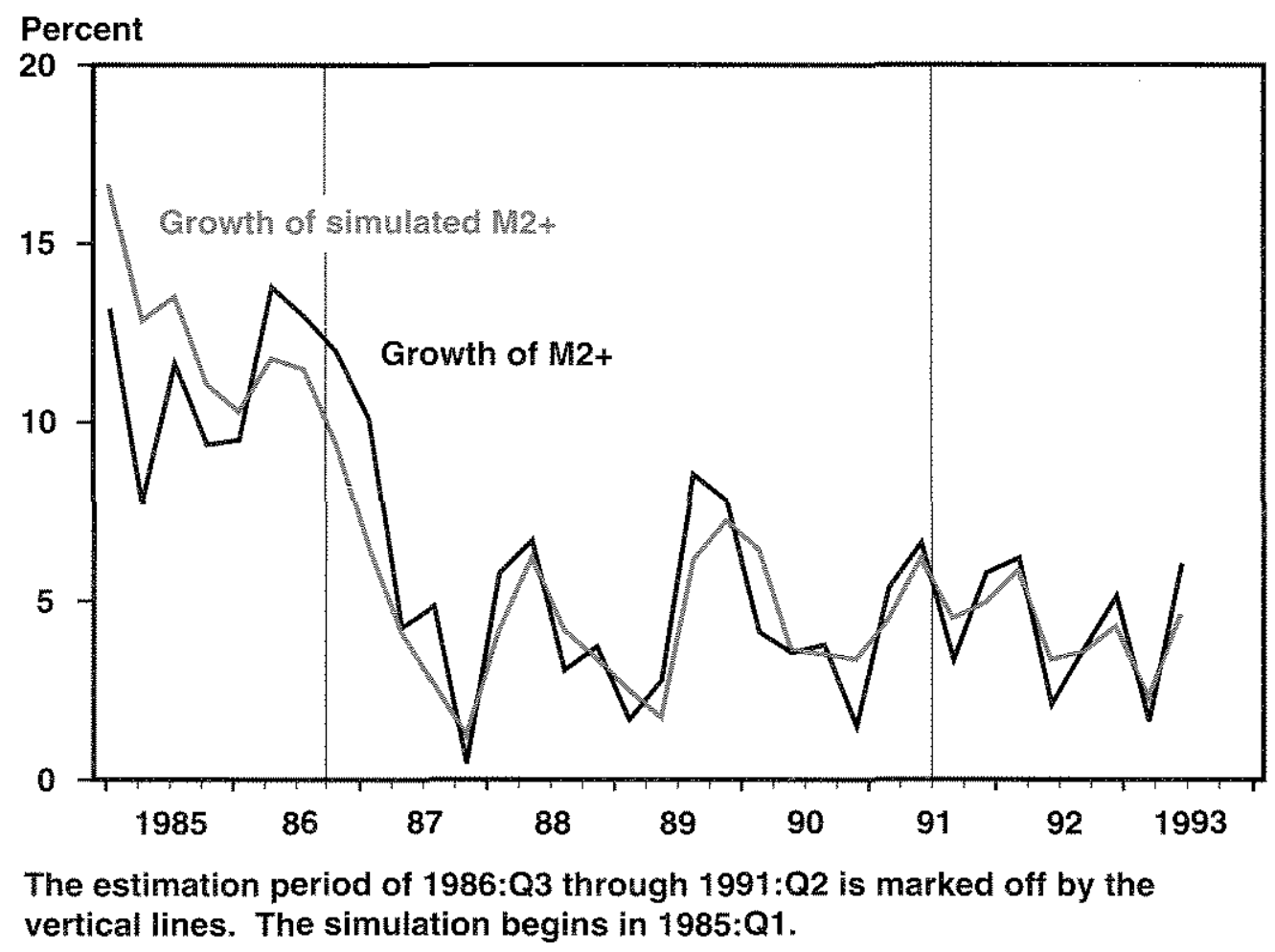

number of reasons. First, 10 years is a very short sample period. Second, within that period there was considerable innovation in the bond and stock fund industry. The weights used in the model of column three of Table 2 are likely at best to capture only broadly the effects on M2+ of such innovations. Third, there are the obvious limitations of the opportunity cost variables in terms of identifying competing rates of return when the aggregate is as broad as $\mathrm{M} 2+$ and in terms of proxying ex ante expected rates of return on bond and stock funds.

Indeed, all three equations in Table 2 fail Chow tests, strongly suggesting a lack of stability. Under these tests, the estimation period is split into two sub-periods, and the estimation results over the two sub-periods are compared statistically. In a less formal check, the model of column three in Table 2 was estimated over a sub-period that starts in 1986:Q3 and ends in 1991:Q2, allowing for an examination of the model's forecasting performance both before and after this period. The simulation shown in Figure 9 shows fairly substantial errors over the pre-estimation period, but reasonable accuracy starting by 1988 and carrying through nearly to the present.

Figure 10 provides some evidence on the historical contribution of capital gains and losses to the growth of $\mathrm{M} 2+$. These can be a guide to the size of the shocks to the growth of $\mathrm{M} 2+$ that might need to be offset if fairly close control of $\mathrm{M} 2+$ were taken seriously. Although these estimates likely are somewhat imprecise, they do show the effects of the stock market crash of 1987 and major market swings. However, since stock and bond funds are becoming a larger proportion of $\mathrm{M} 2+$, the aggregate is probably becoming increasingly vulnerable to swings in capital gains and losses.

\section{THE INDICATOR PROPERTIES OF M2 $\mathrm{AND} \mathrm{M2+}$}

As a final set of statistical comparisons of the behavior of $\mathrm{M} 2$ and $\mathrm{M} 2+$, the ability of these aggregates to predict changes in nominal GDP 
Figure 10A

\section{Quarterly Growth of M2+ Accounted for by Capital Gains*}

\section{Percentage Points}

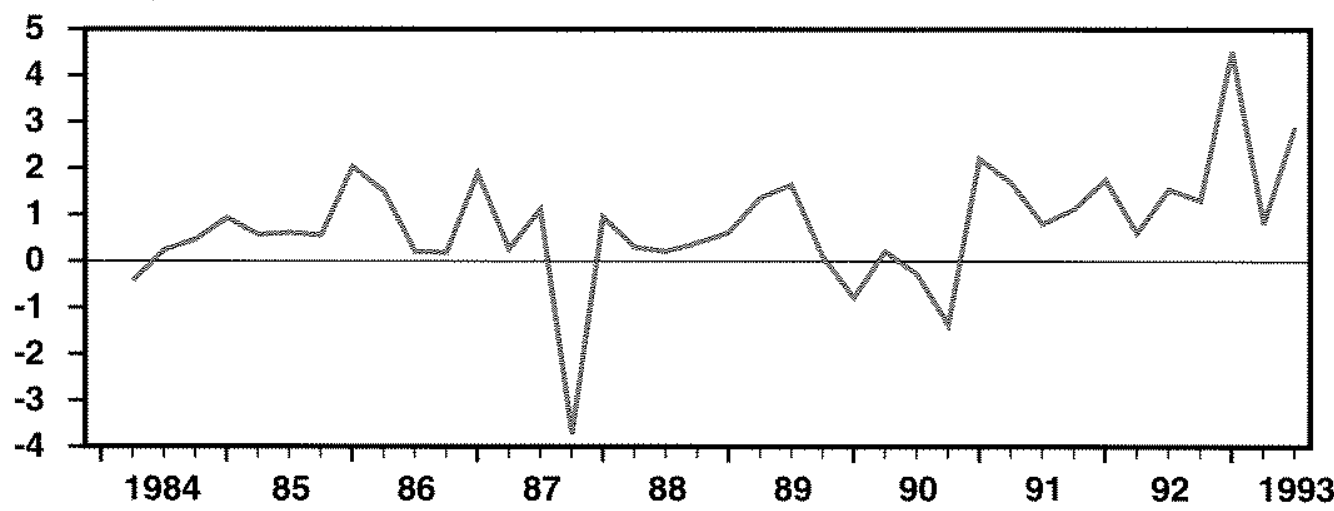

Figure $10 \mathrm{~B}$

Annual (Q4/Q4) Growth of M2+ Accounted for by Capital Gains* Capital gains over the year divided by M2+ of $\mathrm{Q} 4$ of previous year

\section{Percentage Points}

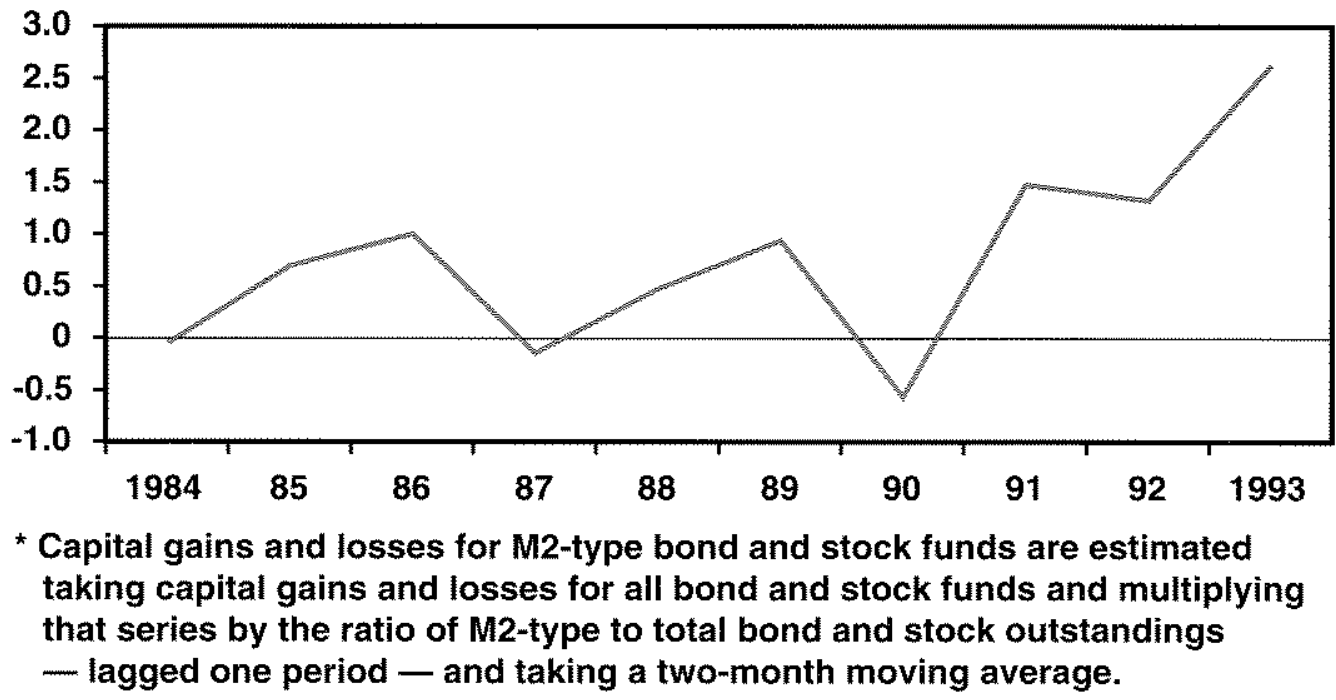

is examined. Each test regresses one-quarter nominal GDP growth on lagged nominal GDP growth, lagged growth in one of the monetary aggregates, and lagged changes in the three-month Treasury bill rate. ${ }^{24}$ The regression models are of the general form:

$\Delta \log \left(G D P N_{1}\right)=B_{0}+\sum_{k=1}^{4} B_{12} \Delta \log \left(G D P N_{t-n}\right)$

$+\sum_{\mathrm{n}=1}^{4} \zeta_{n} \Delta \log \left(\mathrm{M}_{\mathrm{t}-\mathrm{n}}\right)+\sum_{\mathrm{n}=1}^{4} \lambda_{\mathrm{u}} \Delta\left(\mathrm{RTBE}_{\mathrm{t}-\mathrm{n}}^{\mathrm{n}}\right)+\varepsilon_{\mathrm{t}}$,

where
GDPN = nominal GDP.

$\mathrm{M}=$ monetary aggregate, and

RTBE = three-month Treasury bill.

The top panel of Figure 11 presents in-sample measures of the statistical significance of the lagged money measures for a rolling 15 -year estimation window. The measure of significance at an indicated date is the significance level when the estimation period includes 15 years of data ending at that date. By this measure, the two aggregates performed equally well in predicting

24 The observation for $1980 . \mathrm{Q} 2$, during which credit controls were imposed, was omitted from the data. 
Figure $11 \mathrm{~A}$

Significance Levels for the Predictive Impact of M2 and M2+ on Nominal GDP Growth* (15-year window)

Significance level

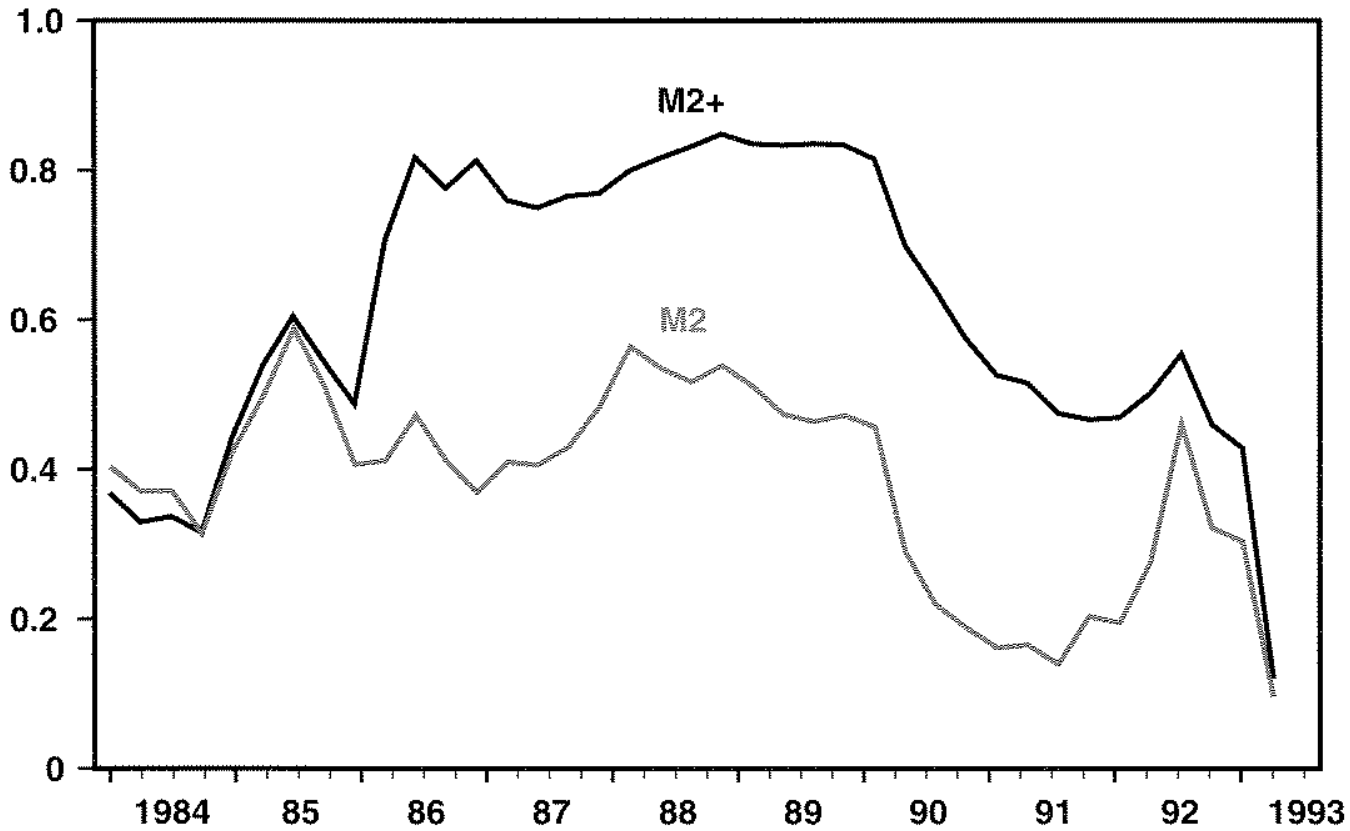

Figure 11B

Significance Levels for the Predictive Impact of M2 and M2+ on Nominal GDP Growth* (71/2-year window)

Significance level

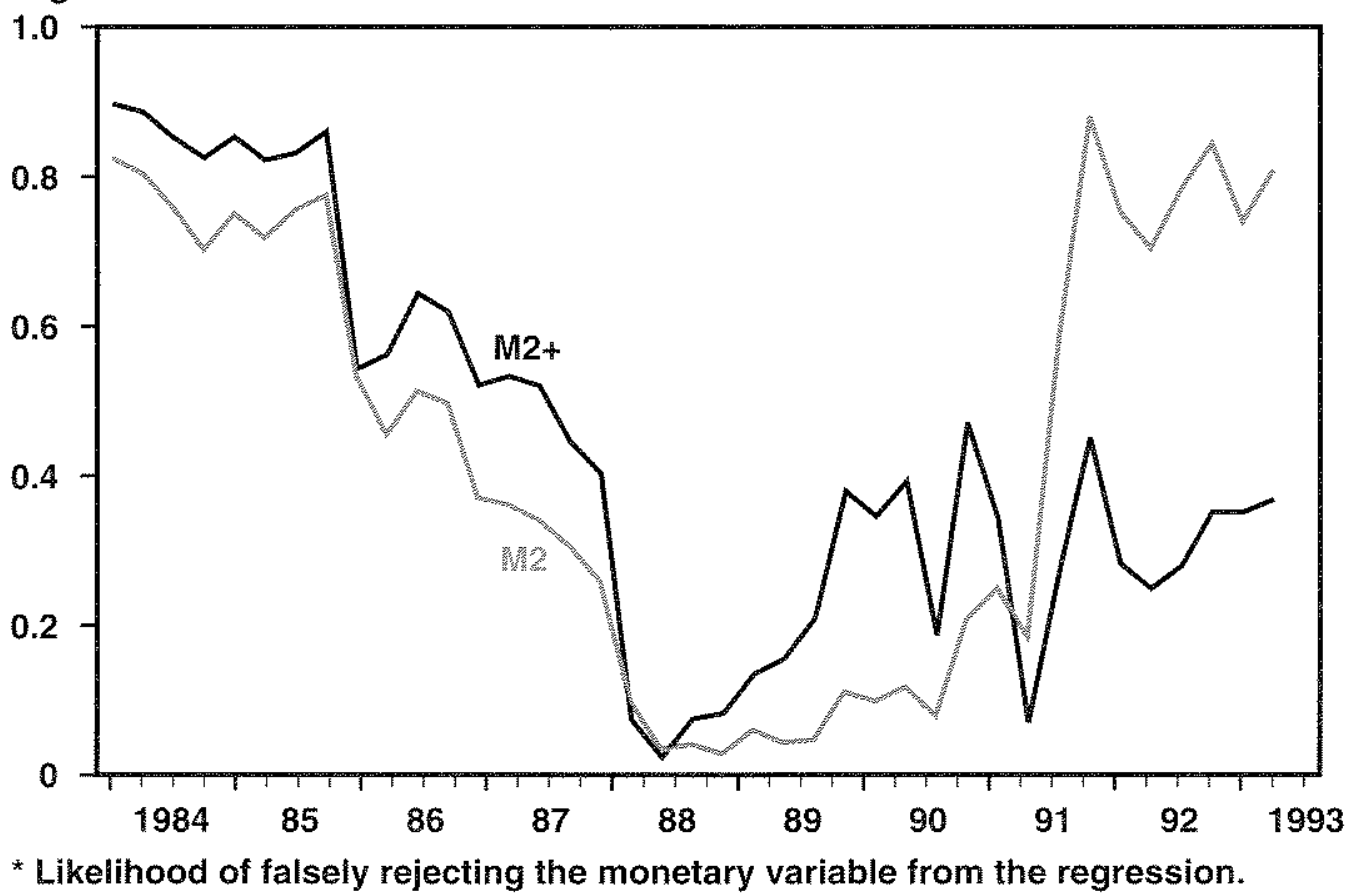


Figure 12A

One-Quarter-Ahead Forecast Errors for Nominal GDP Growth* (15-year window)

Percentage points

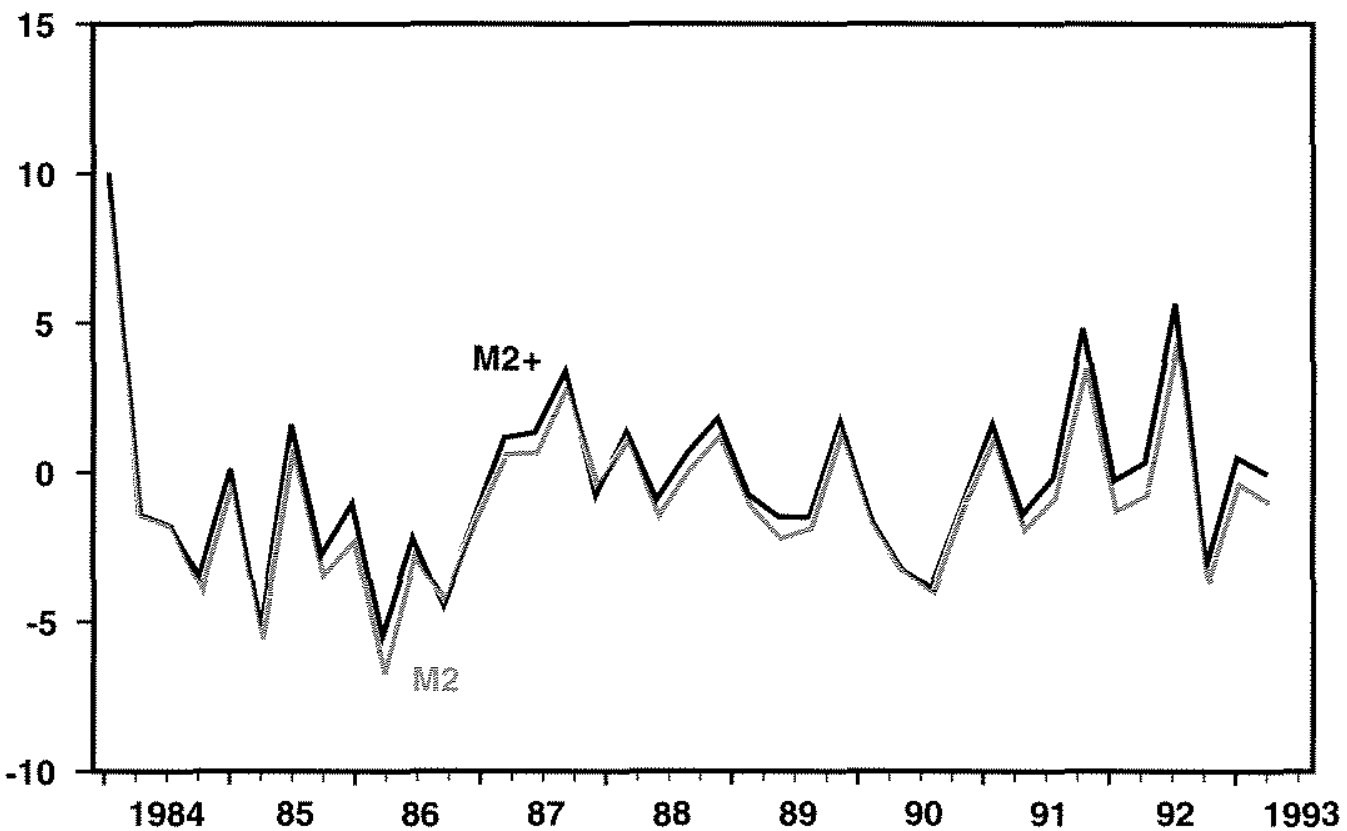

Figure 12B

One-Quarter-Ahead Forecast Errors for Nominal GDP Growth ${ }^{\star}$ (71/2-year window)

Percentage points

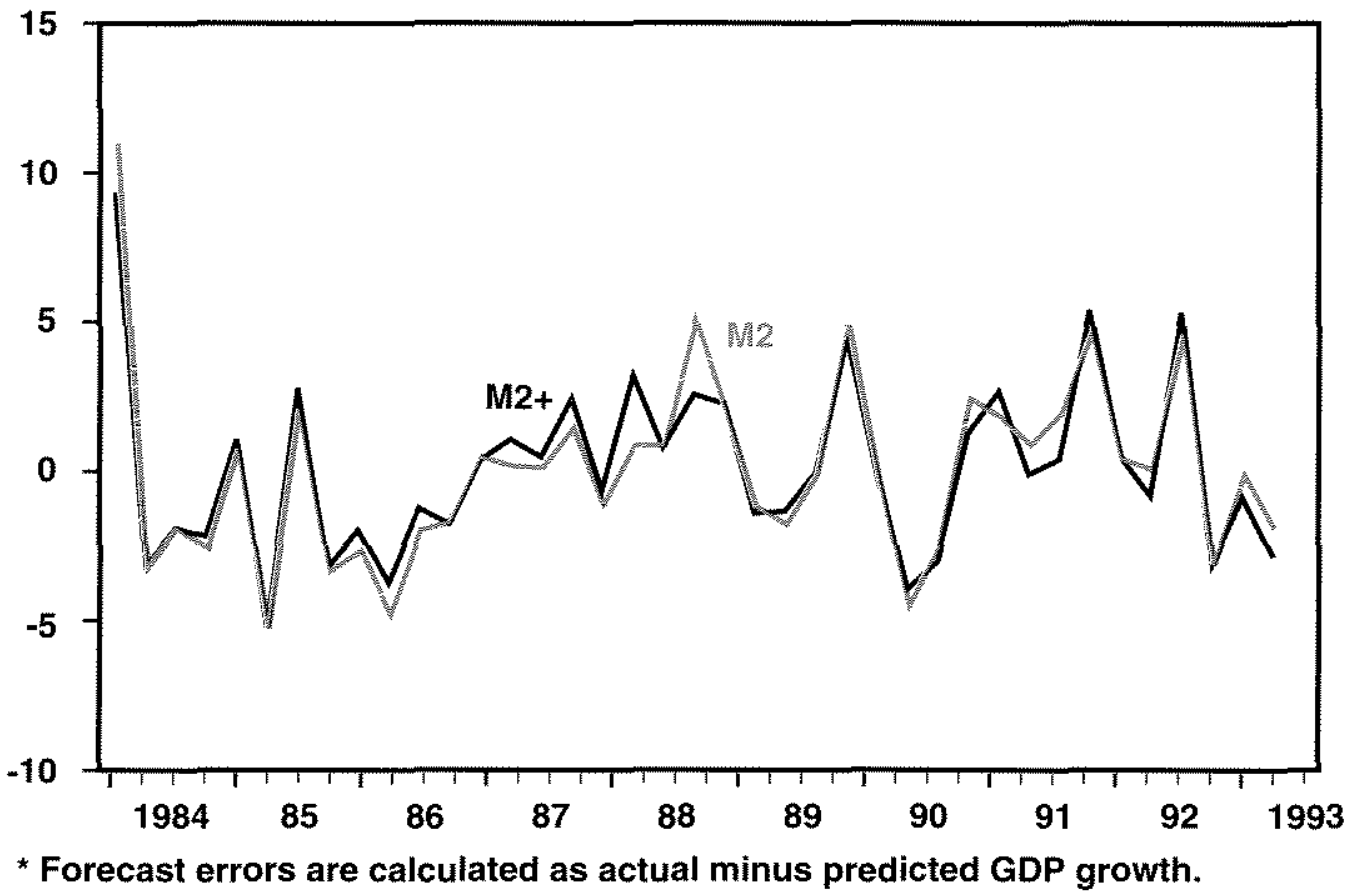


Figure 13A

Four-Quarter-Ahead Forecast Errors for Nominal GDP Growth* (15-year window)

Percentage points

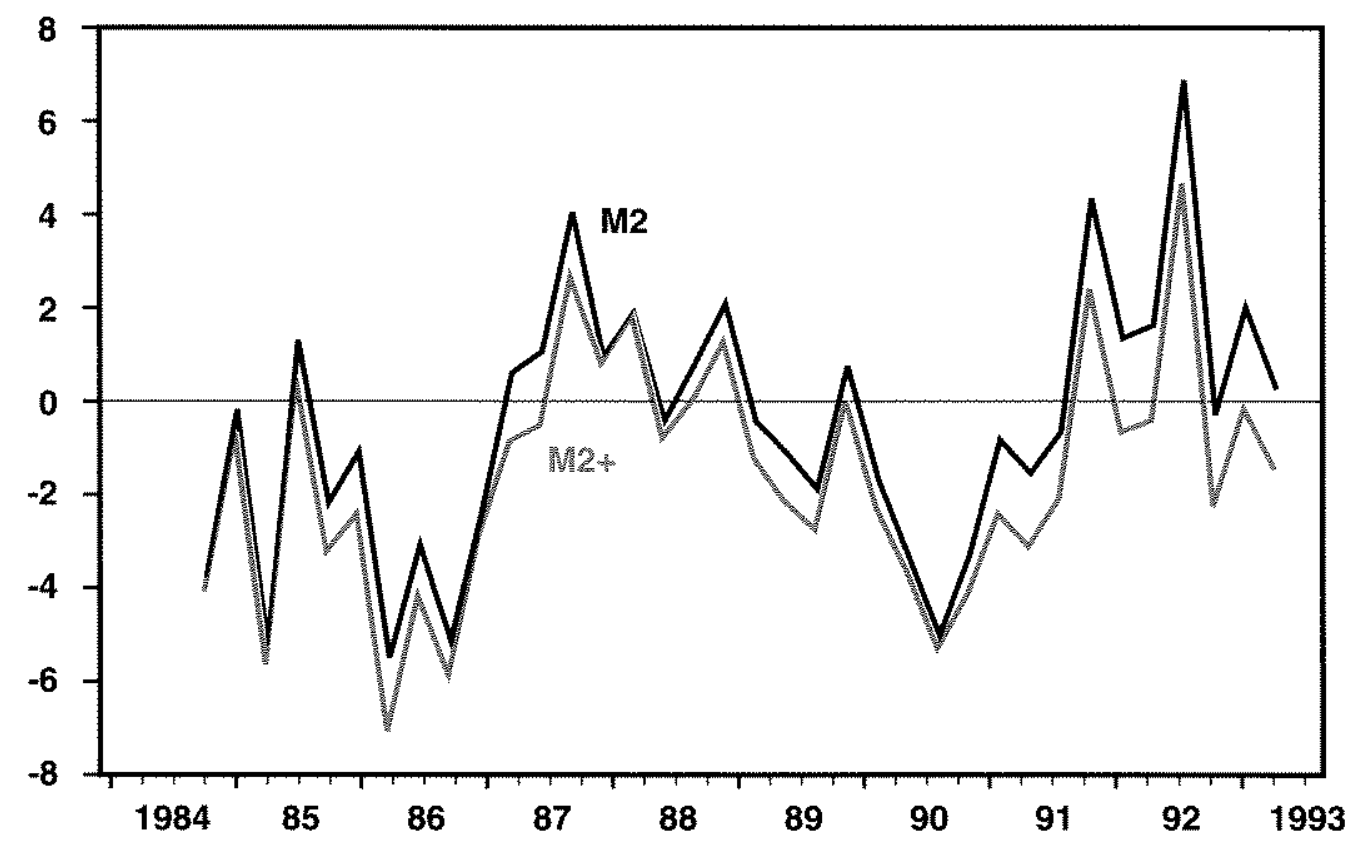

* Forecast errors are calculated as actual minus predicted GDP growth.

Figure 13B

Four-Quarter-Ahead Forecast Errors for Nominal GDP Growth* (71/2-year window)

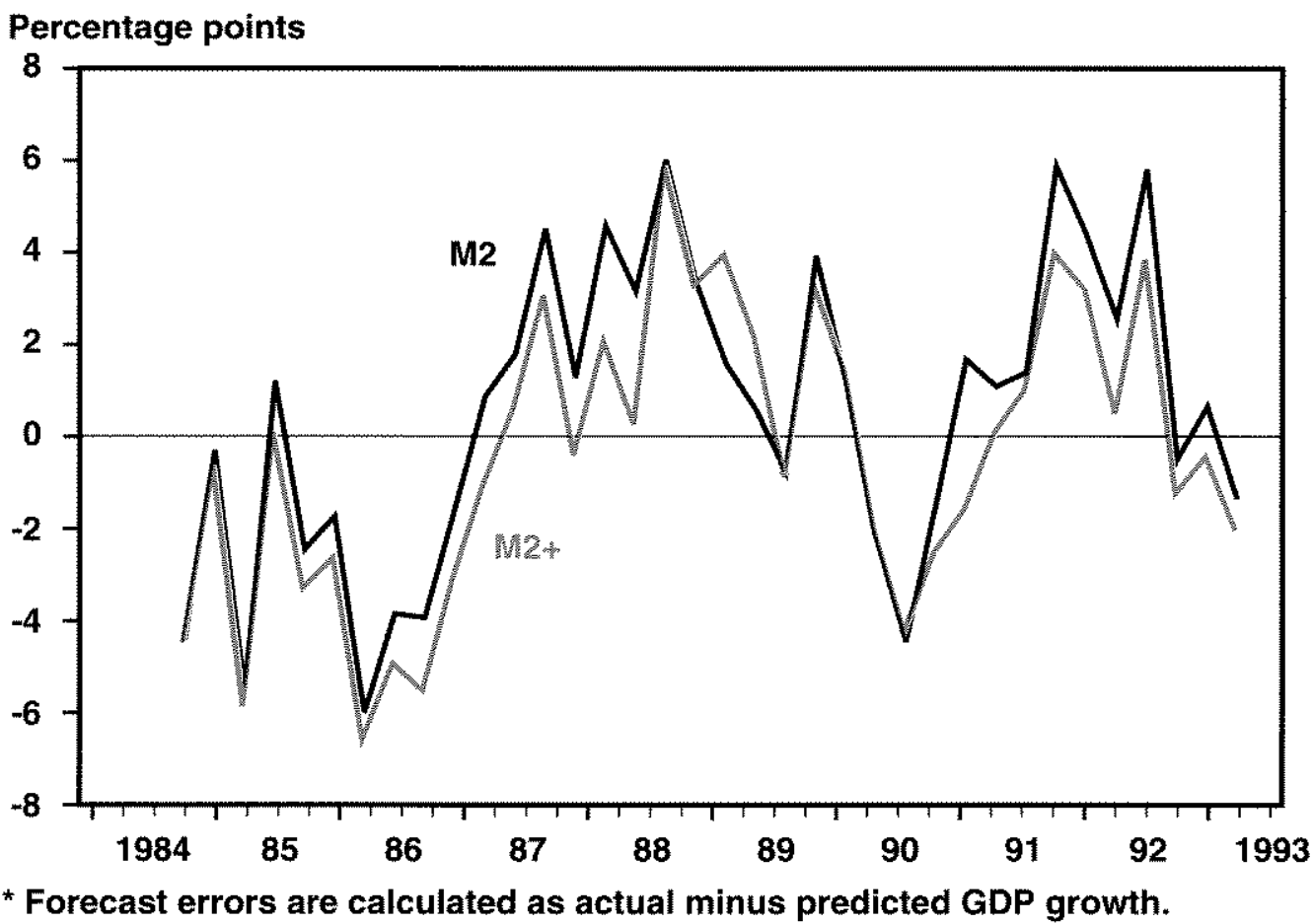


nominal GDP growth until the mid-1980s. In 1986 , inflows to bond and stock funds were heavy in response to falling interest rates, and in 1987 there were modest net outflows when interest rates reversed course early in the year and the stock market crashed late in the year. The resulting swings in $\mathrm{M} 2+$ growth were not subsequently reflected in nominal GDP growth and, thus, the rise in significance levels. In the past couple of years, the significance levels of the two aggregates moved closer together.

The lower panel of the figure presents the statistical significance levels for the same specification using a shorter, seven-and-a-half-year, rolling estimation window. With a shorter estimation horizon, the ill behavior of M2 over the past few years becomes clear with the large significance level since 1991. This increase is not accompanied by the corresponding increase in the significance level of $\mathrm{M} 2+{ }^{25}$

Figure 12 shows the results of out-of-sample experiments that compute one-period-ahead forecast errors based on the regressions used in the previous exercise. Again, the time horizons over which the forecasting equations are estimated are 15 and seven-and-a-half years prior to the forecast date. Figure 13 presents results for four-period-ahead forecasts. The forecast errors in both figures are calculated as actual minus forecasted growth - a positive error indicates an underprediction. Comparing the results for $\mathrm{M} 2$ and $\mathrm{M} 2+$, these figures indicate that the forecast errors for the two aggregates are about the same over the whole period shown, as would be expected given that both aggregates are marginally useful in explaining future nominal GDP growth in-sample. Both aggregates tended to overpredict GDP growth in late 1990. Reasonably strong money growth in the second half of 1989 was not consistent with the subsequent recession at the end of 1990. Both aggregates generally underpredicted nominal GDP growth in 1992, with $\mathrm{M} 2$ + forecast errors being smaller than those of $\mathrm{M} 2$.

\section{RERERNEES}

Clements, Jonathan. "Wait! Don't Write That Mutual Fund Check," Wall Street Journal (November 1993), p. C14.

Collins, Sean, and Cheryl Edwards. "An Altemative Monetary Aggregate: M2 Plus Household Holdings of Bond and Equity Funds," this Review (November/December 1994), pp. 7-29.

Duca, John V. "Should Bond Funds Be Included in M2?" Journal of Banking and Finance (forthcoming).

Feinman, Joshua, and Richard D. Porter. "The Continuing Weakness in M2," Board of Governors of the Federal Reserve System, Finance and Economics Discussion Series Paper \#209 (September 1992).

Investment Company Institute. Trends in Mutual Fund Activity. October 1994.

Mack, Phillip R. "Recent Trends in the Mutual Fund Industry" Board of Governors of the Federal Reserve System, Federal Reserve Bulletin (November 1993), pp. 1001-12.

Mehra, Yash. "Has M2 Demand Become Unstable?" Federal Reserve Bank of Rictimond Economic Review (September/October 1992), pp. 27-35.

Reid, Brian, and David H. Small. "Bank Involvement in the Mutual Fund industry," Board of Governors of the Federal Reserve System, mimeo (September 1993).

Sirri, Eirk $K_{r}$ and Peter Tufano. "Competition and Change in the Mutual Funds Industry," in Samuel L. Hayes, ed., Financial Services: Perspectives and Challenges. Harvard Business School Press, 1993, pp. 181-214.

${ }^{25}$ The results are ittle changed when interest rates are omitted from the equations, although significance levels are lower (money is more important) since money picks up some of the variability of nominal GDP growth explained by interest rates in the broader model. 


\section{William A. Barnett and Ge Zhou}

Willam A. Bamett is professor of economics at Washington University, St. Louis, Ge Zhou recently received a doctorate in economics from Washington University, St. Louis. The authors benefitted from useful discussions with Athanasios Orphanides. Research on the project was partially supported by NSF grant SES 9223557 .

\section{Commentary}

$W_{\mathrm{E}}$ E ARE VERY PLEASED to be invited to comment on the new $\mathrm{M} 2+$ index, recently proposed in interesting papers by some Federal Reserve Board staff members (Collins and Edwards, 1994; and Orphanides, Reid and Small, 1994). The two papers presented at this conference by those Board staff members raise important and challenging questions that we believe should motivate much research in future years. In addition, we wish to commend those Board staff economists for their courage and integrity in pushing past barriers that have intimidated prior researchers and thereby precluded prior research on these difficult matters.

The basic issue is whether riskiness of the investment rate of return on an asset is a characteristic that rules out the possibility of an asset's contribution to the economy's liquidity. Oddly, that issue has largely precluded prior considerathon of risky assets as components of central bank monetary aggregates. Yet clearly the position is groundless. While it is clear that risky assets are not good candidates for legal means of payment, monetary aggregates now contain many assets that are not legal means of payment, It has long been recognized that currency and demand deposits provide much, but by no means all, of the economy's monetary service flow.

No one has suggested that bond or stock mutual funds should be made legal means of payment. In addition, stock and bond mutual funds currently are bundled by companies into packages of funds that include money market funds within the bundle. Hence, it often is as easy as a telephone call to transfer funds from stock and bond funds into checkable money market funds. Although stock and bond funds certainly should not be made legal means of payment, it simply makes no sense to exclude bond and stock mutual funds from consideration as assets contributing monetary liquidity to the economy.

There is no necessary conflict between the existence of risky return and the contribution of liquidity to the economy. The two are not mutually exclusive.' Yet prior researchers have excluded assets having substantial principle risk from consideration as components of monetary aggregates. It indeed is odd that such an obviously groundless prejudice has precluded research by the entire economics profession on an important

\footnotetext{
1 Formally, the correct method used to determine the clustering of components within an aggregation-theoretic monetaty aggregate is testing for blockwise weak separability. An innovative new approech to testing for weak separablity was recently proposed by Swofford and Whitney (1994). Athough risky return complicates testing for weak separability, risk in no way precludes acceptance of that hypothesis. In lact, a successtul test of weak separability with random rates of return is included in Barnett and thot (1994)
} 
topic. The authors of the two Board staff papers are right. The authors have done a service to the profession by exploring the topic for the first time.

\section{CIALIWNGES PRESENTED TO ECONOMI THEORY}

Riskiness of the rate of return simply does not preclude the production of monetary services by an asset. Riskiness of the rate of return, however, certainly does make life more difficult for index number theorists and aggregation theorists. Most of the literature in those fields is produced under the assumption of perfect certainty or risk neutrality, Extensions of that literature to risk aversion were begun recently by Poterba and Rotemberg (1987), Barnett and Yue (1991), Barmett, Hinich and Yue (1989) and Barnett and Zhou (1994). We believe that the important issues raised by Collins and Edwards (1994) and Orphanides, Reid and Small (1994) at this conference should serve as motivation for further research on index number theory and aggregation theory under risk aversion. We do indeed welcome the increased motivation in that area provided by the work of those Board staff researchers.

But there is an even more fundamental problem. The existence of an investment rate of return, even a perfectly certain one, raises questions about how an asset should be incorporated into an aggregate. While the existence of such a rate of return does not prevent an asset from producing monetary services, the share of the asset's services that can be viewed as "monetary" is strongly affected. This comment is directed towards an investigation of that share.

\section{HSTORICA DACKGROUND}

At one time, money was cash plus demand deposits. No controversy existed on that topic. But a sequence of technological changes and innovations occurred, and continued to occur, such that an increasingly large number of substitutes for money produced an increasingly large share of the economy's monetary services. The result was the Bach Commission, the Gurley and Shaw (1960) book, the Pesek and Saving (1967) book, and many other important contributions that influenced the growing movement towards the construction of increasingly broad monetary aggregates. The response of most central banks, however, has been to accept one aspect of that research while conveniently overlooking another closely related aspect.
In particular, the researchers who first worked in that area were very clear on one simple, elementary fact: Investment yield is not a monetary service. There was a reason that all monetary economists once agreed that money included only cash and non-interest-bearing demand deposits. If investment yield were a monetary service, then coal mines would be money. Land would be money. The entire capital stock of the United States would be money.

This is not to deny that assets that produce an investment rate of return, whether risky or not, can produce monetary services. Interest yielding monetary assets, however, are joint products. Some of their services are monetary. Some are not. This fact seems to have escaped many of the world's central banks. To the degree that the economy equates marginal utilities per dollar across assets, the marginal utility of monetary services produced by an asset must decrease as its marginal non-monetary services increaseand investment return is very clearly not a monetary service.

To underscore our point, we bring up the famous diamonds-versus-water paradox. The total utility of water exceeds that of diamonds, even though the marginal utility of diamonds exceeds that of water. In fact, as one moves along a concave utility function, marginal utility varies inversely with total utility. Hence, the statements made above about marginal utilities should not be confused with the total or average monetary service flow produced by an asset. But it is the marginal utilities that are relevant to measuring the prices in index numbers, such as the Divisia, Fisher ideal, Paasche or Laspeyres quantity indexes. We hope that we also do not have to remind this audience that the prices (user costs) in such indexes are not the weights. We nevertheless find that this literature contains many misunderstandings of monetary index number theory, and most of those misunderstandings are produced by confusing prices with weights and marginal utilities with total or average utilities.

\section{FERAAI SPORTS CAMS}

It has been asked at this conference whether stock funds or bond funds are "money," or are they not money. We would like to ask a different question. Are Ferrari sports cars transportation machines or recreational machines? We can imagine a Ferrari owner responding that a 
Ferrari is strictly a transportation machine, and that the high price is produced by the Ferrari's superior performance on highways and on winding roads. Hence, the price of a Ferrari is the discounted present value solely of the transportation services. But I expect that most of the rest of us would view the price of a Ferrari as being the sum of the discounted present values of two different flows: transportation services and recreational services.

Ferraris are joint products, in terms of the services produced. Interest-bearing monetary assets similarly are joint products. Such assets produce both monetary and non-monetary services, whereby the interest yield unquestionably is in the latter category. Hence, the correct answer to the question asked by the Board's staff economists at this conference is that such assets, including stock and bond mutual funds, are partially money and partially not money.

\section{WHAT TO DO NEXT}

We see that we are presented with a paradox. More and more assets are contributing to the economy's monetary service flow. As made clear by the authors of the two Board staff papers, stock and bond funds now are among those assets. The investment yields of that growing collection of assets, however, are not monetary services. If we do not add such assets into the monetary aggregates, we overlook some of the economy's monetary service flow. If we do add those assets into the aggregates, we contaminate the aggregates with non-monetary services.

The answer should be obvious. We must untangle the two discounted present values: the discounted present value of the monetary service flow and the discounted present value of the investment yield. Indeed, it can be done.

\section{THE THOPY}

Barnett (1987) defined the economic stock of money to be the discounted present value of expenditure on the services of monetary assets. Barnett (1991) derived that discounted present value in the form that we display below. During period $s$ let $p_{s}^{*}=$ the true cost of living index, let $M_{i s}$ be nominal balances of monetary asset $i$, let $r_{i s}$ be the nominal expected holding period yield on monetary asset $\dot{i}$, and define $m_{i s}=M_{i s} / p_{s}{ }^{*}$ to be real balances of monetary asset $i$. The current period is defined to be period $t$ so that $s \geq t$. Define the discount rate for period $s$ to be
(1) $\rho_{s}= \begin{cases}1 & \text { for } s=t \\ \prod_{u=t}^{s-1}\left(1+R_{u}\right) & \text { for } s>t .\end{cases}$

By letting the planning horizon, $T$, go to infinity in the second term of Barnett (1978, eq. 2; 1980, eq. $3.3 ; 1981$, eq. 7.3 ), we immediately acquire the following definition for the Economic Stock of Money, first derived as definition 1 and equation 2.2 in Barnett (1991):

Definition 1: Under risk neutrality, the economic stock of money during period $t$ is

(2) $V_{t}=\sum_{s=t}^{\infty} \sum_{i=1}^{n}\left[\frac{p_{s}^{*}}{\rho_{s}}-\frac{p_{s}^{*}\left(1+r_{i s}\right)}{\rho_{s+1}}\right] m_{i s}$.

The concept of economic stock used to produce Definition 1 is the user-cost-evaluated expenditure on the services of the $n$ monetary assets that are its components. It should be observed that the prow cedure used in Barnett (1978, eq. 2; 1980, eq. 3.3; 1981, eq. 7.3) to acquire that discounted present value for finite $T$ was just back substitution and algebraic manipulation of the sequence of flowof-funds identities. Hence, our conclusion is produced entirely from accounting identities.

If we now substitute equation 1 and $m_{i s}=$ $M_{i s} / p_{\mathrm{s}}{ }^{*}$ into equation 2, we acquire the following result:

$$
V_{t}=\sum_{s=t}^{\infty} \sum_{j=1}^{n}\left[\frac{R_{s}-r_{i s}}{\prod_{l=t}^{s}\left(1+R_{u}\right)}\right] M_{i s} .
$$

Unfortunately, this equation includes expected future values of interest rates and of monetary asset holdings. While it may be reasonable to assume that interest rates are stationary, no such easy simplification is available for the stochastic process of future monetary asset holdings. We believe that a useful way to proceed would be to use VAR forecasts of the monetary asset holdings and rates of return. We plan to produce results using that approach. But considering the time constraint that we faced with this conference, we had no choice but to make strongly simplifying assumptions. In particular, we make the assumption which causes equation 3 to collapse into the Rotemberg, Driscoll and Poterba (1994) CE index, first interpreted to be a stock index in Barnett (1991). 
Definition 2: The CE index is

(4) $V_{t}=\sum_{i=1}^{n} \frac{R_{t}-r_{i t}}{R_{i}} M_{i t}$

We seek to find conditions under which equation 4 will equal equation 3 . To that end, suppose that expectations are stationary in the sense that $r_{i s}=r_{i t}$ and $R_{i s}=R_{i t}$ for all $s \geq t$, and consider the static portfolio, $\left(\mathrm{M}_{1 s}, \mathrm{M}_{3 s}, \ldots, \mathrm{M}_{n s}\right)=$ $\left(\mathrm{M}_{1 t}, \mathrm{M}_{2 t}, \ldots, \mathrm{M}_{n t}\right)$, for all $s \geq t$. Equation 3 reduces to

(5) $V_{t}=\sum_{i=1}^{n} \sum_{s=t}^{\infty}\left[\frac{R_{t}-r_{i t}}{\left(1+R_{t}\right)^{s-t+1}}\right] M_{i t}$.

Observe, however, that

(6) $\sum_{s=t}^{\infty} \frac{R_{t}-r_{i t}}{\left(1+R_{t}\right)^{s-t+1}}=\frac{R_{i}-r_{i t}}{R_{t}}$,

since the left side of equation 6 is a convergent geometric series (minus the first term in the series). Substituting equation 6 into equation 5 , we acquire our result:

Theorem 1: Under stationary expectations, the CE index is equal to the Economic Money Stock.

Under the stationary expectations assumption, we easily can discount to present value the expected investment yield flows, $r_{i s} M_{i s}=r_{i t} M_{i t}$ for $s \geq t$ to get the following capitalized value:

(7) $V_{t}^{*}=\sum_{s=t}^{\infty} \sum_{i=1}^{n}\left[\frac{r_{i t} M_{i t}}{\left(1+R_{t}\right)^{s+t i t}}\right]$.

Again, we have a convergent geometric series in the summation over $s$ at any given $i$, so that we find

(8) $V_{t}^{*}=\sum_{j=1}^{n} \frac{r_{i t}}{R_{t}} M_{i t}$

Adding equation 8 to equation 4 , we find that

(9) $V_{i}+V_{t}^{*}=\sum_{i=1}^{n} M_{j t}$.

The conclusion is clear. The simple-sum monetary aggregates measure the stock of money only if the investment (interest) yield of the monetary components is treated as a monetary service. Yet it is difficult to think of any macroeconomic school of thought which has ever viewed the interest yield on monetary assets to be a monetary service. In fact, that possibility was considered carefully and rejected unequivocally in Pesek and Saving (1967).

In the discussion that follows, we shall use this result to decompose the simple-sum aggregates into their investment share and their monetary services share. In each case, the share is produced by discounting the flow to the present value, the interest yield in one and the service flow in the other. The decomposition then is into $V_{t}$ and $V_{t}^{*}$, which partition

$\sum_{i=1}^{n} M_{i t}$

into its two parts, in accordance with equation 9 .

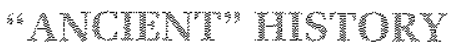

There was a time-mong, long ago-when money was currency and demand deposits, and demand deposits did not yield interest. In those days, we see that

$V_{t}^{*}=0$, so that $V_{t}=\sum_{i=1}^{n} M_{i t}$.

Those were the days when the simple-sum monetary aggregates were created, and we see that the people who created them knew what they were doing. But that simpler world is long gone. Many assets that contribute to the economy's monetary services also yield an investment rate of return.

\section{ThE DATA}

We computed the decomposition into $V_{\mathrm{t}}$ and $V_{t}^{\star}$ of the official simple-sum M1 and M2 indexes along with the corresponding decomposition into $V_{t}$ and $V_{t}^{\star}$ of the newly proposed simple-sum M2+ index. We also computed the decomposition into $V_{t}$ and $V_{i}^{*}$ of bond mutual funds and stock mutual funds as a means of further investigating the source of the difference in behavior of M2 versus $\mathrm{M} 2+$. The attached figures provide the results.

The decomposition depends upon the measurement of the benchmark rate of return $R_{i}$. Clearly, $V_{t}$ increases as $R_{t}$ increases, and $V_{t}^{*}$ decreases as $R_{t}$ increases. Hence, the monetary service share (versus the investment share) of the simple-sum aggregate "joint product" increases as $R_{t}$ increases. The results can be biased in the direction favoring the inclusion of stock and bond funds by choosing an artificially high setting for $R_{t}$. For the purpose of biasing the 


\section{Figure 1}

\section{M1 Joint Product and Economic Capital Stock}

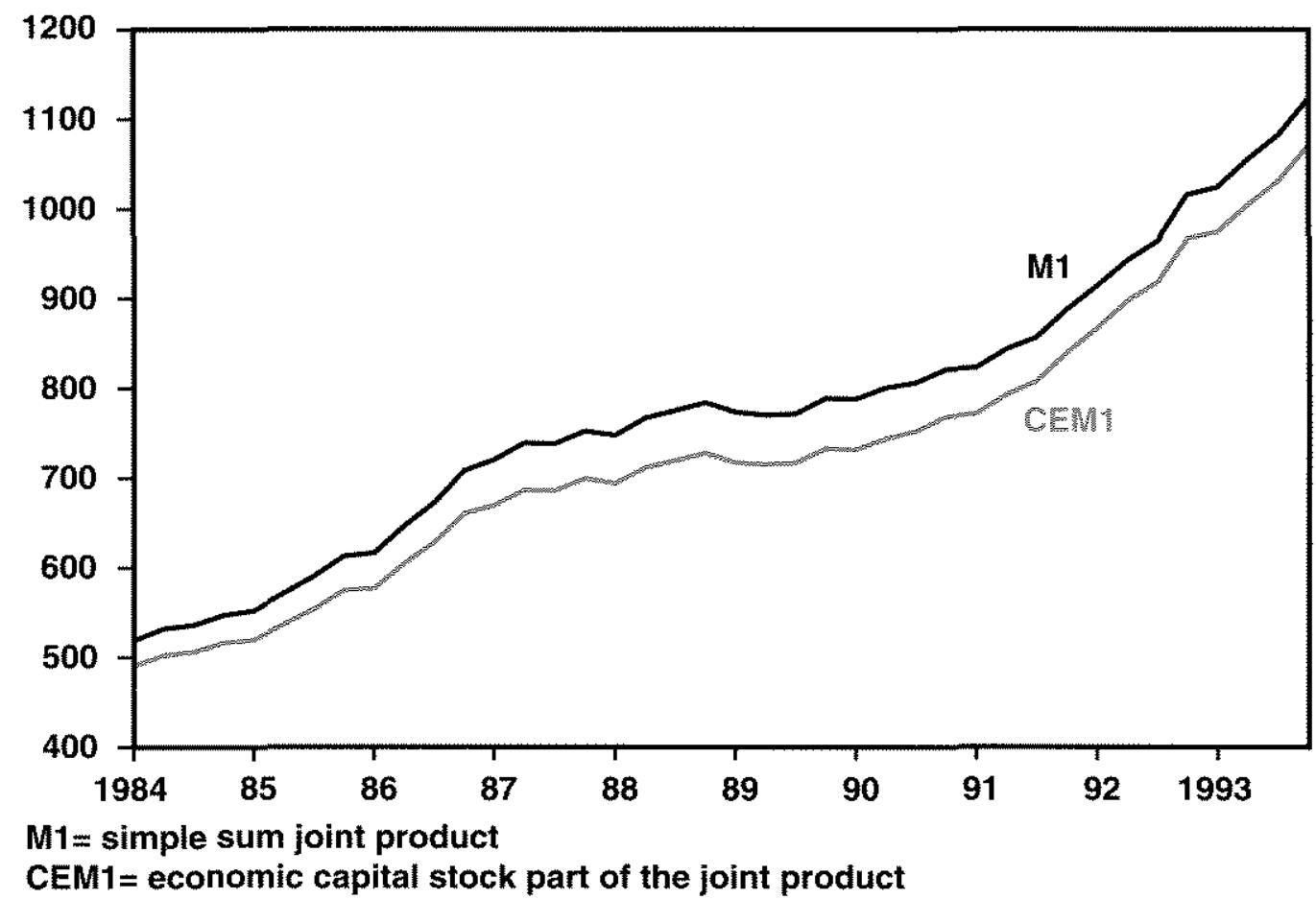

results in that direction intentionally, we chose the highest possible setting for $R_{i}$ that could be connected in any way with the available data.

As shown by Rotemberg, Driscoll and Poterba (1994), $V_{t}$ has a very volatile growth rate and, hence, they advocate smoothing the interest rates to produce smoother growth of the aggregates. This is not surprising, since $V_{i}$ and $V_{i}^{*}$ are stock aggregates which tend to have volatile growth rates. We use the same smoothing method advocated by Rotemberg, Driscoll and Poterba (1994). In particular, we replaced all of the interest rates in the index by 13 -quarter centered moving averages. Since the moving averages are centered, they are not defined for the first six quarters or the last few six quarters. We used the method advocated by Rotemberg, Driscoll and Poterba and phased in the centered moving average from asymmetric averages computed during the first six and last six observations.

Once the smoothed inferest data had been constructed, we searched over those series for the highest smoothed interest rate ever attained by any component asset during our sample.
That ex post rate of return was 24.2 percent, which we selected to be the value of $R_{i}$ for all $t$. In general, there is no reason for the benchmark rate to be a constant or to equal any ex post rate of return, since ex post rates of return tend to be much more volatile than ex ante expected rates of return. Our selection for the benchmark rate, however, produces the largest value that we could connect with the data, and we wanted to produce results that would be biased in favor of the Board staff members' proposal. In interpreting our results, the division of the simple sum into the components $V_{t}$ and $V_{t}^{*}$ should be understood to be biased very strongly towards $V_{t}$ and away from $V_{t}^{*}$. Hence, the monetary services share in the joint product should be viewed as intentionally exaggerated.

\section{TIE RESUITS}

Figure 1 contains the partition of simple-sum M1 into its investment share and its monetary services share. The solid line is the monetary service share produced from the computed value of $V_{i}$. The vertical gap between the solid line and the dotted line is the investment-motivated 
Figure 2

M2 Joint Product and Economic Capital Stock

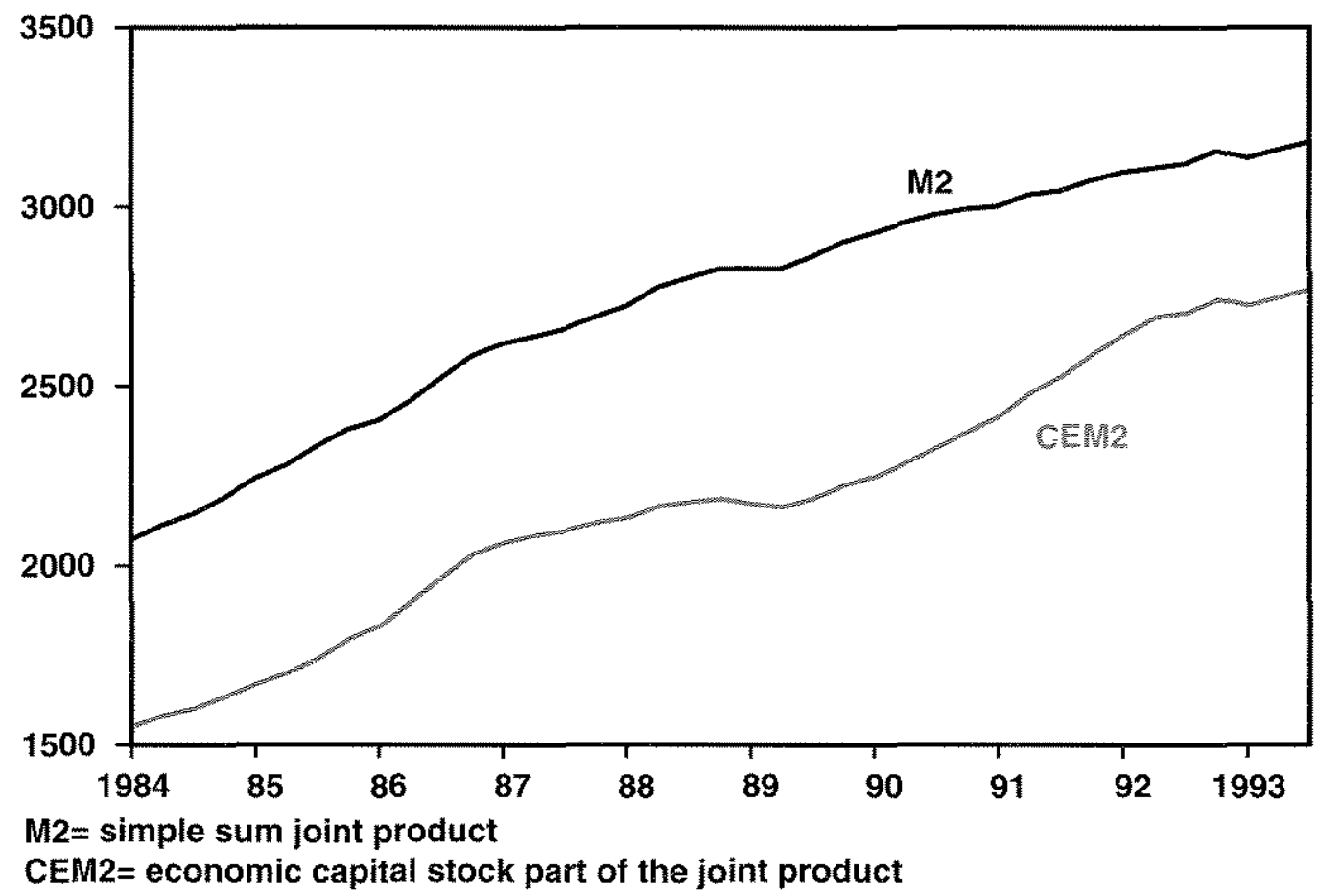

share, $V_{\mathrm{r}}^{*}$, which could be interpreted as the "error-in-the-variable" embedded in the simplesum index, M1. The height of the dotted line from the horizontal axis is the simple-sum index, equaling the sum of $V_{f}$ and $V_{t}^{*}$. As is evident from Figure 1, the error-in-the-variable gap is relatively small and does not vary much over the sample. With a relatively constant vertical gap, the rate of growth of M1 is not greatly affected by the error-in-the-variable gap. For most statistical inferences and for policy, the growth rate of money is what matters. Hence, we see that the existence of the $V_{t}^{*}$ error gap produces little difficulty for M1.

Figure 2 contains the analogous plot and decomposition for the official simple-sum M2 aggregate. Observe that the error-in-the-variable gap is large (and would be much larger for a more realistic choice of $R_{t}$ ). In addition, that gap is variable and trends downward, especially recently. Hence, the existence of the error gap not only effects the short-run growth rate dynamics of the aggregate, but also biases downward the long-term growth rate. Inferences and policy are not invariant to the existence of this gap.

Figure 3 contains the decomposition for the $\mathrm{M} 2+$ aggregate that has been proposed at this conference by Collins and Edwards (1994) and Orphanides, Reid and Small (1994). Observe that while the error gap is even larger than for $\mathrm{M} 2$, the size of the gap is less variable and no longer trends downward. Hence, the growth rate of the error-shifted dotted line approximately tracks the growth rate of the "correct" solid line.

To see why M2+ stabilizes the size of the gap and thereby improves on the aggregate's growth rate performance, see Figures 4 and 5 , which display the decomposition of the stock mutual funds data and the bond mutual funds data into their economic capital stock share and their error-in-the-variable shift. Observe that in each of those two cases, the size of the gap grew rapidly during the past two years. This growing error gap offsets the declining error gap in M2, when the stock and bond fund data are added into M2. 
Figure 3

M2+ Joint Product and Economic Capital Stock

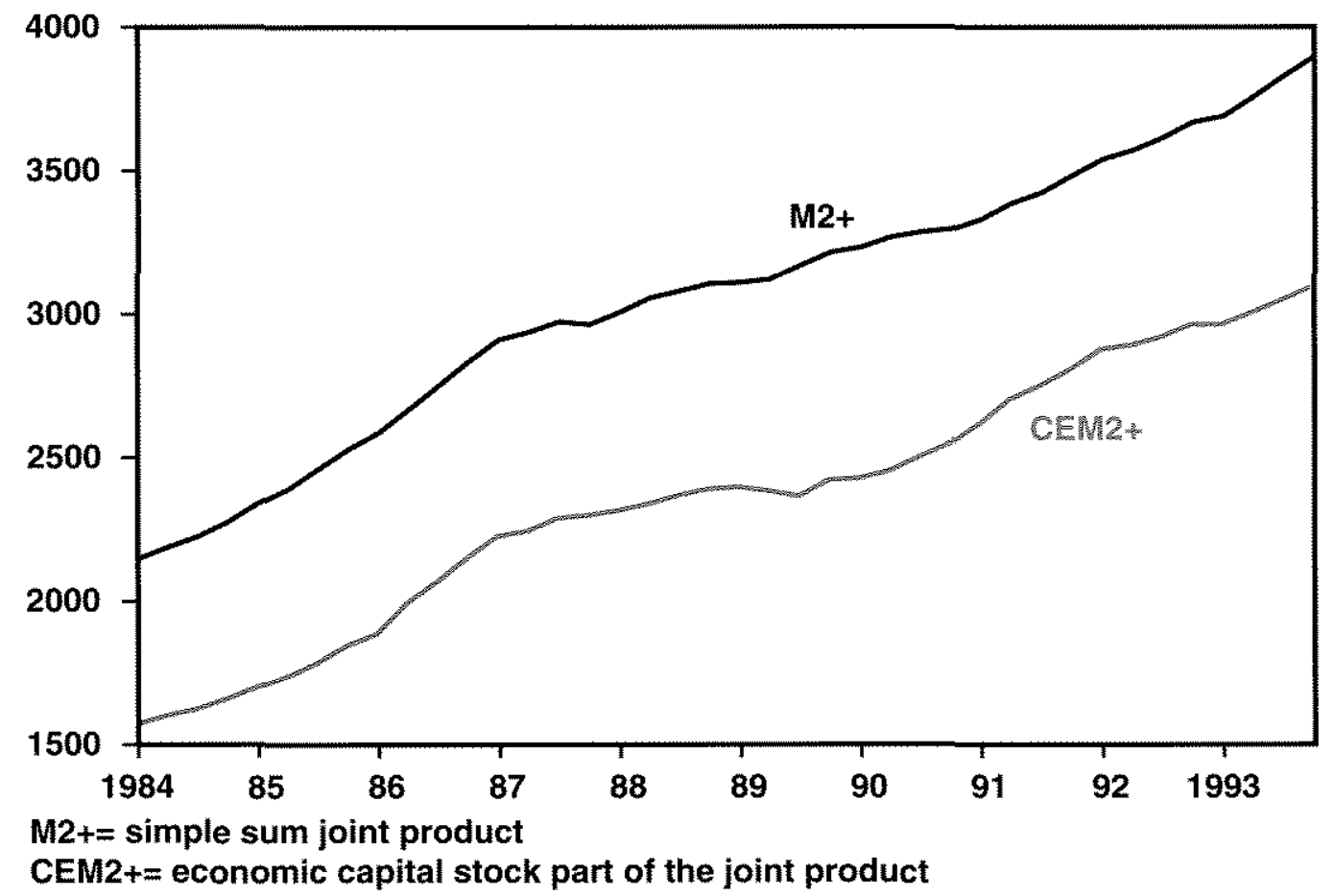

In short, we conclude that the authors of the two papers presented at this conference are correct in concluding that the growth rate behavior of $\mathrm{M} 2$ is improved by incorporating the stock and bond mutual fund data into M2. Indeed, it does appear that substitution from $\mathrm{M} 2$ components into stock and bond mutual funds has become important.

\section{WHERE IS ALL OR THS GONG?}

There is an underlying dynamic to this trend in monetary theory. Stabilizing the size of the error gap requires continually incorporating more assets into the monetary aggregates. The size of the gap keeps growing. The share of the monetary aggregate representing discounted monetary services continues to decrease, and the monetary aggregates look increasingly like pure investment capital rather than money. Even if stabilizing the size of the gap offsets long-run errors in growth rate paths, the short-run dynamics of the aggregates are likely to become increasingly disjoint from monetary services growth.
In this paper we use the CE index, equation 4, to permit easy decomposition of the simple-sum aggregate "joint product" into its monetary service and investment shares. Using the formula in equation 3 with forecasted variables, perhaps by a VAR, would be better. But generating data that depends upon forecasts is unpleasant for data-producing governmental agencies. Smoothing interest rates to decrease the volatility of the resulting aggregate is also unpleasant for governmental agencies. For this conference, decomposition of the stocks in that manner was revealing. But as a means to produce data for a central bank, there is a better way. It is the Divisia monetary aggregates long advocated by Barnett (1980). See Barnett. Fisher and Serletis (1992) and Belongia and Chalfant (1989) for an overview and some of the relevant empirical results.

The Divisia monetary aggregates directly measure monetary service flows, not the discounted stock levels. The Divisia monetary aggregates do not require smoothing of interest rates to smooth the index's growth rate, and the Divisia monetary 
Figure 4

Common Stock Mutual Funds Joint Product and Economic Capital Stock

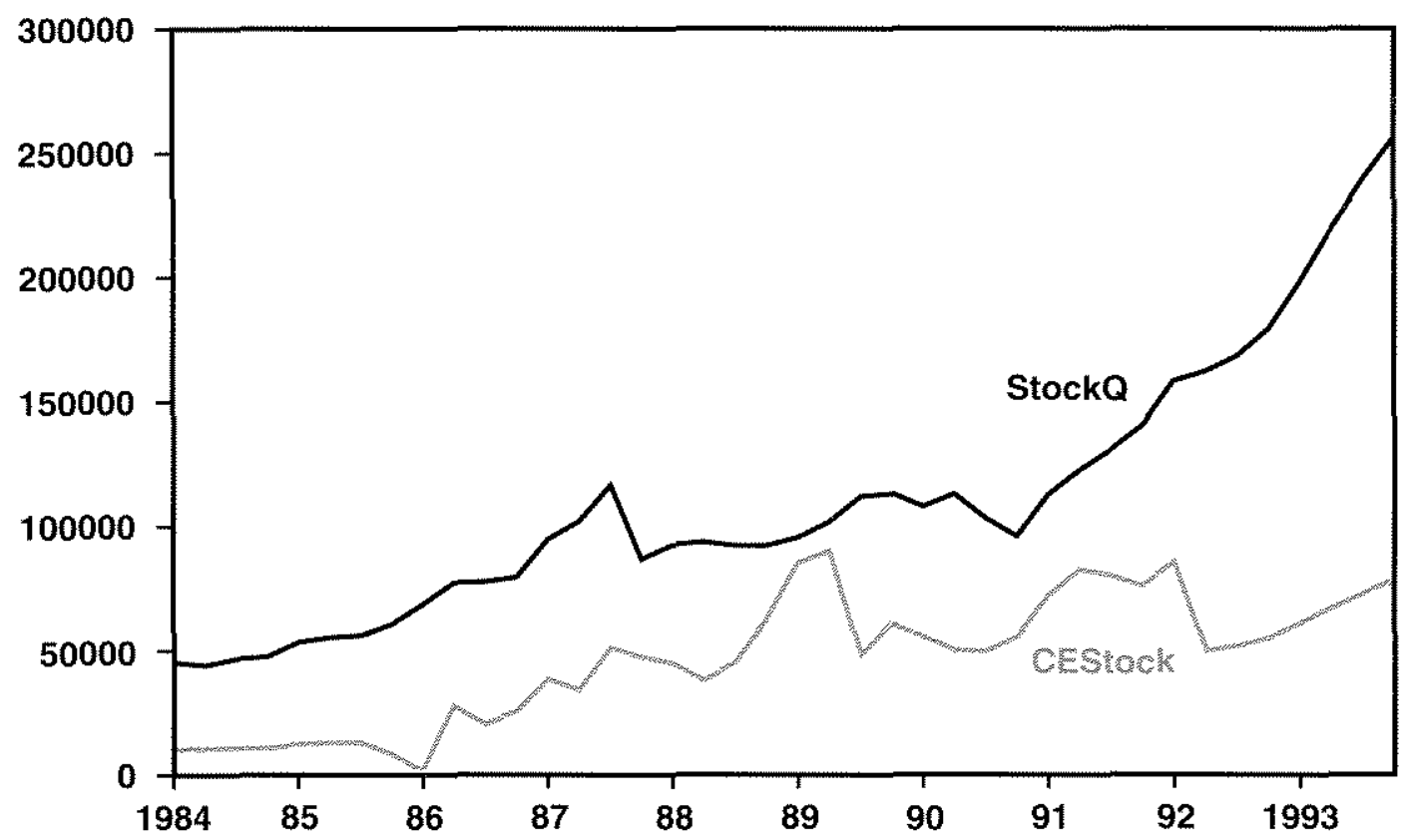

StockQ= simple sum joint product

CEstock= economic capital stock part of the joint product

Figure 5

Bond Mutual Funds Joint Product and Economic Capital Stock

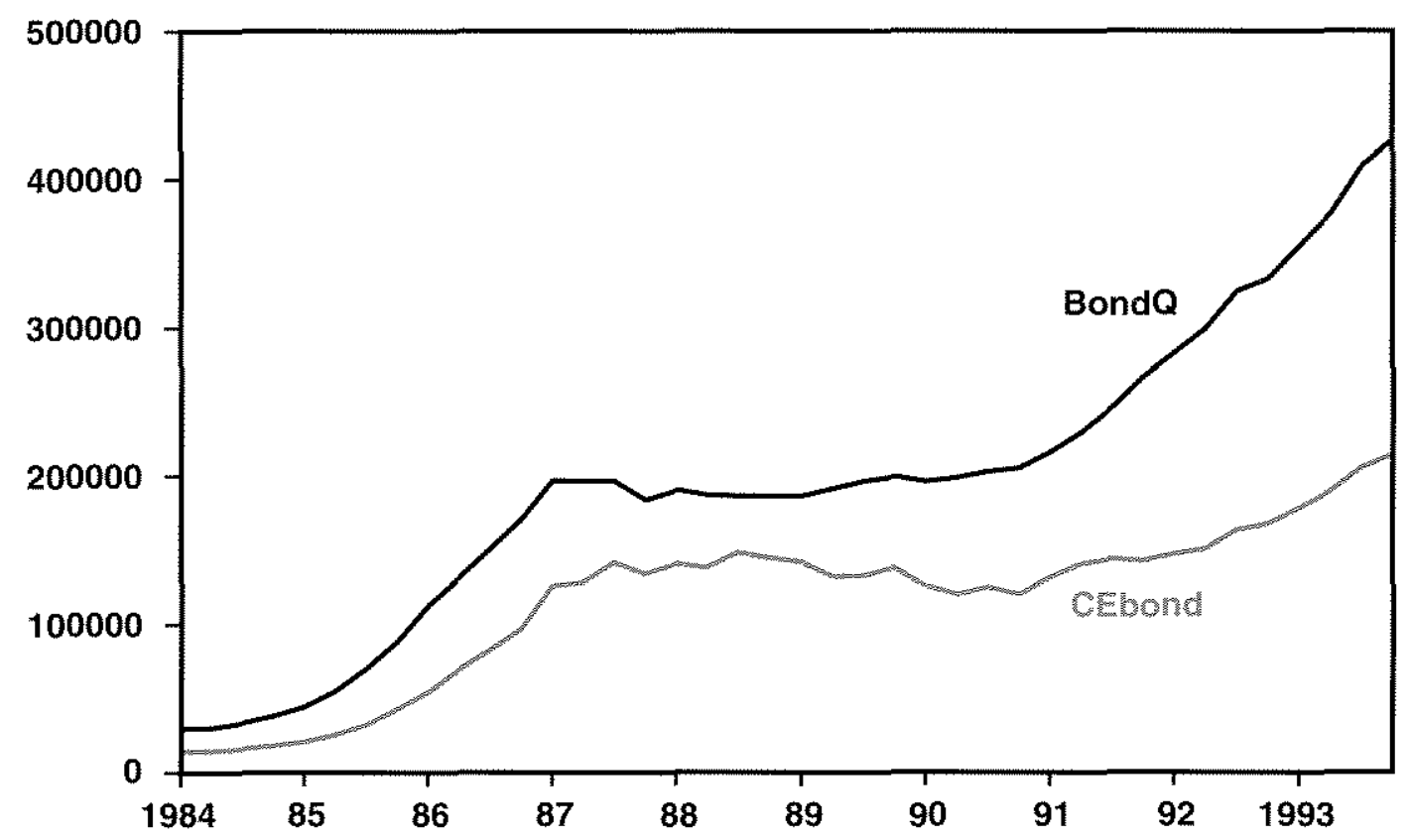

Bond $Q=$ simple sum joint product

CEbond= economic capital stock part of the joint product 
aggregates contain no variables that need forecasting. ${ }^{2}$ In addition, Barnett (1991) proved that if we could do the forecasting needed to compute the monetary capital stock (equation 3), the result would be identica to that produced by discounting to present value the huture stochastic process of the Divisia monetary aggregate.

\section{The}

Bamett William A. "Reply to Julio J. Rotemberg," in Michael T. Betongia, ed., Monetary Policy on the 75 th Anniversary of the Federal Reserve System; Proceedings of the Fourteenth Annual Economic Policy Conference of the Federal Reserve Bank of St. Louis. Kluwer Academic Publishers, 1991, pp. 232-43.

"The Microeconomic Theory of Monetary Aggregation," in Wiltam A. Barnett and Kenneth J. Singleton, eds., New Approaches to Monetary Economics, Proceedings of the Second International Symposium in Economic Theory and Econometrics. Cambridge University Press, 1987 . pp. 115-68.

"The Optimal Level of Monetary Aggregation;" Joumal of Money, Credit and Banking (February 1982), pp. 687-710.

Consumer Demand and Labor Supply: Goods Monetary Assets, and Time. North-Holland, 1981.

"Economic Monetary Aggregates: An Application of Index Number and Aggregate Theory." Journal of Econometrics (summer 1980), pp. 11-48.

"The User Cost of Money," Economics Letters, vol. 1 (1978), pp. 145-9.

and Ge Zhou (1993), "Financial Firm's Production and Supp:y-Side Monetary Aggregation Under Dynamic Uncertainty," this Review (March/Aprit 1994), pp. 133-65.

Douglas Fisher, and Apostolos Serietis. "Consumer Theory and the Demand for Money." Journal of Economic Literature (Decembef 1992), pp. 2086-119. and Piyu Yue. "Exact Monetary Aggregation Under Risk," Washington University (Department of Economics), St. Louis, Working Paper \#163 (December 1991).

Melvin Hinich, and Piyu Yue. "Monitoring Monetary Aggregates Under Risk Aversion," in Michael T. Belongia, ed., Monetary Policy on the 75th Anniversary of the Federal Reserve System: Proceedings of the Fourteenth Annual Economic Policy Conference of the Federal Reserve Bank of St. Louis. Kluwer Academic Publishers, 1989, pp, 189-222.

Belongia, Michael T, and James Chalfant. "The Changing Empirical Defintion of Money: Some Estimates From a Model of the Demand for Money Substitutes," Joumal of Political Economy (April 1989), pp. 387-97.

Collins, Sean, and Cheryl L. Edwards. "An Altemative Monetary Aggregate: M2 Plus Household Holdings of Bond and Equity Mutual Funds" this Review (November/December 1994), pp. 7-29.

Gurley, John and Edward S. Shaw. Money in a Theory of Finance. Brookings Institution, 1960.

Orphanides, Athanasios, Brian Reid, and David H. Small. "The Empirical Properties of a Monetary Aggregate That Adds Bond and Stock Funds to M2." this Review (November/December 1994), pp. 31-51.

Pesek, B.P., and T.R. Saving. Money, Wealth and Economic Theory. Macmillan, 1967.

Poterba, James M., and Julio J. Rotemberg. "Money in the Utility Function: an Empirical implementation," in William Barnett and Kenneth Singleton, eds., New Approaches to Monetary Economics, Proceedings of the Second Intemational Symposium in Economic Theory and Econometrics. Cambridge University Press, 1987, pp. 219-40.

Rotemberg, Julio J., John C. Driscoll, and James M. Poterba "Money, Outpul, and Prices: Evidence From a New Monetary Aggregate." Joumal of Business and Economic Statistics (forthcoming).

Swofford, James L., and Gerald A. Whitney. "A Revealed Preference Test For Weakly Separable Utility Maximizalion With Incomplete Adustment," Joumal of Econometrics (Jan $a$ ary/February 1994), pp. 235-49.
2 It is necessary to measure the benchmark rate, $R$, to construct the Divisia monetary aggregates, and we advocate the use of the upper envelope of the yield-curve-adjusted, holdingperiod yields on all of the components in the broadest aggregate. Obviously, we do not advocate the use of the extreme, constant setting of 24.4 percent, chosen for an illustrative purpose in this paper. However, it should be observed that the behavior of the Divisia monetary aggregate is much more robust to variations th the method of measuring the benchmark rate than is the $\mathrm{CE}$ index, which is very sensitive to that rate's selection. The reason is that the benchmark rate appears symmetricaly in both the numerator and denominator of the share weights of the Divisia index, which in turn is a growth-rate index. Since the $C E$ index is a level index, variations in any interest rate, including the benchmark rate, produce jumps in the level of the unsmoothed index. Jumps in levels produce spikes in growth rates. 



\section{Jacob S. Dreyer}

Jacob S. Dreyer, former chief economist at the Investment Company institute, is president of IDA intemational, a consulting firm.

\section{Commentary}

I on the papers by Collins and Edwards, and Orphanides, Reid and Small because I spent a good portion of the last six years looking at the "+," that is, on the assets, the desirability of whose inclusion into a broadened monetary aggregate is the subject of these deliberations. It is true that I not only watched stock and bond fund assets, and money market fund assets, but also had some influence on their definition, methods of collection and aggregation, and similar mundane matters. So, when the yield curve steepened a few years ago and, consequently, the flow of retail savings into longer-term debt instruments intensified, those who were uncomfortable with the apparent unresponsiveness of M2 to consecutive reductions in the Fed funds rate frequently used me as a sounding board for all sorts of proposals to redefine this monetary aggregate. In other words, I have been exposed to the alleged problems and proposed solutions before and I am pleased to discuss them once again.

However, since I was asked to specifically comment on the presented papers, and duty comes before pleasure, let me start with the papers and then move on to the broader issue of re-definition of monetary aggregates.

I will begin with the article examining empirical properties of an expanded M2, M2+. The authors of this article, Orphanides, Reid and Small, do an excellent job of examining the stability, indicator properties and, to some extent, controlability of $\mathrm{M} 2+$ (that is, M2 plus assets of bond and equity mutual funds) by trying to determine the demand for $\mathrm{M} 2+$, including reduced-form relationships that presumably would capture the determinants of supply as well.

To specify the demand for $\mathrm{M} 2+$, they correctly recognize the importance of specifying the ex ante retum on its close substitutes-real assets such as commodities and durable goods, as well as financial assets such as direct holdings of shortterm instruments, bonds and stocks. However, they note the difficulty of measuring such returns. They also note that M2+ would include the capital gains and losses on stock and bond mutual funds, because of the difficulty-I would say impossibility - of removing such ex ante gains and losses from the mutual fund component. Not incidentally, they do not believe such gains and losses should be removed, a subject to which I shall return later.

It is important for me to summarize their conclusions because I will be using them in commenting on the other article. The authors conclude from their analysis, and I agree with their conclusions, that:

1. On stability:

"...the estimated demand functions are not very stable. Hence, the usefulness of these equations in interpreting and forecasting movements in M2+ may prove to be limited."

2. On indicator properties:

"In terms of their information content, M2+ and M2 do not appear to have differed 
significantly." Both overpredicted nominal GDP before and during the last recession.

“... capital gains and losses cause growth of $\mathrm{M} 2+$ to be more volatile than that of M2.

Moreover, the capital gains and losses in M2+ may cause movements in the aggregate that neither reflect shifts in the stance of monetary policy nor provide appropriate signals for changes in policy."

\section{On controllability:}

The authors do not explicitly examine this aspect but, based on their previous statement just quoted, presumably would agree that $\mathrm{M} 2+$ is far less controllable than M2, which itself has not proven to be controllable at all during the period when it was the major monetary aggregate targeted by the Federal Reserve.

On the basis of these conclusions, they doubt that anything would be gained by expanding M2 to include assets of stock and bond mutual funds. I agree completely.

By contrast, the authors of the second paper, Gollins and Edwards, still consider M2+ (and its companion, $\mathrm{M} 3+$ ) a worthwhile replacement for M2. They argue that $\mathrm{M} 2+$ is less worse than any other proposed replacement, first because the added components, that is, assets of long-term mutual funds, have enough moneyness - their medium-of-exchange and liquidity attributes, and second, because, as intermediation continues to shift wealth from present components of M2 to long-term mutual funds, $\mathrm{M} 2+$ should, in fact, grow in value as an indicator of economic activity.

The authors of the paper recognize the potential pitfalls of using $\mathrm{M} 2+$. For example, some of the components of $\mathrm{M} 2+$ will have to be interpolated from annual data to monthly series in order to net out the institutional assets that would otherwise lead to double counting. Such interpolation drastically reduces the indicator properties of an aggregate for short-tem purposes. Even if we leave the interpolation problem aside, the usefulness of $\mathrm{M} 2+$ as a long-run indicator also would be limited: For the demand for $\mathrm{M} 2+$ to be properly specified, one would need to specify $\mathrm{ex}$ ante returns-a task bordering on the impossible, as the authors of both papers seem to acknowledge.
The technical issue then appears to be, at least in part, whether the moneyness attributes of the "+" make its components so indistinguishable from the components of M2 proper as to warrant the expansion of M2 despite the deficiencies of the broader measure established by Orphanides, Reid and Small, and pitfalls of using it as recognized by Collins and Edwards. A broader issue is, of course, what would be gained, if anything, by including assets of stock and bond funds into an expanded M2.

So now, as my principal assigned duty is fulfilled, I feel I am entitled to express my other thoughts on this matter. In order not to keep the audience breathless, I shall state at the outset that I disagree with the conclusions of the paper by Collins and Edwards and think that nothing would be gained by introducing yet another, broader monetary aggregate.

First, if the demand for $\mathrm{M} 2+$ is neither stable nor more informative than that for $\mathrm{M} 2$, as Orphanides, Reid and Small show, then deciding to adopt it because it is less worse than other proposed aggregates is a most unusual criterion for selection. I shall elaborate on this in a moment.

Second, it is fairly easy to show that the added components making up M2+ lack moneyness, contrary to what the authors of the second paper claim. Table 1 gives the turnover of some of the major components of M2 (those in columns one through four, and six and seven of the table; small time deposits, overnight repurchase agreements and overnight Eurodollar deposits were not available) and the turnover of bond and equity funds (the last two columns).

The striking feature of the table is that the turnover rates for the bond and equity funds are so much lower than that for any other financial assets. They are less than 10 percent of that of general-purpose money market funds, and less than 0.07 percent of that of demand deposits outside of New York City banks. Moreover, in contradistinction to demand deposits and even money market funds whose turnover ratios have tended to driff upwards over the nine years portrayed in the table, turnover ratios on bond and equity funds have declined or remained constant. Thus, their relative moneyness, at least as measured by turnover ratios has, in fact, decreased.

I may add that the turnover ratio has in its numerator the sum of debits, that is, it includes exchanges out of these funds. These in most 
Table 1

Turnover of Deposits, MMMFs and Bond \& Equity Funds, 1984-92

\begin{tabular}{|c|c|c|c|c|c|c|c|c|c|}
\hline & \multicolumn{4}{|c|}{ Deposits at commercial banks } & \multicolumn{2}{|c|}{ Momirs } & \multicolumn{3}{|c|}{ Eond \& equity funds } \\
\hline & $\begin{array}{l}\text { Denand deposits } \\
\text { Nre banks }\end{array}$ & $\begin{array}{l}\text { Denand deposits } \\
\text { other banks. }\end{array}$ & ocbs & Savings & Instifution & $\begin{array}{l}\text { Erokeff } \\
\text { dealer }\end{array}$ & $\begin{array}{l}\text { Eeneral } \\
\text { purpose }\end{array}$ & $\begin{array}{l}\text { Bond } \\
\text { Income }\end{array}$ & Equity \\
\hline 1984 & 1,843 & 269 & 15.8 & 50 & 4,2 & 30 & 22 & 0.4 & 0.3 \\
\hline 1985 & 2169 & 302 & 167 & 45 & 5.0 & 3.5 & 2.5 & 0.8 & 0.4 \\
\hline 1986 & 2461 & 327 & 16.8 & 3.0 & 4.6 & 3.4 & 29 & 0.3 & 0.5 \\
\hline 1987 & 2.671 & 357 & 138 & 3.1 & 4.6 & 37 & 30 & 0.5 & 0.6 \\
\hline 1988 & 2897 & 930 & 132 & 229 & 4.6 & 35 & 24 & 0.8 & 0.5 \\
\hline 1988 & 3.42 & 109 & 152 & 80 & 4.5 & 36 & 24 & 03 & 0.4 \\
\hline 1990 & 3,620 & 465 & 165 & 62 & 4.3 & 32 & 22 & 10.3 & 0.4 \\
\hline 1991 & 4271 & 448 & 162 & 56 & 48 & 32 & 2.3 & 0.3 & 0.4 \\
\hline 199 & 2.4798 & 186 & (1, & $47 \%$ & 6.9 & 3.6 & 27 & 0.8 & $\sqrt{0}$ \\
\hline
\end{tabular}

cases represent changes in asset composition of a shareholder's overall portfolio rather than debit to a checking account or a money market fund which has for its counterpart acquisition of, say, a new suit. Excluding exchanges out that is, redemption exchanges) from debits would make the already low turnover ratios for long-term funds considerably lower. In any event, the low turnover of bond and equity funds indicates that they probably have far less to do with the types of transactions that might influence GDP over the span of time normally adopted in framing monetary policy. In fact, it seems plausible that a switch of, say $\$ 1,000$, from my money market fund or bank account to a bond or stock fund, suggests a decision to move a potential near-term $\$ 1,000$ purchase into the future, quite possibly beyond the relevant time frame. Consequently, it seems to me that, contrary to the claims of Collins and Edwards, very little, if any, moneyness resides in the bond and equity components of $\mathrm{M} 2+$. I think that the extremely low transaction cost of converting these assets into cash creates this illusion of moneyness.

Third, adopting M2+ because it might eventually have better indicator properties and would, at least, in the meantime, envelop close substitutes for M2 assets, leads me to ask where will the broadening end? Milton Friedman recognized many years ago that the definition of money was as much an empirical as a theoretical matter, but deciding where to draw the line is not easy and, under current law, the Federal Reserve must decide where to draw it. Now, I don't want to get into a largely doctrinal argument over the wisdom of the requirement to set targets for monetary aggregates. However, because financial institutions are able and willing to grant credit lines collateralized by all types of assets, it does seem to me that broadening the definition to envelop close substitutes has as its feasible upper limit all of household wealth if not all of national wealth. I can get liquidity out of my home equity by simply opening my desk drawer, grasping my pen and writing out the amount I wish to spend. Moreover, I don't have to fear the tax consequences of my decision because I don't have to compute and report any of the capital gain on my home at the time I wrote the check. By contrast, if I were to write a check on my bond fund this would be a capital transaction requiring relatively complex computations of my cost basis for reporting short- or long-term capital gains. In this sense, a home equity line of credit has greater moneyness than a stock or bond fund. Thus, rather than stopping with including bond and equity mutual funds, shouldn't we go all the way and include home equity, margin credit, other lines of credit, 
including signature loans and, eventually, as our experience with financial innovation suggests, any assets that can be sold or borrowed against?'

This third comment brings me to a question that has been too easily dismissed by Collins and Edwards. Has the definition of money gone in the wrong direction? It seems to me that is a conclusion a reasonable person could draw from the experience of the past several decades as the Federal Reserve tended to broaden the definition of money. Despite the view of the authors that the Federal Reserve now would be reluctant to backtrack towards narrow measures of money, it is my humble opinion that the movement has been indeed in the wrong direction.

Although we all understand that monetary aggregates are not the ultimate objectives of policy-sustained growth and low inflation are really the measures by which the Federal Reserve policies will be judged-I have always been struck by the fact that the Federal Open Market Committee (FOMC) has typically used various components of bank reserves as internal guides for its open market operations even as it was proceeding in evolutionary steps from narrow to broad definitions of money when communicating its objectives to the public.
Of course, I don't want to give the impression that the links between narrow aggregates like reserves or the monetary base and the ultimate policy objectives are any more precise than the links between broader aggregates and those objectives. Nevertheless, the place of such narrow aggregates in the interplay of policy, ultimate objectives and information variables (such as commodity prices, interest rates, yield curves and exchange rates) has been more "enduring" in the conduct of monetary policy than any of the publically targeted monetary aggregates.

To summarize both papers, I agree with Orphanides and others and disagree for the same reasons with Collins and Edwards that adding M2+ to the monetary zoo would not make monetary policy more effective in achieving its ultimate objectives or make the Fed's stance more trans. parent to the Congress and the public.

I have tried to put the work of the two papers in the larger context of either being prepared to draw the line at total wealth rather than repeatedly drawing the line, erasing it, and redrawing it again and again at arbitrary segments of the wealth spectrum or, on the other hand, of moving back towards narrower aggregates which the Federal Reserve uses and can control. To me the choice is obvious.

\footnotetext{
1 I can understand the ferdency to resort to broader definitions if the desire is to incorporate wealth effects into the formation of monetary policy. However, such effects tend to have little explanatory power from quarter to quarter, or from year to year, in explaining movements in aggregate demand, production, employment and especially inflation.

Furhermore, if this were the case, all assets that can easily beliquified would have to be included into such a weatheffect-capturing aggregate.
} 


\section{John V. Duca}

John V. Duca is a research officer at the Federal Reserve Bank of Dallas. The author thanks Anne King and Chih-Ping Chang for their excellent research.

\section{Commentary}

\section{SOME BACKGROUND ON MONET.

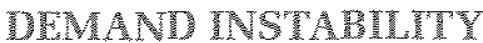

PAST EPISODES OF MISSING money can shed light on whether bond and/or equity funds should be added to M2. My perspective on how to analyze monetary aggregates can be characterized as a dynamic market-share approach. If financial aggregates have a stable relationship to nominal GDP and if banks have a stable share of the financial market, then bank-based monetary aggregates like M2 will be helpful indicators. The two most pronounced episodes of missing money, M1 in the mid-1970s and M2 in the early 1990 s, occurred when the competitiveness of the banking system declined.

In the mid-1970s, firms shifted away from bank loars toward commercial paper at a time when Regulation Q induced banks to ration credit and banks were passing along the heightened cost of reserve requirements when interest rates were high. On the liability side, binding deposit rate ceilings and high interest rates led firms and households to adopt cash management and to use money market funds which purchased commercial paper and Treasury bills. In terms of flows, firms used the proceeds from issuing paper to pay off bank loans while banks used these funds to pay off depositors who were shifting assels into money funds. In Figure 1, the development of money funds allows part of the flow of short-term finance to bypass the banking system.

By comparison, the bypassing of the banking system in the early 1990 s occurred in the flow of medium- to long-term finance (Figure 2). Higher deposit insurance premiums and more costly risk-based capital standards led banks to boost. the spread of prime over short-term rates, which helped induce firms to shift toward bond and equity financing. At the same time, wider net interest margins stemming from regulatory changes, coupled with a steep yield curve, encouraged households to shift out of small time deposits into bond and equity funds. In terms of flows, firms paid off bank loans with proceeds from issuing bonds and stocks bought by mutual funds whose purchases, in turn, were inanced by assets that households shifted out of bank deposits. Both episodes show how the banking system is not a closed loop, because agents innovate to circumvent banks when banks become relatively more costly to use.

\section{THE CENTRAL WNOTRIOAI, ISSUE}

If one could model the shocks to money demand, then modified money-demand models would work. However, if households have fundamentally changed their asset behavior, then it may be better to broaden an aggregate. In assessing the impact of Resolution Trust Corporation (RTC) activity and the yield curve on $\mathrm{M} 2$, I have found that M2 plus non-IRA/Keogh household bond funds is more explainable than M2 using Federal Reserve Board-style (circa 1990) M2 models (Duca, forthcoming). This suggests that the behavioral relationships have changed. However, given that bond funds were negligible prior to the mid 1980 , the analysis was effectively conducted. over a period when bond fund assets did not suffer sizable capital losses. The issue of 
Figure 1

\section{Short-Term Finance}

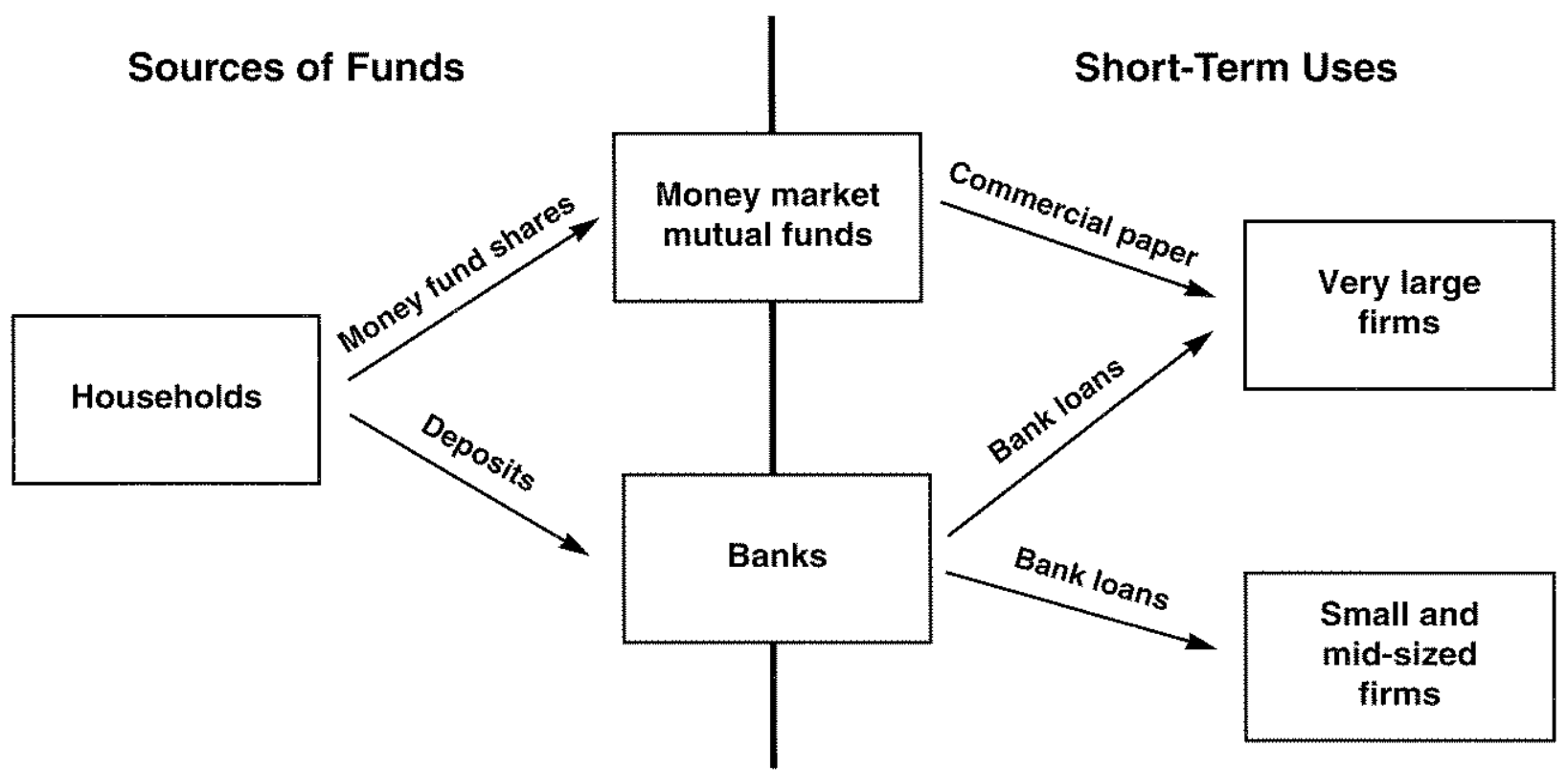

whether to add bond or bond and stock funds to $M 2$ is an empirical one and boils down to whether we lose more from making $M 2$ more vulnerable to capital gains and losses than we gain from internalizing portfolio shifts between $M 2$, and bond and equity funds.

\section{A COMMENT ON COLINS AND WDWARDS}

This is a good paper. The authors are very careful in how they construct and describe the data used in building M2+. This study will be a helpful resource for many analysts.

\section{SONE COMUIIS ON ORPIIANDS. RED AND SMALI (ORS)}

Overall, this is a very nice and careful study. The only suggestion I have regards how the atthors assess the indicator properties of M2 and $M 2 *$. I have some reservations about using only Granger regressions of GDP and money growth rates to assess indicator properties in the ORS study. This approach has the problem of letting bygones-be-bygones. That is, variability in money and GDP growth may obscure any information in long-run relationships between money and nominal output, if such relationships still exist. On this point, ORS could look into a simple errormcorrection model of nominal GDP that imposes a long-run velocity relationship. They then could compare results using M2 versus $\mathrm{M} 2+$ as additional evidence about indicator properties.

To shed some light on this point, consider some forecasts of inflation using a framework that imposes a long-run relationship between money and nominal output. Namely, the (in) famous P-star model. Figure 3 shows out-of-sample forecasts of inflation, as measured by the implicit GDP deflator. These extend recent research with Zsolt Becsi (Becsi and Duca, forthcoming). As we can see, the P-star model using M2 severely under-predicts inflation to the point of forecasting deflation in 1993. By contrast, M2 plus bond funds (M2B) and $\mathrm{M} 2+$ do a good job of tracking this inflation measure since 1991 , with a slight edge to M2B. Interestingly, M2 does a better job in predicting inflation during the mid-1980s* surge in bond and equity funds, whereas $\mathrm{M} 2+$ and M2B do better during the early-1990s' surge in mutual funds. Why? 


\section{Figure 2}

\section{Long-Term Finance}

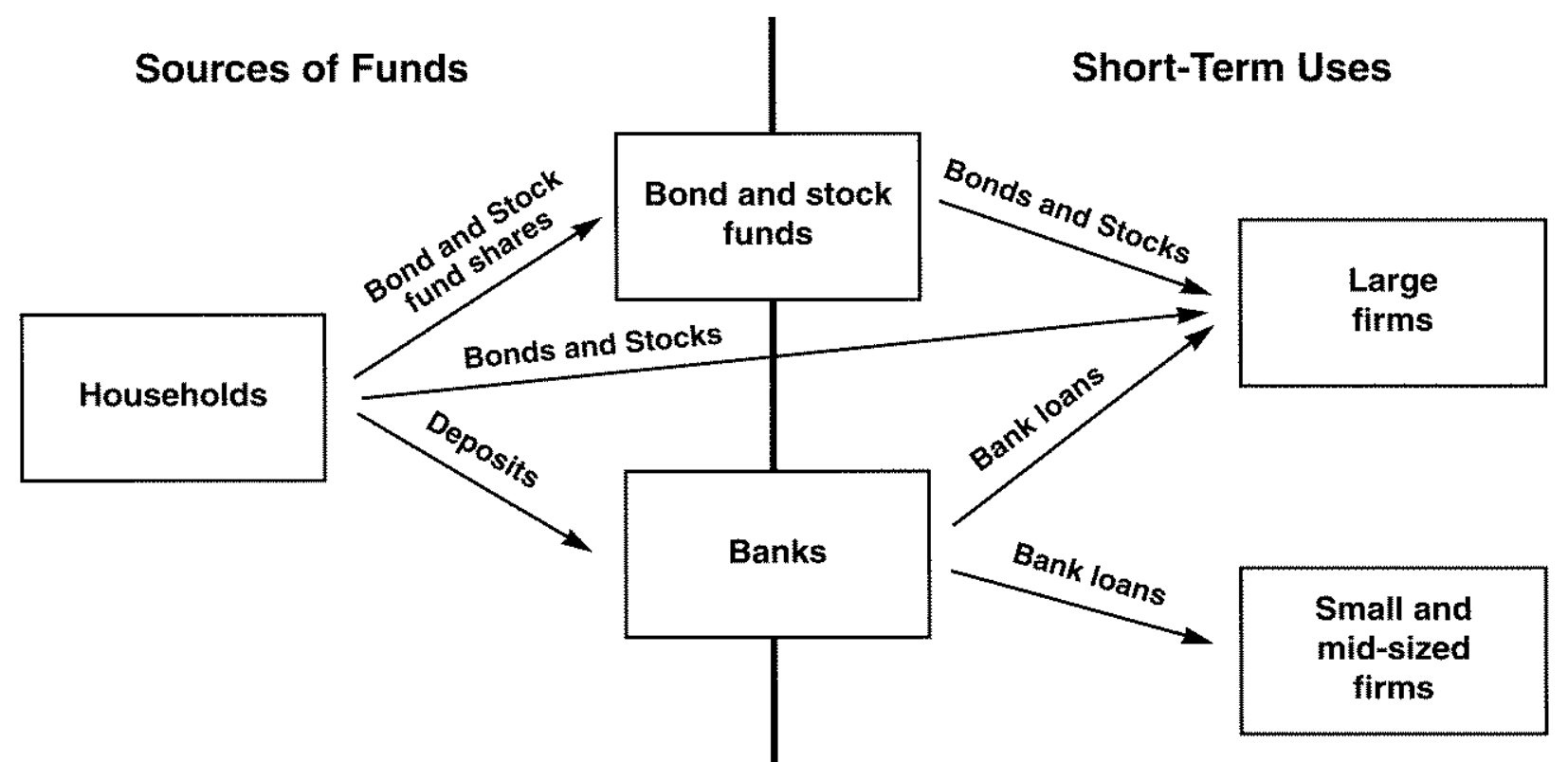

\section{WHY THE MID $19805^{3}$ SUGE MUTUAL WUNDS DI TERS FOMM THE $19905^{9}$ SURG}

I believe that the answer reflects differences in the sources of inflows during these episodes. The surge of the mid-1980s came shortly after IRA, 401K and Keogh regulations were liberalized. Given the incentives to use these retirement vehicles, many households learned more about mutual funds and likely applied this knowledge to other asset holdings. This is consistent with the fact that household holdings of IRA/Keogh and non-IRA/Keogh bond and equity fund balances grew rapidly in the mid-1980s. It is also consistent with flow-of-funds data, which suggest that the assets that households shifted into bond and equity funds came more from direct holdings of bonds and equities than from M2 deposits. This finding is also consistent with the relatively good fit of $\mathrm{M} 2$ demand models in the mid-1980s.

By contrast, flow-of-funds data suggest that more of the inflows into bond and equity funds during the early-1990s reflected shifts out of M2 deposits rather than out of direct bond and equity holdings. This is consistent with the missing M2 phenomenon of recent years.

Four factors may explain why the inflows into bond and equity funds came more from M2 in the early-1990s relative to the mid-1980s. First, compared to the mid-1980s, the yield curve was steeper for a longer period of time in the early1990s. Thus, households had a greater incentive to shift out of M2 deposits in recent years. Second, because short-term rates fell much more in the early 1990 s than in the mid-1980s, there were negative income effects on retirees holding small time deposits that encouraged them to shift out of bank CDs into higher -earning bond and equity funds. Third, declines in loads and fees on mutual funds (as shown by ORS) reduced the cost of shifting into mutual funds. Milbourne's (1986) modified Miller-Orr model implies that smaller loads will induce shifts from M2 into bond and stock funds. The fourth factor reflects the realization during the early-1990s that jobs are less secure-especially for professionals. As the world becomes more Schumpeterian, households will increasingly rely on portable, defined contribution pensions. Such plans typically require that households make investment 


\section{Figure 3}

\section{Actual and Forecasted Inflation from the $P^{\star}$ Model (Implicit GDP Deflator, SAAR)}

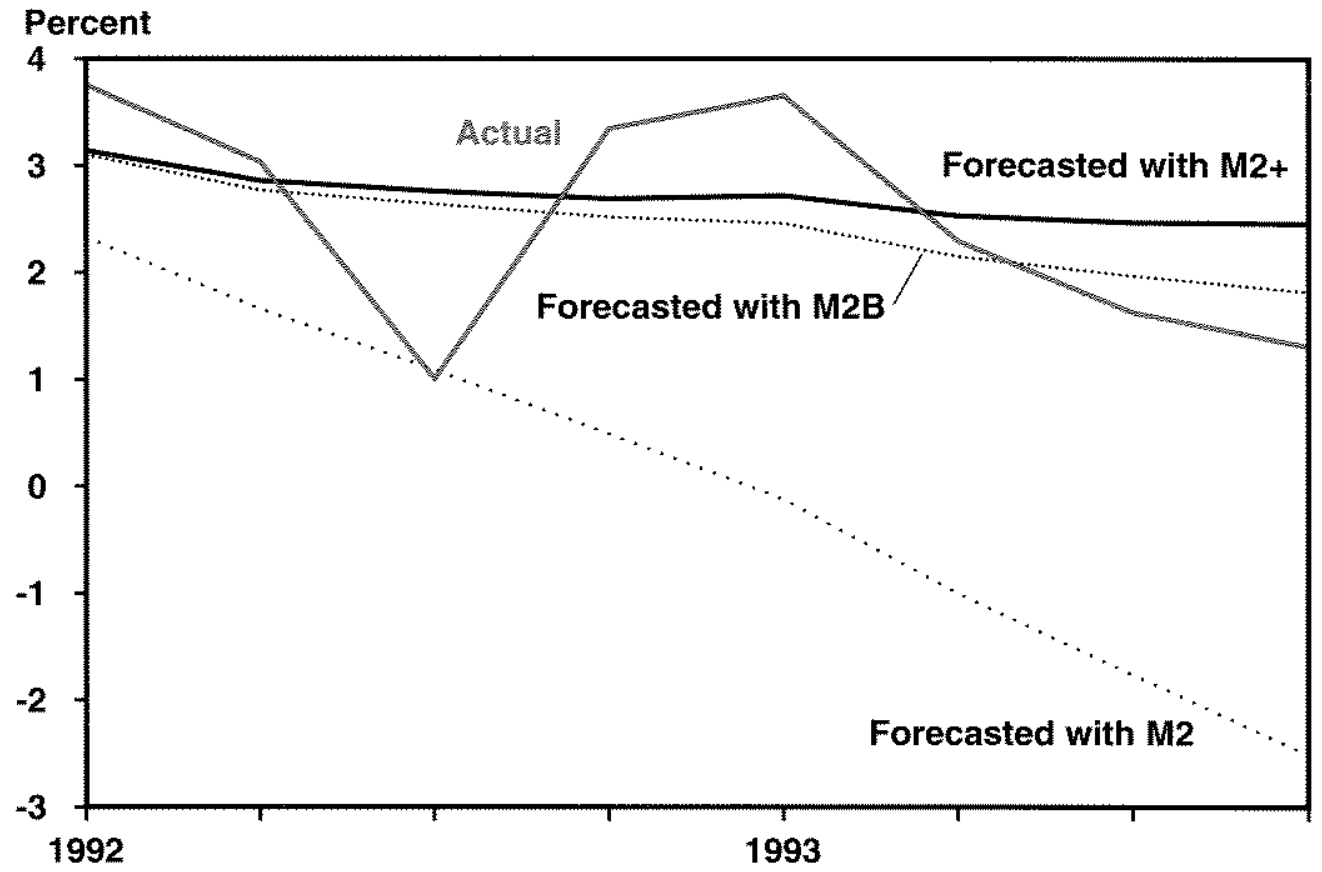

decisions. As a result of being more active in managing their retirement assets, households are becoming increasingly aware of altematives to $\mathrm{M} 2$ and are becoming better managers of their assets.

Differences between the mid-1980s and early 1990 imply that future research should examine the substitutability of bond and equity funds not only for M2, but also for direct holdings of bonds and equity. In addition, future work that applies learning models to bond and equity funds may prove fruitful.

\section{WHAT SHOUD TH THE DO?}

I favor an eclectic approach to conducting monetary policy because innovation by the private sector at times causes breakdowns in the relationship between financial variables and the economy. That said, part of our job at the Fed is to update financial indicators in light of those innovations.

As for using monetary aggregates as indicators, I have two positions. First, since recent innovations are mainly affecting the non-M1 component of M2, narrow money measures, net of currency, could be used as information variables within models that control for the high sensitivity of narrow money to interest rates and mortgage refinancing activity. Nevertheless, the high rate sensitivity of narrow aggregates limits their usefulness as monetary targets under the Humphrey-Hawkins Act. Second, I would also monitor M2 and M2 broadened to include bond and/or equity mutual funds, keeping in mind that capital gains and losses will have direct price effects on $\mathrm{M} 2$ + and $\mathrm{M} 2 \mathrm{~B}$ balances and will induce portfolio substitution between M2 and these broader aggregates.

\section{REFERENCES}

Becsi, Zsolt, and John V. Duca. "Adding Bond Funds to M2 in the P-Star Model of Inflation," Economics Letters (forthcoming).

Collins, Sean and Cheryl L. Edwards. "An Alternative Monetary Aggregate: M2 Plus Household Holdings of Bond and Equity Mutual Funds," this Review (November/December 1994), pp. 7-29.

Duca, John V. "Should Bond Funds Be Included in M2?," Journal of Banking and Finance (forhcoming).

Mitboume, Ross. "Financial Innovation and the Demand for Liquid Assets," Journal of Money, Credit and Banking (November 1986), pp. 506-11.

Orphanides, Athanasios, Brian Reid, and David H. Small. "The Empirical Properties of a Monetary Aggregate that Adds Bond and Stock Funds to M2," this Review, (November/December 1994), pp. 31-51. 


\section{Joshua Feinman}

Joshua Feinman is vice president of Banker's Trust.

\section{Commentary}

I SYMPATHIZE WITH THE DIFFICULTIES that the authors have had in trying to explain and model the financial innovation intermediation that has been occurring in recent years, and the ways that these changes have affected the relationships between monetary aggregates and GDP, In fact, I grappled with some of these issues myself when I was at the Board of Governors. I certainly appreciate the difficulties and potential pitfalls.

At the Board, I had it a bit easier than these authors, since I was mainly working on modeling M2. These authors have taken it a step further by constructing and modeling a new aggregate, $\mathrm{M} 2+$, that really goes in a very different direction and takes us in ways that the traditional monetary aggregates have not had to deal with.

A starting point for discussing the behavior of any monetary aggregate- $\mathrm{M} 2, \mathrm{M} 3$ or $\mathrm{M} 2 \div$, or any other-has to be the changes that have occurred in our financial system in recent years. Particularly important have been the shifts in the patterns of financial intermediation and the efforts by both borrowers and lenders to adopt a more cautious approach to leverage. The most important change in financial intermediation has been the relative shrinkage of the depository sector. At the same time, perhaps the most important financial innovation has been the proliferation of information about the accessibility and liquidity of mutual funds.

Both of these changes reflect the effects of a dramatic shrinkage of the government subsidy to the depository system in recent years. This shrinkage has manifested itself in a variety of ways, including higher deposit insurance premiums, more stringent capital standards, and tighter supervision, regulation and examination. All this has resulted in a smaller amount of depository intermediation in the economy and a smaller share of the economy's overall credit being recorded on the books of depositories. In addition, we have seen a smaller share of that smaller amount of depository credit being funded through deposits, in part because of increases in deposit insurance premiums.

The pie charts shown by Cheryl Edwards and Sean Collins illustrate the decreasing importance of deposits as a share of total household assets. This is obviously just the flip side of the depository shrinkage. The banking system has been less aggressive in pursuing deposits in recent years, and households have reacted by reducing their deposits accordingly. The larger upshot of this, of course, has been major shifts in the relationships between broad monetary aggregates-composed primarily of the liabilities of the depository sector-and GDP. This has resulted in the recent record-high GDP velocities of the broad monetary aggregates.

I believe this explains the major part of what has been happening. Although the steepening yield curve has certainly played a role, I never thought that was the key thing. Even though I've used yield curve spreads myself in modeling, I've always had problems with it on theoretical grounds. First, you have the theoretical problems arising from the expectations view of the yield curve. 
Saying people simply pick the highest point on the yield curve flies in the face of economic theory. But even more to the point, I think there's nothing per se that prevents banks, if they want to, from going out the yield curve and pursuing longer-term CDs more aggressively. If you didn't have the shrinkage in the banking system going on-which I think has been the fundamental thing-banks could and probably would have been more aggressive in pursuing longer-dated CDs with more aggressive pricing.

The bottom line is, in my opinion, the shrinkage of depository sector. This has been accompanied by increases in the direct-placement credit market and by the growth of new financial intermediaries. Obviously, the most visible new intermediary has been the mutual fund industry that we are discussing. That is why, at a very simple level, it is extremely appealing to want to create an aggregate that adds in these mutual funds to M2. The charts in the paper by Athanasios Orphanides and his colleagues show clearly that we have had outflows from M2 and its components while we have had strong inflows into these mutual funds; from the surface it looks appealing to build a new aggregate including these mutual funds.

Building a broad monetary aggregate that internalizes substitution among alternative assets also was the intent of the Federal Reserve Board staff when they defined the current M2 in 1980. At that time, the substitution was from M1 to, primarily, small CDs and money market mutual funds (MMMFs). Including the close alternatives to M1 meant that the new broader aggregate was much less sensitive to market interest rates. This is for two reasons. First, the rates paid on the deposits included in the non-M1 component of the new M2 aggregate tended to adjust much more quickly to changes in market rates then did rates paid on M1. This sharply reduced the incentive to substitute away from $\mathrm{M} 2$, into assets not included in M2, when market rates changed. Second, the broader aggregate captured internally the substitution from liquid deposits into small time deposits when market rates increased and vice versa.

When we look at the charts shown today, it is very tempting to say that a new, broader aggregate could capture some part of the substitu* tion away from small time deposits and MMMFs and into bond and equity mutual funds. Even so, having stated that, I think the articles suggest - and I agree-that we must be skeptical about the usefulness of an aggregate that adds these stock and bond funds to M2. To avoid getting into a tremendous amount of detail, I would just highlight a couple of points. Obviously, the capital gains issues that both Athanasios Orphanides and Cheryl Edwards mentioned is critical. It's hard to know what might be the correct answer. It's somewhat arbitrary to exclude capital gains completely. If you exclude them initially, however, you must decide when to include them in the aggregate. At what point do the capital gains start looking to households just like regular money? That's a problem. On the other hand, when you include capital gains as they do, you bring up another whole set of other problems. The monetary aggregate is going to be extremely responsive to moves in the stock market, for example. Could you ever target such an aggregate? Scenarios under this which could lead to some pretty silly policy responses are not too hard to concoct.

I believe that if you ever consider going operationally to such an aggregate, you would almost have to begin with a Q4 base period and try to differentiate over the course of the year what is contributing to that growth, separating how much is coming from capital gains, how much is coming from net inflows, and so on. I don't know if you can do that in a timely enough way for policy analysis, however. Once you start following the components of an aggregate rather than the aggregate itself, I'm not sure that you gain a lot by defining the aggregate in the first place. That's an obvious problem, but really the main reason we're here.

The second problem is one with the modeling exercise: Are there good, timely measures of the expected returns on these stock and bond mutual funds? These are the returns that belong in a money-demand equation. If you try to form these returns ex post in a backward-looking manner, you have a lot of theoretical problems in trying to justify it. If you try to look ahead, you have to specify the processes generating the data and how much people know about them. I know l'm not saying anything new here, but I want to highlight what I think is obviously a big problem.

Finally, I would say that (as Athanasios pointed out) M2+ doesn't really seem to have been a better indicator of GDP than M2, except perhaps during the last couple of years. We just don't have a very long history, and we know 
things are obviously still evolving. There may not, in fact, be stable demand function for $\mathrm{M} 2+$ that we can estimate. If doesn't seem to have any history of being a better indicator of GDP. It's more variable than $M 2$, or at least not any less variable. Finally, the kinds of institutional changes that have affected the traditional relationships between M2 and nominal GDP are continuing. These changes even today are affecting the development of $\mathrm{M} 2+$. Their strength likely makes any kind of historical data not terribly useful for looking ahead.

We should keep in mind that when things settle down-when the depository sector completes its shrinkage and stabilizes - the velocities of our current aggregates, particularly M2, might stabilize again, albeit at a permanently higher level. In addition, the short-run relationships between M2 and its opportunity cost that we relied on in the past might well re-emerge. In fact, unnoticed by many analysts, M2 velocity and its opportunity cost have increased in a roughly parallel way since early 1992 , suggesting that this pattern might already be emerging. Unfortunately, at this point the jury is clearly still out and we really can't answer that question definitively.

The evidence that I've seen presented suggests that there is no other monetary indicator that is going to provide monetary policy with a long-term nominal anchor the way we thought $\mathrm{M} 2$ did prior to 1990 . In the absence of such an anchor, it seems to me that monetary policy will continue to be made basically as it has been for some time now, without a monetary aggregate, by adjusting the nominal federal funds rate in response to activity in the real economy. 



\section{George G. Pennacchi}

George $G$. Pennacchi is professor of economics in the Department of Finance at the University of Illinois, UrbanaChampaign.

\section{Commentary}

$F_{1}$ to obscure traditional measures of monetan policy and efforts to find an improvement are now underway. A new, potentially superior monetary aggregate, M2+, is carefully analyzed in the complementary papers by Sean Collins and Cheryl Edwards, and Athanasios Orphanides, Brian Reid and David Small. The Collins-Edwards (CE) paper provides a thoughtful discussion of issues dealing with the construction of $\mathrm{M} 2+$, while the Orphanides, Reid and Small (ORS) paper considers the empirical qualities of this new aggregate. I wish to complement both sets of authors for their work. Given their research objectives, these papers are professionally executed and insightful.

As CE notes, M2 became uncoupled from nominal income beginning in 1990. During this period of slow M2 growth, funds invested in bond and stock mutual funds increased dramatically. However, before simply assuming that $\mathrm{M} 2$ can be resurrected by adding in bond and stock mutual fund balances, CE sensibly investigate whether flows from M2 into these mutual funds were the only problems occurring with M2. Bearing in mind CE's warning that it is "tricky business" to explain the weakness in M2 based on an analysis of its components, I would like to further discuss movements in the components of M2. I believe that a great deal of information is present in the individual components of monetary aggregates. Table 1 presents a very simple description of recent changes in these components.

The table confirms CE's observation that the small time deposit component of $\mathrm{M} 2$ declined substantially during this period. Where did these funds go? Based on the negative correlation between small time deposits and liquid bank deposits, CE believe it is likely that funds moved into liquid liabilities such as demand deposits, other checkable deposits (OCDs), savings deposits and money market demand accounts (MMDAs). The deposit turnover rates that I give in the table provide additional evidence of this movement. Deposit turnover in OCDs declined substantially from 1990 to 1993 , suggesting that these accounts were increasingly being used for savings rather than for transaction purposes. I believe that the cause of this intrabank shift was the reduction in the opportunity cost between small time deposits (for example, CDs) and OCDs (for example, NOWs). For instance, the average spread between six-month consumer CDs and NOW accounts was approximately 208 basis points in 1990 . By November of 1993, that margin was reduced to approximately 103 basis points. ${ }^{1}$ Changes in intrabank opportunity costs that lead to flows from non-reservable to reservable deposits will increase the demand for high-powered money and thereby lead to monetary tightening, even 


\section{Table 1}

\section{Selected Components of Monetary Aggregates (in billions, seasonally adjusted)}

\begin{tabular}{|c|c|c|c|c|c|}
\hline Component & $\begin{array}{l}\text { Ouantify } \\
1989,12\end{array}$ & $\begin{array}{l}198912 \\
199311\end{array}$ & Change & Tumover & $\begin{array}{l}\text { Turnover } \\
1993 \text { ? }\end{array}$ \\
\hline Curencyt & 2227 & 972 & $4.6 \%$ & & \\
\hline Travelers checks & 69 & 13 & $15.9 \%$ & & \\
\hline Denand deposist & 279.9 & 1054 & $37 \%$ & 7978 & 8246 \\
\hline OHerchedkable depositst & 2853 & 1274 & $447 \%$ & 165 & 117 \\
\hline Savings and MMOAst & 8910 & 3236 & $36,3 \%$ & 62 & 4.8 \\
\hline Money narket funds (CP BD) & 3174 & 19 & $60 \%$ & $30^{2}$ & \\
\hline Money market lunds (10) & 1088 & 879 & $80.8 \%$ & 30 & \\
\hline Overnight repos 8 Eurost & 775 & 78 & $101 \%$ & & \\
\hline Ternerops \& Gurosl & 1784 & 329 & $18.4 \%$ & & \\
\hline Small time depositst & 11527 & 364.5 & $316 \%$ & 1015 & 10015 \\
\hline Large time depositstl & 5488 & 2161 & $394 \%$ & & \\
\hline
\end{tabular}

1 Component of M1 $\mathrm{NL}$, and $\mathrm{MB}$

t Component of $\mathrm{M} 2$ and $\mathrm{M3}$

11 Comporent of 113

- Tumover rates are seasonally adusted Figure for 1993 , sor month of September.

2 Tumover tiquic is an average for all WMMis, see Gorton and Pentacch (1993)

2 heported in Collne and Edwards 1994 , besed on Federal Reserve Board staft ectimate

though the level of reported M2 (or M2+) may not change. Hence, these intrabank opportunity costs, in addition to the opportunity cost of holding M2 measured by the spread between the Treasury bill rate and the average rate on M2's components (see Figure 1 in CE), need to be considered.

As the table points out, the components of current monetary aggregates have displayed very different movements over the last few years. However, a general observation that is consistent with each of the component changes in the table is that, on net, funds have flowed from non-demandable/redeemable assets into demandable/redeemable assets. This observation is also consistent with the net flow of funds into (openended) bond and stock mutual funds whose shares are redeemable as well. Perhaps this represents a permanent shift in investment behavior that is unrelated to the current slope of the term structure. Investments in money market and bond mutual funds can provide investors with rates of return that are nearly identical to investments in term CDs (the funds can hold these CDs themselves), but with the added convenience of mutual fund redeemability. One might argue that bond mutual funds now dominate a CD investment.

A caveat to the redemption feature of bond and stock mutual funds is that liquidating shares may not always be costless. As ORS points out, redeeming bond and stock mutual fund shares can have capital gains tax implications (in addition to possible back-end loads). There are a number of somewhat complicated methods for calculating a mutual fund capital gain, each having possibly different tax implications. This could be a significant deterrent to frequent mutual fund withdrawals. Of course, this is not a problem affecting money market mutual funds, since they are permitted to use an "amortized cost" method of security valuation and the "penny rounding" method of share pricing that enables them to maintain a fixed share price.

Therefore, I would predict that withdrawals from bond and stock funds would tend to be significantly less volatile than those of money market funds. For example, money market fund assets declined by over 30 percent during the 13-month period from December of 1982 to 
January of 1984 , a time when bank deposit interest rate ceilings were lifted. I doubt that redemptions of that magnitude are likely for bond and stock funds. However, as the empirical work of ORS suggests, the share price volatility of bond and stock funds, leading to capital gains and losses, will undoubtedly add volatility to $\mathrm{M} 2+$, especially since these funds' current 15 percent share of $\mathrm{M} 2+$ is likely to grow.

ORS examine the demand for balances in stock and bond mutual funds, as well as the demand for $\mathrm{M} 2+$ as a whole. Following previous money demand formulations that include proxies for the opportunity cost of various monetary components, they experiment with various quarterly measures of the "ex ante perceptions of returns" on stock and bond mutual funds. In my opinion, this is an exceedingly difficult empirical exercise and theoretically suspect as well. The empirical difficulty is that, unlike other components of $\mathrm{M} 2+$ which have nearly risk-free returns, stock and bond funds have high rate-of-return volatility. Even if one assumed that the expected rates of return on these funds were constant, rather than varying on a quarterly basis, it could take decades of data before a reasonably accurate estimate of their expected returns could be found. These assets' rates of return variances overwhelm their expected rates of return; that is, there is too much "noise" (variance) to be able to infer these assets" desired "signal" (expected rate of return). ${ }^{2}$

Economic theory may also suggest that the opportunity costs of stock and bond investments will always be approximately zero. Unlike other bank liabilities that are not necessarily competitively priced (for example, demand deposits, NOWs, MMDAs, small CDs), there is likely to be little "opportunity cost" of holding stock and bond investments, even via mutual funds. Demands for these assets should not depend on expected rates of return but risk-adjusted expected rates of return. A number of general equilibrium models predict that the best measure of this risk-adjusted return is the current short-term, risk-free rate, for example, the current Treasury bill rate. But, of course, this then implies that the opportunity cost for competitively priced assets will be zero. In the context of bonds, it is well known that a steeper yield curve will not necessarily indicate that (longterm) bond funds are more attractive than when the yield curve is flat or inverted. A higher slope may simply reflect the expectation of rising short-term interest rates or a risk premium on more volatile long-maturity bonds. To justify their proxies, I believe the authors would need to argue that their measures reflect the actual "perceptions" of relatively unsophisticated mutual fund investors. But even if this were the case, these "misperceptions" are likely to be temporary. Following a significant correction in stock and bond markets, investors are apt to quickly learn that recent stock performance or the steepness of the yield curve have little predictive power for future investment returns.

Given the above difficulties in modeling and estimating risky asset demands, it is not surprising that ORS find evidence of instability in their estimated demand curve for M2+. I would not be surprised, however, if M2+ turns out to better predict nominal GDP than other monetary aggregates. The reason for this is that changes in $\mathrm{M} 2+$ may not proxy for changes in "money" but for changes in nominal "wealth" due to the capital gains on its stock and bond components. If one views wealth as the capitalized value of future income, then changes in wealth may indeed be a good forecast of changes in nominal GDP. Hence, M2+ may be a good indicator, but for the wrong reasons.

My last comment concerns the general approach that is used to revise monetary aggregates in response to financial innovation. CE is explicit in desiring a relatively simple aggregate that is constructed in a parallel fashion to previously existing aggregates. They imply that more complicated monetary indicators are problematic, because they make adjustments using a "modelbased procedure that the public (Congress in particular) might have trouble understanding [quote from previous draft-Editor]." If this is the case, perhaps the Federal Reserve should (already does?) report an easily understood aggregate to the public, but then use a more complicated monetary measure for internal decision-making.

In my opinion, if we truly wish to understand the inherently complex effects that financial innovation have on the conduct of monetary policy, we need to abandon the simple approach of merely adding new asset categories to old aggregates. As indicated by the turnover rates in the table and ORS' estimated turnover rate of

\footnotetext{
${ }^{2}$ See Merton (1980) on this point.
} 
bond and stock funds of 0.3 , these new asset categories are very distant substitutes for highpowered money, the economy's numeraire for pricing goods and services. ${ }^{3}$ As noted by ORS, the justification for adding bond and stock funds to M2 should not be based on these "balances having become a better transaction medium, but rather will be based on their substitutability for small time deposits or other M2 balances as savings vehicles." But, if small time deposits are held for savings, rather than transaction purposes (as indicated by the turnover rate of 1.0-1.5), would it not make more sense to lessen the effects of small time deposits in a monetary measure rather than adding another, even less moneymlike asset? The approach represented by $\mathrm{M} 2+$, which simply adds new non-monetary assets to correct problems with old non-monetary assets, is not unlike curing a hangover by having another drink. It may appear to be a good solution in the short run, but (as financial innovation continues) the ultimate consequence is a much larger hangover-or the need for an even larger drink.

Developing aggregates based on their (historical) empirical fit is unlikely to be a successful endeavor in an environment in which new financial instruments continue to be developed. A more Bayesian or "model-based" approach, such as the work of Barnett (1980) and Spindt (1985) would seem to be more appropriate. A general modeling of the demand for high-powered money could also potentially consider the effect of non-monetary transaction technologies, such as credit cards, or the effect of dollar-currency demand by foreigners. In other areas of economics, we do not insist that multi-good demand relations be a function of a linear combination of those goods, each having a coefficient of unity. Why do we continue this practice in monetary economics?

\section{䈍ERERENGS}

Bamett, William A. "Economic Monetary Aggregates: An Application of Index Numbers and Aggregation Theory," Journal of Econometrics (summer 1980), pp. 11-48.

Fama, Eugene F". "Banking in the Theory of Finance," Journal of Monetary Economics (January 1980), pp. 39-57.

Gorton, Gary B. and George G. Pennacchi. "Money Markel Funds and Finance Companies: Are They the Barks of the Future?," in Michael Klausner and Lawrence J. White, eds., Structural Change in Banking. Business One lwwin, 1993. pp. 173-214.

Hutchison, David E. and George G. Pennacchi. "A Framework for Estimating the Value and interest Rate Risk of Retall Bank Deposits, "Federal Reserve Bank of Chicago Working Paper WP-92-30 (December 1992).

Merton, Robert $\mathrm{C}$. "On Estimating the Expected Return on the Market: An Exploratory Investigation," Joumal of Financial Economics (December 1980), pp. 323-61.

Spindt, Paul A. "Money Is What Money Does: Monetary Aggregation and the Equation of Exchange," Joumal of Political Economy (February 1985), pp. 175-204.

${ }^{3}$ Fama (1980) provides an insightful discussion of issues

involving monetary policy and price-tevel control. 